SAND89-0017

DE9 1001045

TTC -0883

Unlimited Release

Printed June 1990

\title{
A ROBOTIC SYSTEM TO CONDUCT RADIATION AND CONTAMINATION SURVEYS ON NUCLEAR WASTE TRANSPORT CASKS*
}

\author{
Ray W. Harrigan \\ Intelligent Machine Systems Division (1414) \\ Computer Sciences Department \\ Sandia National Laboratories \\ Thomas L. Sanders \\ Transportation Systems Development and Testing Division (6323) \\ Transportation System Development Department \\ Sandia National Laboratories**
}

\begin{abstract}
ABSTRAC1
The feasibility of performing numerous spent fuel cask operations using fully integrated robotic systems is under evaluation. Using existing technology, operational and descriptive software and hardware in the form of robotic end effectors are being designed in conjunction with interfacing cask components. A robotic radiation and contamination survey system has been developed and used on mock-up cask hardware to evaluate the impact of such fully automated operations on cask design features and productivity. Based on experience gained from the survey system, numerous health physics operations can be reliably performed with little human intervention using a fully automated system. Such operations can also significantly reduce time requirements for cask-receiving operations.
\end{abstract}

*This work performed at Sandia National Laboratories, Albuquerque, New

Mexico, supported by the U.S. Department of Energy under Contract

DE-AC04-76DP00789.

$* *$ A United States Department of Energy Facility.

$$
\text { iii/iv }
$$




\section{ACKNOWLEDGMENTS}

The authors wish to acknowledge several people who made significant technical contributions to the RRSAS project. These people are J. Bailer, W. Davidson, J. Jones, J. Littlejohn, D. Miller, A. Morimoto, B. Petterson, L. Ray, C. Selleck, D. Strip, and S. Thunborg--a11 of Sandia National Laboratories (SNL), and G. Starr of the University of New Mexico.

In addition, we wish to thank L. Barrett, N. Burre11, C. Dwight, F. Falci, K. Golliher, L. Harmon, W. Lake, and E. Wilmot of the U.S. Department of Energy for supporting the SNL robotics programs. Finally, special thanks go to P. Bennett, J. Moya, and M. Warrant of SNL, P. Reardon of Gram, Inc., and the staff of Creative Computer Services for their review efforts and assistance in preparing this manuscript. 


\section{CONTENTS}

Section

Page

1.0 INTRODUCTION $1-1$

2.0 BACKGROUND
$2-1$

2.1 Cask Development and Design Issues $r-1$

2.2 Tirnes for Cask-Handling Operations $2-1$

2.3 Occupationa1 Exposures Resulting From Cask-Hand1ing Operations $2-2$

2.4 Remote Cask Handling 2.5

2.4.1 Proof-of-Principle Experiment $2-5$

2.4.2 Experiment Results 2-9

2.5 Technology Development Issues for Remote Cask Handling 2-10

2.6 An Approach to Evaluating Advanced Remote Cask-Handling
Technology

3.0 RRSAS DESCRIPTION 3-1

3.1 Cask Location $\quad 3-1$

3.2 Cask Identification $3-3$

3.3 Remote Visual Inspection and Radiation Survey $3-3$

3.4 RRSAS Control Concept $3-13$

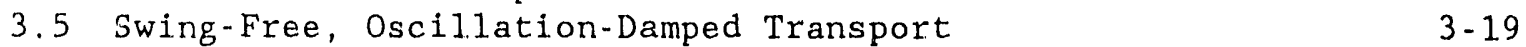

$\begin{array}{ll}3.6 \text { Summary } & 3-21\end{array}$

4. 0 CONCLIISTONS $4-1$

4.1 Technical Achievements $4-1$

4.2 Feasibility of Using Integrated Robotic Systems
for HLW Shipping Cask Operations

4.3. Cask and Handling System Design Implications $4-2$

4.4 Transportation System Impacts $4-3$

REFERENCES $4-5$

APPENDICES

Appendix A FORCE SERVO CONTROL OF A COMMERCIAL GANTRY ROBOT Appendix B COMPUTER VISION FOR SHIPPING CASK LOCATION Appentix $G$ SUPERVISORY CONTROL FOR A COMPLEX POBOTIC SYSTEM $\quad C-1$ Appendix D A DISPENSER MECHANISM FOR STACKABLE THIN-EDGED OBJECTS D-1 Appendix E OSCILLATION-DAMPED MOVEMEN: OF SUSPENDED OBJECTS $\quad$ E-1 
2-1 Master/Slave Manipulators 2-6

2-2 Pedestal-Mounted Commercial Robot Used for Proof-of-

Principle Testing

2-3 Ful1-Scale DHLW Truck Cask and Canister

$2-8$

$2-4$ A Comparison of Expected Cask-Handling Times Based on Current Experience and Predictions Derived From Conceptual Analysis and Proof-of-Principle Experiments

A-1 Position Control Servo Loop Used in the XR 6100 Gantry

D-1 Planchet Used for the Swipe Survey

D -2

Magazines Placed in the Dispenser and Storage Mechanisms

D -2

Dispenser for the Alpha-Beta-Gamma Detector

D -3

D -3

Turntable for the Alpha-Beta-Gamma Detector

D -4

D -4

Diagram of Disk and Reference Frames

D -4

D- 6

D- 6

Dispenser Carrier and Disk in the Dwell Phase

D -7 
FIGURES (Concluded)

Figure

Page

D-7. Dispenser Carrier and Disk in the Second Fhase D-7

D-8 Dispenser Carrier and Disk in the Final Phase (Drop-off) D- 8

D-9 Dispenser Carrier and Disk After Drop-off D-8

D-10 Three-Dimensional Representation of the Cam D-9

D-11 Assembly Drawing of the Dispenser Mechanism D-10

D-12 Assembly Drawing of the Locking Mechanism D-15

$\begin{array}{ll}\text { D-13 Flow Diagram for Control of the Dispenser } & \text { D-17 }\end{array}$

E-1 Diagram of the Transportation System E-3

E-2 Acceleration Profile E-3

E-3 Angular Displacement vs. Normalized Time E-5

E-4 Error in Computed Pendulum Periods E-5

E-5 Surface Defining Nonlinear Approximation E-7

E-6 Surface Defining Linear Approximation E-8

E-7 Implemented Contro1 Strategy E-9

E-8 Simply Suspended Object E-15

\section{TABLES}

$\underline{T a b l e}$

2-1 Productivity Increases Asso :iated with Reduced Cask Turnaround Times 2-2

2-2 Contributions of Various Cask-Handling Activities to Total Repository Occupational Dose? $2-4$

3-1 RRSAS Operation Times 3-22

A-1 Electronic Delays Between Force Transducer and Robot Servos

B-1 Repeatability of Cask Location B-8

E-1 Results for Implemented System E-11 


\subsection{INTRODUCTION}

The Nuclear Waste Policy Act (NWPA) of 1982 authorized the U.S. Department of Energy (DOE) to establish a national system for disposing of commercially generated high-level radioactive waste (CHLW) and spent nuclear fuel. The NWPA established the Office of Civilian Radioactive Waste Management (OCRWM) to carry out these activities (NWPA, 1982). In addition, the DOE is responsible for permanently disposing of defense high-level radioactive waste (DHLW) currently in interim storage at several reprocessing sites (Zimmer and Madsen, 1985). Disposal activities include receipt of spent fuel, CHLW, and DHLW from commercial reactors and reprocessing sites; transport to a federal repository where the waste is received and prepared for disposal; and final emplacement of the waste in a deep geologic repository.

The DOE is committed to carrying out these activities in a safe ard cost-effective manner, ensuring public and occupational safety while reducing handling and transport costs (Zimmer and Madsen, 1985; DOE, 1986). Development activities are under way to optimize many facets of the transport system, including identifying cask features that will increase waste transport cask productivity by improving cask-handling operations at shipping and receiving facilities. These development activities are consistent with the DOE's efforts to reduce life-cycle costs of the transportation system and to maintain total radiological risks, including public and occupational risks, within the guidelines of the as low as reasonably achievable (ALARA; philosophy (DOE, 1981).

Sandia National Laboratories (SNL) is developing advanced cask-hand'ing techniques and investigating the feasibility of using robotic systems for cask and radioactive waste-handling operations at nuclear waste receiving sites. The primary objectives for these development activities are the following:

- to demonstrate the feasibility of using robotic systems for cask handling tasks, and

- to identify cask design features and operations that strongly affect robotic handling.

A prototype robotic system, the Remote Radiation Survey and Analysis System (RRSAS), has been developed to conduct remote radiation and contamination surveys on nuclear waste transport casks. This report reviews the development work for the RRSAS. Section 2.0 presents background information related to the develcpment of the RRSAS, including cask design development issues, cask-handling operations, early conceptual design work, proof-ofprinciple testing, and technology development issues for automated cask handling. Section 3.0 presents the details of the RRSAS operations. Section 4.0 summarizes technical achievements of the RRSAS project and includes insights into the technical feasibility of further automating cask operations. Section 4.0 also includes conclusions about the impacts of automated handling on cask designs and waste management systems based on the experience gained from the RRSAS project.

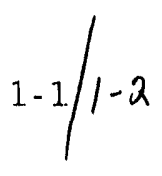




\subsection{BACKGROUND}

\subsection{Cask Development and Design Issues}

The efficiency of a nuclear waste transport cask depends primarily on its carrying capacity or payload. Transport cask productivity is defined by the number of high-level waste containers, or spent fuel assemblies, moved per year from a shipping facility to a receiving site. Cask productivity is primarily affected by the carrying capacity and the time spent loading and preparing the cask for shipment, unloading and preparing the cask for return shipment, and transporting a cask between two points. A number of opportunities exist to increase the productivity of the next generation of waste transport casks. This is particularly important since the number of future shipments of spent 1ight water reactor (LWR) fuel to repositories will be substantially greater than current shipments. To date, U.S. shipments over the last 25 years total 6,000 metric tons of uranium (MTU). For comparison, approximately 3,000 MTU of spent fuel will be transported each year when a repository is available.

In the future, casks will also be required to accommodate much older ipent fuel than is common today. Age of spent fuel is derived from the time of its removal from the reactor. Current casks are predominantly designed for spent fuel cooled for short time periods, i.e., 180 days out of the reactor. Generally, the increase of older spent fuel shipments and the potential for large increases in the number of spent fuel assemblies, or payload capacity, warrants developing more efficient "new generation" casks. As new casks are developed, private industry is being encouraged to be innovative in designing features to enhance both safety and productivity.

Improving cask productivity reduces life-cycle transportation costs and helps maintain radjological risks within ALARA guidelines*(DOE, 1981). For example, increased cask capacities will reduce the total number of shipments required to transport a given amount of fuel. Fewer shipments will reduce the number of handling operations at shipping and receiving facilities, which, in turn, will decrease total cask-handling time. Improving caskhandling times will reduce the number of casks needed to maintain a specific waste-handling rate. Fewer shipments and lower time requirements for caskhandling operations will likely reduce staffing requirements, as well as capital cost for waste shipping and receiving facilities, and decrease occupational radiological exposure. Fewer shipments will also reduce public radiological exposure. Occupational radiological exposures can also be reduced by removing personnel from the immediate vicinity of a cask and by performing cask-handling operations remotely. Unfortunately, such remote operations historically have resulted in significant increases in the time required to perform cask-handling tasks.

\subsection{Times for Cask-Handling Operations}

The effect of cask turnaround time on transport cask productivity at shipping and receiving facilities was analyzed (Winson et a1., 1980). As shown in Table 2-1, if turnaround times for existing legal weight (LWT) and overweight (OWT) truck casks could be reduced from current requirements of 12 and 16 hours at each facility, respectively, to 4 hours each, cask 
Table $2-1$

Productivity Increases Associated with

Reduced Cask Turnaround Times (Winson et al., 1980)

\begin{tabular}{|c|c|c|c|}
\hline & \multicolumn{3}{|c|}{ Type of Cask } \\
\hline & LWT* & OWT $\star *$ & $\operatorname{Rail}$ \\
\hline \multicolumn{4}{|l|}{$\begin{array}{c}\text { Turnaround } \\
\text { Time } \\
\end{array}$} \\
\hline $\begin{array}{l}\text { Current } \\
\text { Reduced }\end{array}$ & $\begin{array}{r}12 \text { hours } \\
4 \text { hours }\end{array}$ & $\begin{array}{r}16 \text { hours } \\
4 \text { hours }\end{array}$ & $\begin{array}{r}6-8 \text { days } \\
4 \text { days }\end{array}$ \\
\hline $\begin{array}{l}\text { Productivity } \\
\text { Increase }\end{array}$ & $28 z$ & 628 & 198 \\
\hline $\begin{aligned} * \text { LWT } & =\text { Legal } \\
\star * \text { OWT } & =\text { Over }\end{aligned}$ & $\begin{array}{l}\text { lck cask. } \\
\text { cask. }\end{array}$ & & \\
\hline
\end{tabular}

productivity would increase approximately 28 and 62 percent, respectively (Winson et al., 1980). If the rail cask turnaround time at each facility could be reduced from 6 to 8 days, to 4 days, productivity would increase approximately 19 percent. The lower increase for rail is due to more dominant in-transport factors. In terms of costs, one analysis indicates that a 4- to 8-hour reduction in truck and rail cask turnaround times, respectively, could reduce life.cycle transportation costs (excluding facility capital costs) considerably (Shirley, 1983).

While these analyses consider only current generation transport casks, the potential effects of productivity increases are equally applicable to future generation casks. With their projected higher capacities, future generation casks will. have even greater potential for increased productivity (Sanders et al., 1987). Performance goals for future generation spent fuel transport casks require turnaround times of 8 hours for truck casks and 4 days for rail casks (DOE, 1986).

\subsection{Occupational Exposures Resulting From Cask-Handling Operations}

To accommodate the large number of shipments expected at repositories in the future while maintaining occupational expostres within ALARA guidelines, significant changes in waste-handling methods are needed. An early analysis has been conducted to evaluate several concepts for reducing radiological exposure: Three general recomendations for reducing exposures have been derived: maximize cask shielding, maximize facility shielding, and implement remote-handling techniques (Shirley, 1983). 
A more recent ALARA analysis evaluates several alternative methods for reducing occupational exposures from spent fuel transport (Schnelder et al., 1987). Radiation doses resulting from cask-handling operations at a postulated reference repository are estimated by analyzing hypothetical receiving and handling facilities. Estimates of the distances between the cask surface and operating crew members during handling activities are based on current cask-handling practices. Contact-handling dose estimates for these activities are based on near-cask dose rates and background area dose rates for typical cask-handling areas, staffing and time estimates representative of current experience, and the expected location of workers relative to the casks. All cask-handling activities are assumed to be accomplished with conventional equipment and procedures.

'he facility is assumed to recelve shipments 24 hours a day, 7 days a week. Assuming continuous cask operations, estimates of cask turnaround time at the facility range from 14.6 hours for a truck cask containing pressurized water reactor (PWR) fuel assemblies, to 1.6 .3 hours for a truck cask containing bolling water reactor (BWR) fuel assemblies. Rail cask turnaround estimates are 2.1 .6 hours for a PWR cask to 30.1 hours for a BWR cask. The average waiting times for casks outside the receiving and handling building are estimated at 1.4 hours for each truck cask and 20 hours for each rall cask.

Specific handling activitles considered in the ALARA analysis are 11lustrated by Schnelder et al. (1987). Upon receipt, the cask and transport. vehicle are inspected at the repository's outside security gate. They are then transported to and from a queuing area and then to a wash-down area where they are washed and dried before moving to the receiving and handling area. While in the wash-down area, a health physics survey is performed on cask enclosures, tiedowns, and impact limiters. The cask is then removed from the transport vehicle, placed on a mobile cart, and moved into the handling room. Activities in the handling room include pressure and cover gas testing, outer lid removal, and mating to a hot cell port. A lifting adapter for the inner 1 id and a contamination barrier adapter are also installed at this time.

In the hot cell, several remote cask operations are performed, including unloading and internal cavity inspection and sleaning. Unloaded spent fuel assemblies, or high-level waste canisters, are placed into temporary storage cells within the hot cell.

The empty cask is then prepared for shipment by reversing the above process. Closure $11 \mathrm{ds}$ are installed, the cask exterior is decontaminated, and the cask is placed on the transport vehicle. The cask tiedowns, impact limiters, and personnel barrier are reinstalled, and the vehicle is prepared for departure.

Only a few of the above activities account for approximately 90 percent of the occupational dose, as illustrated in Table 2-2. For example, the activities performed in the handling room to prepare the cask for unloading account for 67 to 75 percent of the collective dose ieceived by repository cask-handling workers, Removing closure lid bolts contributes most to the total collective dose recelved by workers: 36 percent per truck cask 
Table 2-2

Contributions of Various Cask-Handling Activities to Tota1 Repository Occupational Dose (Schneider et al, 1987)

\begin{tabular}{|c|c|}
\hline Activity & $\begin{array}{l}\text { Contribution to } \\
\text { Total Dose ( } 8)\end{array}$ \\
\hline \multicolumn{2}{|l|}{ Hand ling Room } \\
\hline $\begin{array}{l}\text { Closure work, gas/pressure testing, } \\
\text { installing contamination and } \\
\text { lifting system }\end{array}$ & $67-75$ \\
\hline $\begin{array}{l}\text { Removing closure lid bolts } \\
\text { (included in above activities) }\end{array}$ & $\begin{array}{l}{[36(\text { truck })]} \\
{[43(\text { rail })]}\end{array}$ \\
\hline \multicolumn{2}{|l|}{ Preparation Tasks } \\
\hline $\begin{array}{l}\text { Health-physics surveys, removing } \\
\text { impact limiters, removing tieduwns }\end{array}$ & $17-19$ \\
\hline $\begin{array}{l}\text { Cleaning. Monitoring, Inispection, } \\
\text { Cask Movement }\end{array}$ & $3-11$ \\
\hline
\end{tabular}

(100 person-mrem) and 43 percent per rall cask (200 person-mrem). Other preparation tasks, such as health-physics surveys, removing impact limiters, and removing tiedowns, will contribute 17 to 1.9 percent of the collective dose to repository workers (54 person-mrem for each truck cask and 79 personmrem for each rail cask). Cleaning, monitoring, inspection, and cask movement tasks account for most of the remainder. As shown in Table 2-2, these tasks result in 95 to 97 percent of the collective loccupational dose at the repository for truck and rall cask handling, respectively.

The total operational dose per cask load is approximately 280 personmrem per PWR or BWR truck cask load (approximately 300 person-mrem/MTU spent fuel). The dose is approximately 465 person-mrem per PWR or BWR rall cask load (approximately 70 person-mrem/MTU spent fuel). One to two percent of the total dose results from background radiation doses (1.e., from other site radiation sources) in the work area.

These reference repository analyses indicate d relatively small number of repository personnel could recelve average individual doses as a result of cask-handling operations as large as 13 person-rem/yr, and the average for each worker could be approximately 3.7 person-rem/yr. This is well above the 1 person-rem/yr ALARA objective for an individual worker. 


\subsection{Remote Cask Handiing}

Remote cask-handling techniques are being considered to reduce these occupational exposure levels at a repository. The traditional means of handling materlals remotely requires master/slave manlpulators, in which a remote mechanical manipulator (the slave) is directly coupled to a mechanism (the master) controlled by the operator (Figure 2u1). The slave manipulator essentially repeats the master's movements exactly. Due to the reduced degree of freedom of master/slave devices and environmental sensing limitations, remote manipulation using such devices is difficult even for experienced operators and, depending on the complexity of the system, can take 3 to 15 times as long as manual operations for identical tasks (Strip, 1987). As a result, interest in developing programmable devices, or robots, for remotehandling operations has increased.

Development has been proceeding since 1983 on advanced methods for performing high-level waste cask operations in radioactive waste shipping and receiving facilities. In 1983, a conceptual evaluation of remote-handiing. equipment and procedures for cask shipping and receiving operations was initiated by SNL and Hanford Engineering and Development Laboratory (HEDL). This effort concluded that worker exposures can be significantly reduced if such remote-handling systems are developed and used to perform what typically have been hands-on tasks (Yount and Berger, 1984). The evaluation determined that if commercial robots were incorporated into a remote-handing system, worker exposure could be reduced to acceptable levels while maintaining or possibly increasing material throughput.

\subsubsection{Proof-of-Principle Experiment}

To substantiate the conclusions drawn from conceptual analyses, a limited proof-of-principle experiment was initiated at HEDL in 1984 to test the applicability of robotic systems to waste-handling operations (Berger, Gneiting, and Sanders, 1986). An available commercial robot system has been used to evaluate whether a variety of cask operations could be automated using existing technology and whether a robot system could be used in a master/slave control to respond to unstructured, off-normal events.

A pedestal-mounted commercial robot (Figure 2-2) has been modified for man-in-the-loop control and used to perform selected cask-handling activities. For the demonstration, a full-scale carbon steel mock-up of a DHLW cask (Figure 2-3) has been bullt, complete with functioning seals and captive closure bolts (Madsen et a1., 1987). Also, a nonradioactive DHLW canister (Figure 2-3) has been obtalned for cask-unloading operations. A shipping skid with captive hinged tiedowns has been fabricated to simulate features that could be designed into a dedicated traller.

To accommodate unplanned events, the robot's standard teach pendant has been replaced with a more functional joystick controller. The joystick allows the operator to use natural motions rather than push buttons to control robot movements, making manual control easier. A control station has been developed that incorporates the foystick controller, a microprocessor, the closed-circuit television monitors, a remote crane control pendant, and a 


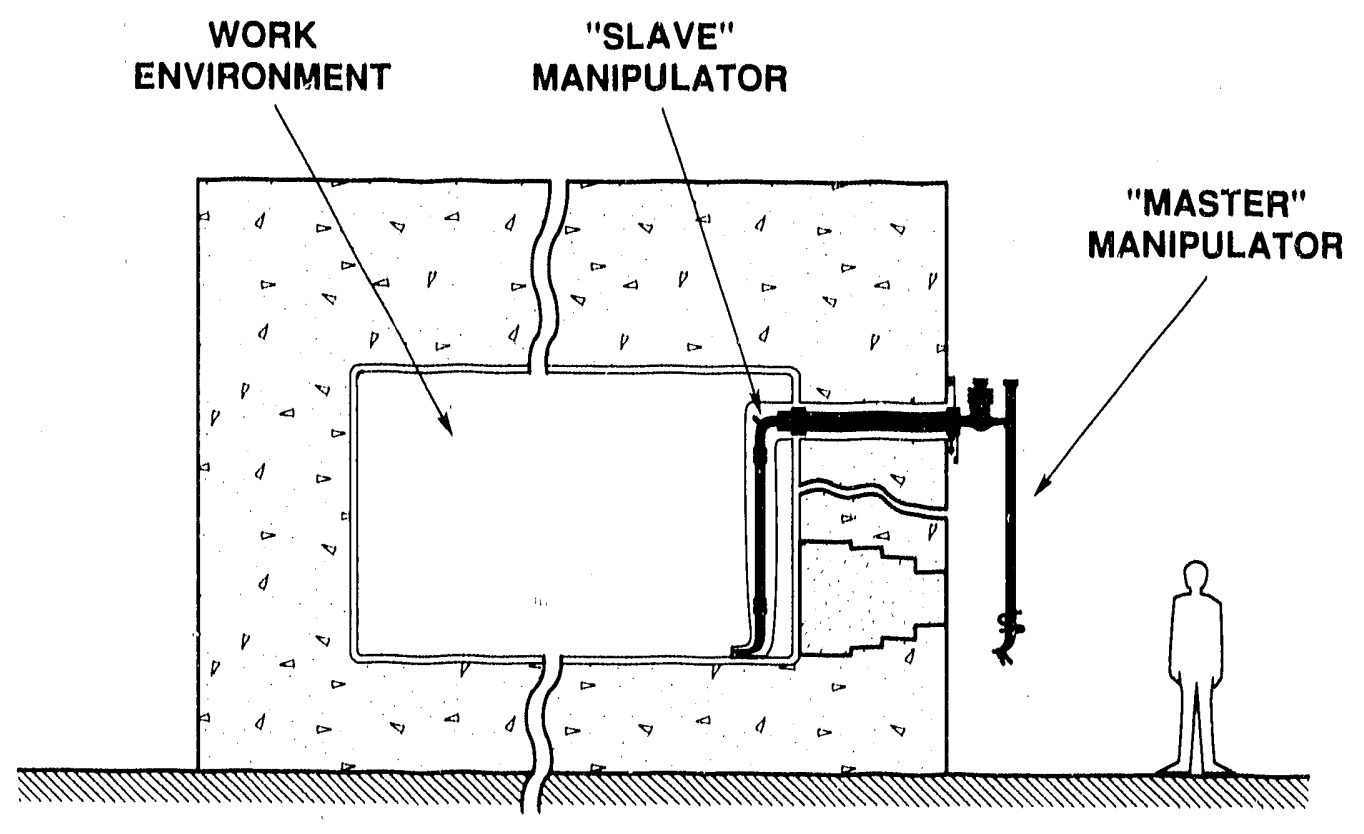

Figure 2-1. Master/Slave Manipulators 


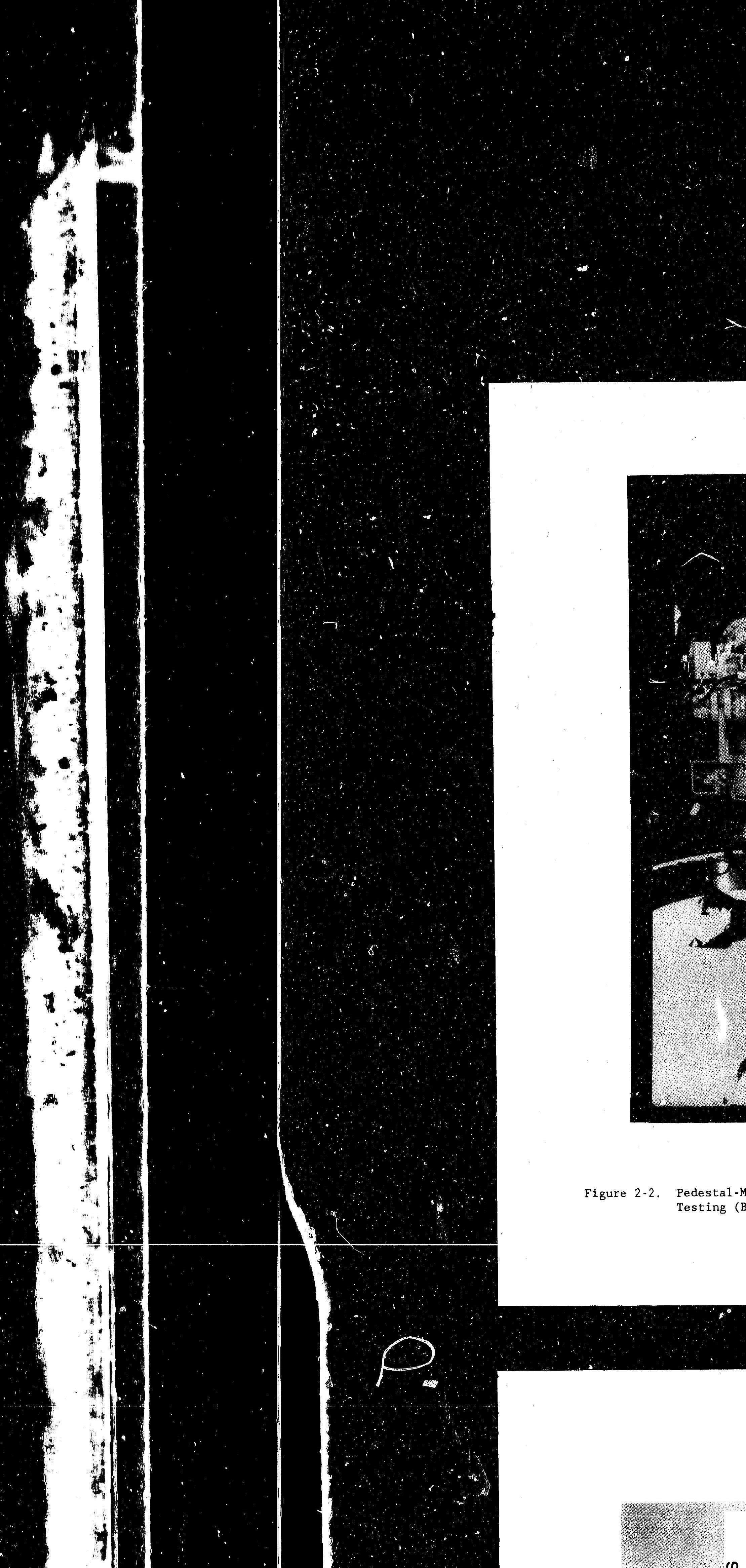




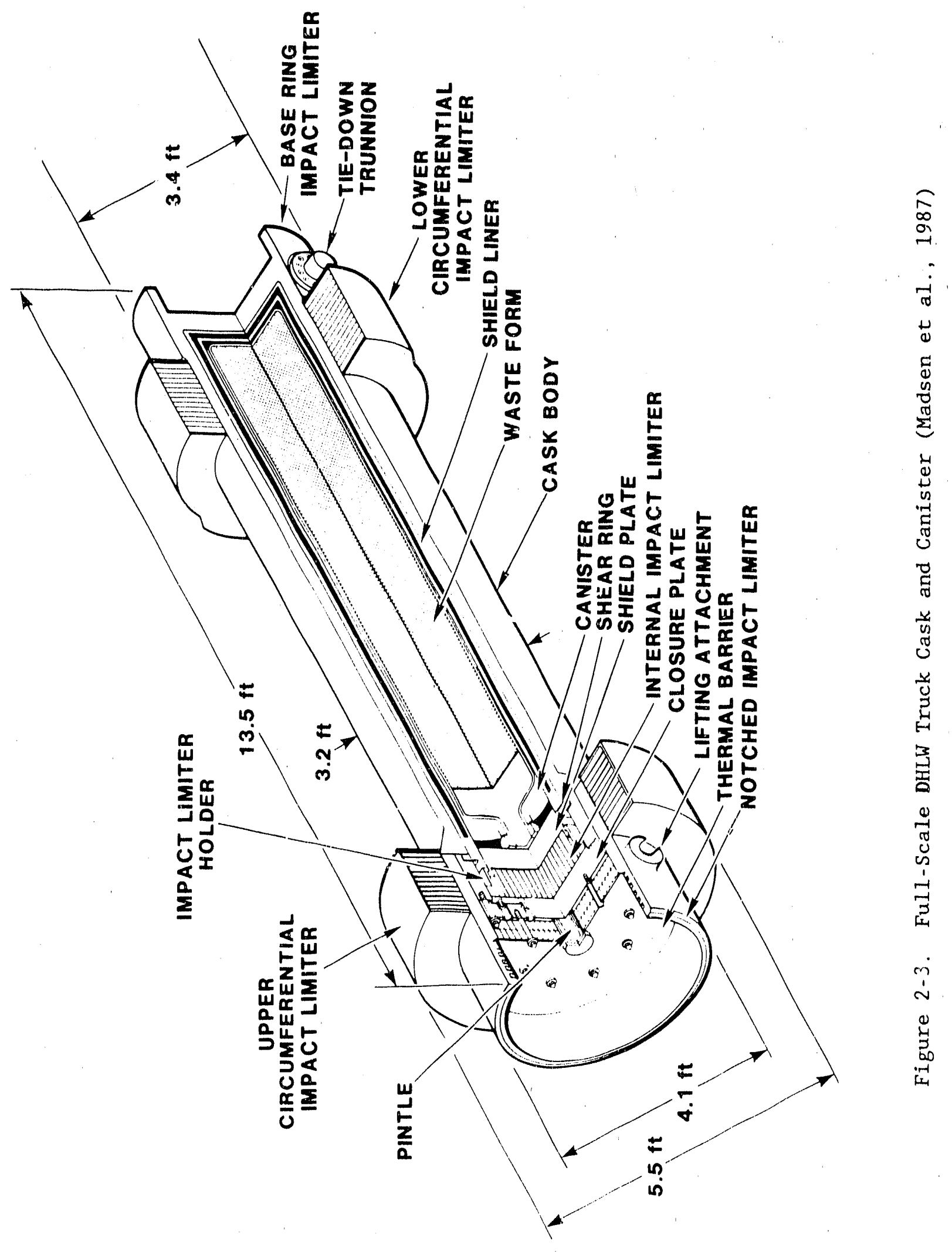


programmable controller. Dual three-degree-of-freedom joysticks are used to position and orient the tools used for specific operations.

A communications package has also been developed to interface the robot controller with a microprocessor. The package is necessary to establish a computer communications link and transfer data to and from the robot controller. Included in the package is the capability to store process data and adjust the coordinates of cask features as necessary, based on spatial reference points. Because the heary cask could not be exactly fixed in a wel1-defined position, reference points on the cask are determined manually with the robot in a manipulator mode. Once this is accomplished, all other coordinates of the cask features relative to the robot are automatically determined.

The DHLW cask has an outer lid that functions only as a dust cover. A lifting fixture has been designed for handling the cask dust cover. The fixture also provides reaction points for the torque wrench (features against which the wrench could rest to absorb the torques) during dust cover fastening or unfastening operations.

During the demonstration, the DHLW cask mock-up is removed from the shipping skid and placed into a vertical support fixture that simulates a facility cask cart. Cask location has been determined by establishing reference point coordinates on the dust cover and the side of the cask by touching those points. The dust cover is then removed, using a gripper end effector and a lifting fixture. The cask mock-up is then prepared for unloading, using the robot under both master/slave and automatic, preprogrammed control. A gas sampling operation is simulated, and the bolts on the cask lid are loosened. The bolts are spring-captured and remain fixed to the lid. The closure and the DHLW waste canister are removed, using a grapple and a remotely uperated crane, followed by reinstallation to simulate a loading operation. Finally, the robot is used to reverse the operational procedure.

The demonstration is conducted using simplified laboratory systems. operations are conducted with closed-circuit television and no direct viewing, which represents a worst-case situation. Even with these limitations, the proof-of-principle test successfully demonstrates several remotehandling operations for a waste transport cask. While the operations are slow, the feasibility of performing all caisk lifting, preparation, and unloading operations from a single control station using remote controls and viewing is demonstrated.

\subsubsection{Experiment Results}

A principal benefit of the proof-of-principle demonstration is the data collected which allowed a comparison of actual operating times with those predicted by the initial conceptual analyses (Yount and Berger, 1984). Operating times derived in the conceptual analysis are predicted, assuming enhanced robotic equipment, software, and programmable manipulators are available and comparable to those used in the proof-of-principle experiment. This analysis predicts that such equipment could reduce the total cask operating times by approximately 30 percent of current manual requirements 
(Berger et al., 1986). In addition, it is predicted that a fully remote system could reduce personnel exposure to near zero for normal operations.

The operating times obtained during proof-of-principle testing is in close agreement with the operating times predicted by the conceptual analysis. Because the proof-of-principle experiment employs standard commercial equipment, the values predicted in the conceptual analysis are conservative. This comparison is illustrated in Figure $2-4$.

The information obtained during the proof-of-principle demonstration has been used to estimate the impact of advanced handling methods on the design and operation of shipping casks (Berger et al., 1986). Two important conclusions about the technical feasibility of using currently available robotic systems for remote cask-handling activities have resulted from the proof-ofprinciple testing: (1) man-in-the-loop control of lifting, moving, and manipulation activities could result in handling time requirements in excess of similar contact operations and the need for rigid structures for cask components and equipment; and (2) the restriction of remote-handling methods to currently available commercial technology could result in significant cask design, fixturing, and tooling impacts.

\subsection{Technology Development Issues for Remote Cask Handling}

While robot control technology is limited in the commercial sector, applicable advanced technology is rapidly being developed in the research and development sector. Commercially available robot control technology typically restricts robot operations to repetitious movements to and from previously programmed locations. These locations must be rigidly fixed in the robot workspace.

Teaching, the most common mode of robot programming, involves moving the end point of the robot manipulator under operator control to a location in the environment and storing that position in the robot's computer memory. Manual programming of robot trajectories (paths through the environment) is normally accomplished using a teach pendant, or joystick, that allows the operator to move the robot to various work points. From these points, the robot can be commanded to move to other taught points.

Usually, the robot workspace must be rigidly structured by jigs and fixtures to ensure that the work pieces always have the position and orientation expected by the preprogrammed robot. Often this careful fixturing of work pieces may not be sufficient for certain robotic activities which require careful contact with objects. A robot never returns exactly to taught locations. The position error that occurs when a robot fails to exactly return to a taught location is the robot's repeatability. Typical repeatabilities for high-quality robots range from \pm 0.010 to \pm 0.001 in. Position errors of this magnitude can seriously affect a robot's ability to accurately and safely contact an object, such as a cask, during radiological swiping operations (Griesmeyer and Thunborg, 1988).

If a robot is commanded to return to a previously taught location where it was touching the desired point, the robot may, in fact, not contact the object. This would occur if the robot repeatability resulted in it moving to 


\section{CASK HANDLING OPERATION}

REMOVE CASK TIEDOWNS

UPRIGHT CASK

TRANSFER TO CART

REMOVE TOP COVER

SAMPLE GAS

PREPARE CLOSURE FOR REMOVAL

REMOVE CLOSURE

REMOVE CANISTER

REPLACE CLOSURE

TORQUE CLOSURE BOLTS

INSTALL TOP COVER

TRANSFER TO TRANSPORTER

INSTALL TIEDOWNS

\section{CUMULATIVE TIME IN MINUTES}

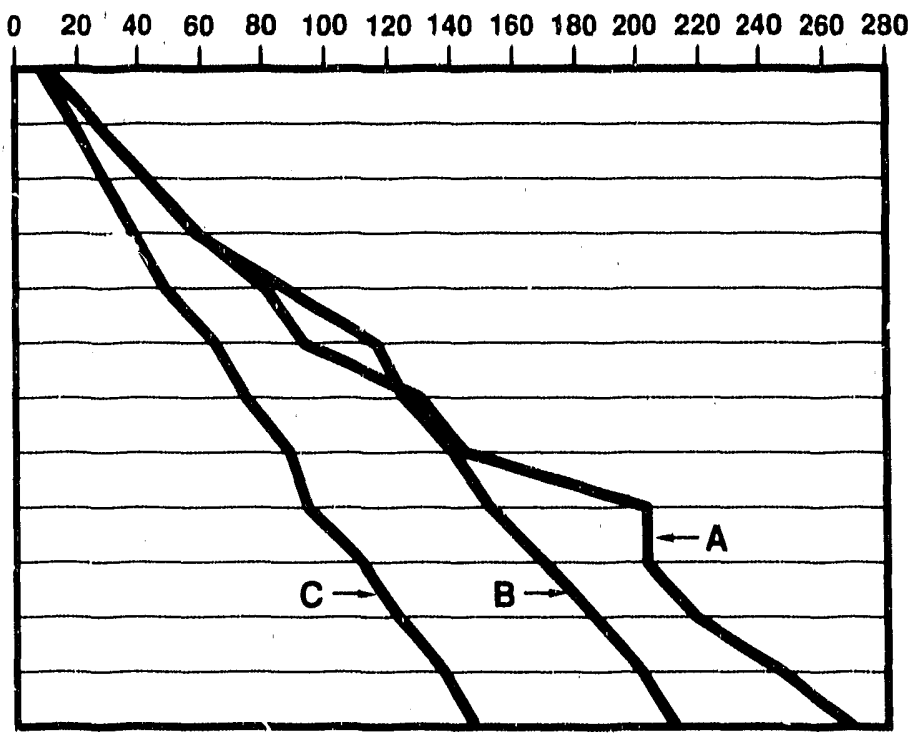
A Current Manual Operations
B Based on Conceptual Analysis
C Based on Proof-of-Principle Demonstration

Figure 2-4. A Comparison of Expected Cask-Handling Times Based on Current Experience and Predictions Derived From Conceptual Analysis and Proof-of-Principle Experiments (Berger, Gneiting, and Sanders, 1986) 
a point slightly above, but not in contact with, the surface. Such action during some cask operations would be unacceptable.

Similarly, if a robot tried to return to a previously taught surface point on a rigid object, but instead moved to a point beneath the surface due to poor repeatability, large forces would be generated. This could lead to damage of the object or the robot.

Thus, operations in which the robot must make contact with objects are best performed using force control. During force control, the robot moves to achieve a desired force and a desired position. Force-controlled robots are designed to comply with forces encountered, and such control is frequently termed active compliance.

Robot compliance can also be obtained by integrating substances, such as springs and foam rubber, that deform under force. Thus, when the robot contacts an object, the compliant substance deforms slightly, acts as a shock absorber, and forces on the robot and object increase slowly. This type of robot compliance accommodates small robot positioning errors and is termed passive compliance. Passive compliance occurs when forces generated upon contact are not actively controlled to achieve a desired force; contact forces are simply absorbed by the compliant substance.

Force-control research has shown the feasibility of using robots to make controlled contact with objects (see Appendix A). Most implementations of force control in robots employ a combination of active and passive compliance, termed stiffness control. In stiffness control, the known characteristics of passive compliance are employed ta determine the appropriate move by the robot to achieve the desired force. Thus, if the robot is contacting a surface with a resulting force, the known stiffness coefficient of the compliant material is used to predict the amount of robot movement required to achleve the desired force. Typically, the stiffness of the compliant material selected is matched to the robot's position control characteristics to provide responsive, active force control for the robot.

Unfortunately, commercial force-controlled robots are currently unavail. able. However, advanced research robots have demonstrated the feasibility of force control. In addition, these advanced systems have shown the feasibility of using other sensors, such as vision, for servo control of robots in general. With restricted personnel access to robot workspaces in nuclear environments, the manual teaching approach to robot programming is difficult. Such sensor-based servo control would allow robots co sense objects in the environment and respond to them without direct operator intervention.

Current commercial controllers often must be modifled to implement sensor feedback. However, conversations with selected robot manufacturers, such as Adept, CIMCORP, and Cincinnati Milcron, indicate that future controllers may provide for sensor feedback incorporation (Griesmeyer and Thunborg, 1988).

In advanced robotic applications, the robot control functions w111 be integrated primarily through supervisory computers using models of the robots and their environment, 1.e., model-based control. Typically, in research 
robotic systems currently under development, several. computers external to the robot controlle: are provided to allow for interrogation of sensors, collection and storage of data, coordination of the robot system with other process flows, and operator interface with the system. Sensor information is used to monitor system operation and to provide updates that are sent to the robot controller; this process provides a form of sensor-based servo control.

Model-based control of robots with sensor feedback requires less structure in the environment in the form of $\mathrm{jigs}$ and fixtures (see Appendix $\mathrm{C}$ ). Using a computing system to provide sensor interpretation can, in some instances, allow an existing commercial robot to perform complex tasks requiring the robot to adapt to its environment during task execution. In addition, the robot can recognize and respond to off-normal conditions, resulting in increased system efficiency and safety.

The procedures and tools necessary to perform cask operations are generally developed by the cask designer; the user is then trained to use these procedures and tools. However, for advanced robotic cask-handling applications, procedures and operational descriptions must be integrated into the software control system of the recelving facility. This requires that cask descriptive software, which contains digitized coordinates of features and mathematical dascriptions and definitions of surfaces, be of approximately the same level of detail as the final drawings for the hardware.

\subsection{An Approach to Evaluating Advanced Remote Cask-HandIing Technology}

In 1984, SNL initiated a comprehensive effort to integrate advancing robotics technology with cask-handling feasibility assessments. This advanced technology is also transferred to private industry to ensure avallability for actual repository operations.

An experimental approach is being used to evaluate speciflc cask operations; the RRSAS has been the first test of thls approach. Using existing technology, operational and descriptive software and hardware in the form of robotic end effectors are designed in conjunction with the interfacing cask component desigu. Software and hardware requirements are being developed for remotely identifying a cask or component, establishing the cask's position in three-dimensional space, and Integrating a software description of the cask, its components, and contents with operational features and sensory feedback control systems. Conceptual designs of specific cask features, operating software, and end effectors for performing these operations are developed and tested in actual feasibility demonstrations.

Resulting design constraints for cask and robot system interfaces are incorporated into cask interface specifications (Griesmeyer and Thunborg, 1988). Handirig times for speciflc operations are recorded and implemented into a data base to correlate expected cask turnaround times and exposure estimates with specific design features for future system trade-off analyses.

The priority of addressing specific cask operations was determined by (1) the potential benefit in time and exposure reductions, (2) the avallabil. ity of applicable technology, and (3) the applicability of the technology required for a specific operation or series of operations to subsequent 
feasibility evaluations of other operations (Strip, 1987). Since healthphysics operations account for a significant portion of worker dose during cask-handiing operations, and automation of such activities requires numerous capabilities that apply to virtually all cask operations (Griesmeyer and Thunborg, 1988), the RRSAS profect was inftiated to address radiation and contamination surveys on waste transport casks. The balance of this report describes and summarizes the achlevements of the RRSAS. 


\subsection{RRSAS DESCRIPTION}

As part of cask-handling operations at nuclear waste ruositories, workers will perform two types of radiation surveys. A nuncontact energy survey slowly moves a radiation countex system near the cask's surface to measure neutr in and gamma radiation originating from the cask's contents. A second particulate contamination survey, or swiping, wipes the cask with filter paper to remove particles from the cask's surfa:e. The filter paper is then placed in a special instrument to measure any alpha, beta, and gamma radiation originating from any contamination by radioactive particles present on the cask's surface.

Occupational radiation exposure can be substantially reduced if radiation and contamination surveys are performed remotely, because manual surveys require long personnel exposure times (see Section 2.3). Also, swiping is not a repeatable operation when performed by humans. Robotic systems, however, can standardize swipe parameters, such as contact area and force. In addition, robotic control systems can automatically maintain accurate records of where swlpes are performed on the cask surface and the contamination level at that location. Finally, computer analysis of the radiation survey results can be accomplished quickiy; the results are automatically correlated with the cask model, operational history, and operatinnal limits. This process simplifies records maintenance and improves quality assurance. Also, task results can be immediately displayed graphically to inform operations personnel of survey results.

The RRSAS was developed to examine the relationship between cask design and the use of robots for conducting noncontact and swiping surveys on nuclear waste transport casks. The complete system, shown in Figure 3-1, consists of a CIMCORP XR ${ }^{\circledR} * 6100$ gantry robot, modified for force-controlled operation. This prototype robotic system performs five major tasks:

(1) determines the cask's location after delivery in relation to the robot's workspace, (2) identifies the cask and automatically formulates a comprehensive survey plan, based on cask contents, the results of past radiation and contamination surveys, and the results of random generation of survey locations: (3) performs a remote visual inspection of the cask for mechanical damage; (4) executes contamination and radiation surveys of the cask exterior; and ( 5 ) analyzes and presents survey results to the operator during system operation.

The following sectlons review the tasks executed by the RRSAS and the equipment required to perform those operations. Detalled, technical descriptions of the RRSAS and specific subsystems are contained in the appendices.

The system control approach is discussed, and the results of RRSAS uperations are also reviewed.

\subsection{Cask Location}

Once a cask has been delivered, the RRSAS automatically determines the position and orlentation of the cask with a computer vision subsystem (see Appendix B). Deslgn specifications for future nuclear waste repositories provide that a driver deliver the shipping cask and transporter to a position

*XR ${ }^{\circledR}$ is a registered trademark of CIMCORP Inc. 


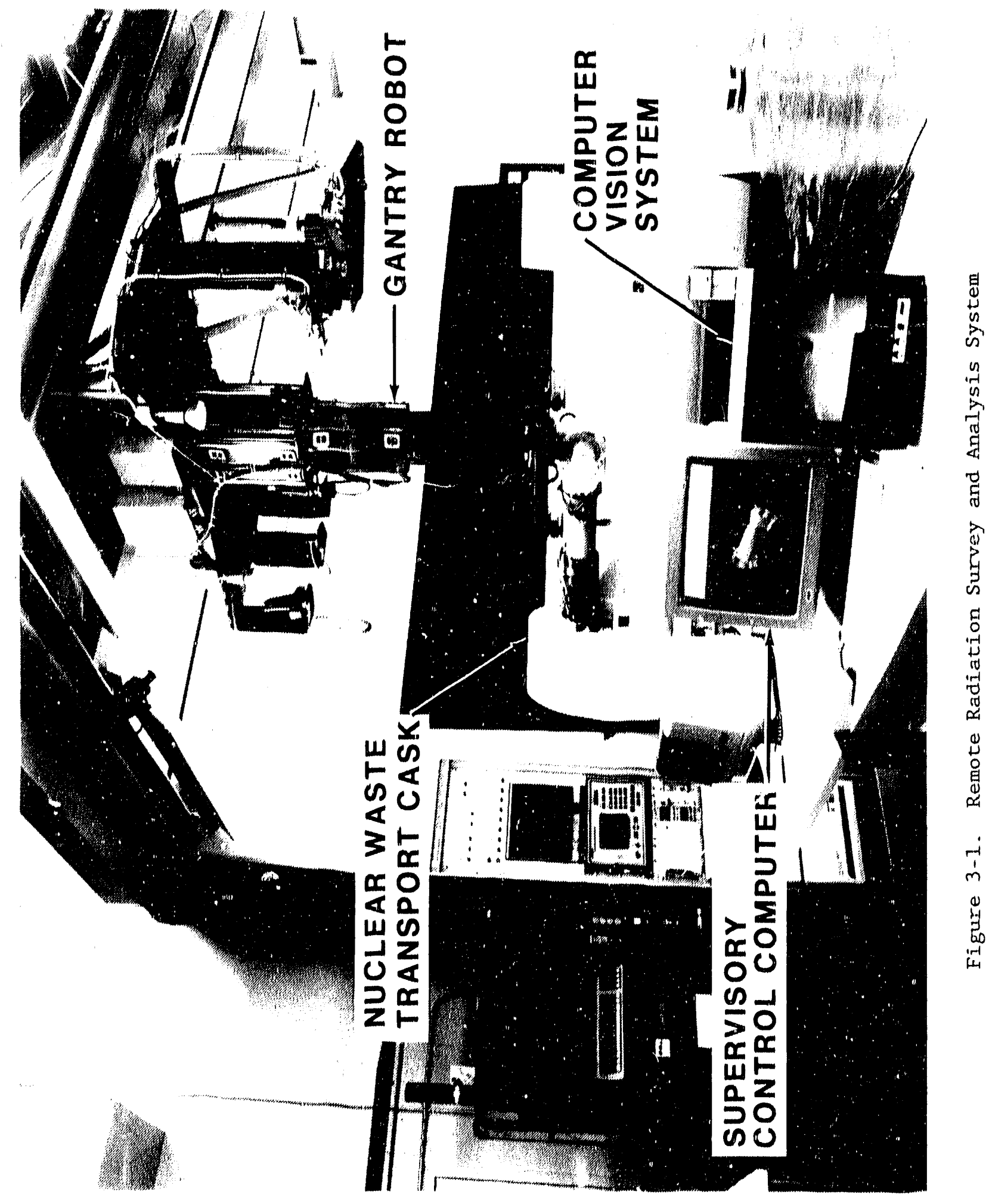


under the gantry robot. An operator manually enters the baslic cask type lnto the supervisory computer, thereby providing the robot with the approxinate location of known visual reference points on the cask surtiace. The system handles up to 15 basic cask designs. The robot then positions itself to allow its cameras to locate the visual reference polnts and, hence, determines the cask's location with respect to the robot.

The RRSAS uses two cameras mounted on the robot's vertical mast to determine the three-dimensional location of each visual feature, such as the square lugs shown in Figuie 3-2. The cameras allow the computer system to triangulate and, thus, compute the three-dimensional location of each visual. feature. By locating two visual reference polnts on the near side of the cask and one point on the far side, the RRSAS can determina the location and orientation of the cask to within $0.060 \mathrm{in}$. The computer vision system automaticaliy correcta for changes in illumination error; carefully control. led lighting is not required.

The system also compares the distance between the visual reference polnts on the cask with distances contained in a computer model of the cask. If errors are found, it repeats that portion of the computer vision task automaticaliy, without operator intervention.

\subsection{Cask Identifleation}

The specific radiation survey to be conducted on each cask depends on i.ts contents and history; therefore, each cask must be associated with software data bases identifying this information. The RRSAS uses a commerctal bar code reader, which is simllar to those used in grocery stores, to scan a bar code on the end of the cask (Flgure 3-3). The supervisory computer then retrleves from memory a mathematical. description of the cask, which is a computer-alded design (CAD) model, as well as a record of the cask's histary and contents. The computer then develops a detalled survey plan basod on this information. If the cask history reveals previous hot spots, 1.e., areas with higher-than-normal radlation or contamination levels, these points are selected for close evaluation.

\subsection{Remote Vlgual Inspection and Radfation Survey}

The first phase of the survey performed by the RRSAS is the noncontact radiation survey. Visual inspection of the cask for mechanical damage is combined with the radiation survey. The robot uses a tool consisting of a radiation detector and a closed-circult video camera (Flgure 3-4). Noncon. tact radiation surveys are performed using a Gelger-Muller radiation counter. to scan the cask surface. The closed-circult video linage 1 s displayed to the operator in the control room. The operator checks for physical clanage to the cask and for any unauthorlzed objects that may have been placed on the cask transporter. The amount of detected radiation is promptly displayed to the operator using computer graphics. Figure 3-5 shows the RRSAS display of: noncontact radiation survey results after a typlcal cask survey, the computer remembers the locations of all survey points and can automaticali.y return for a detalled resurvey, lf destred.

Health physiclsts at SNL determined the proper survay scan rate. Currently, the noncontact radlation scan rate $1 \mathrm{~s} 6 \mathrm{ln} . / \mathrm{s}$. Linear scans are 

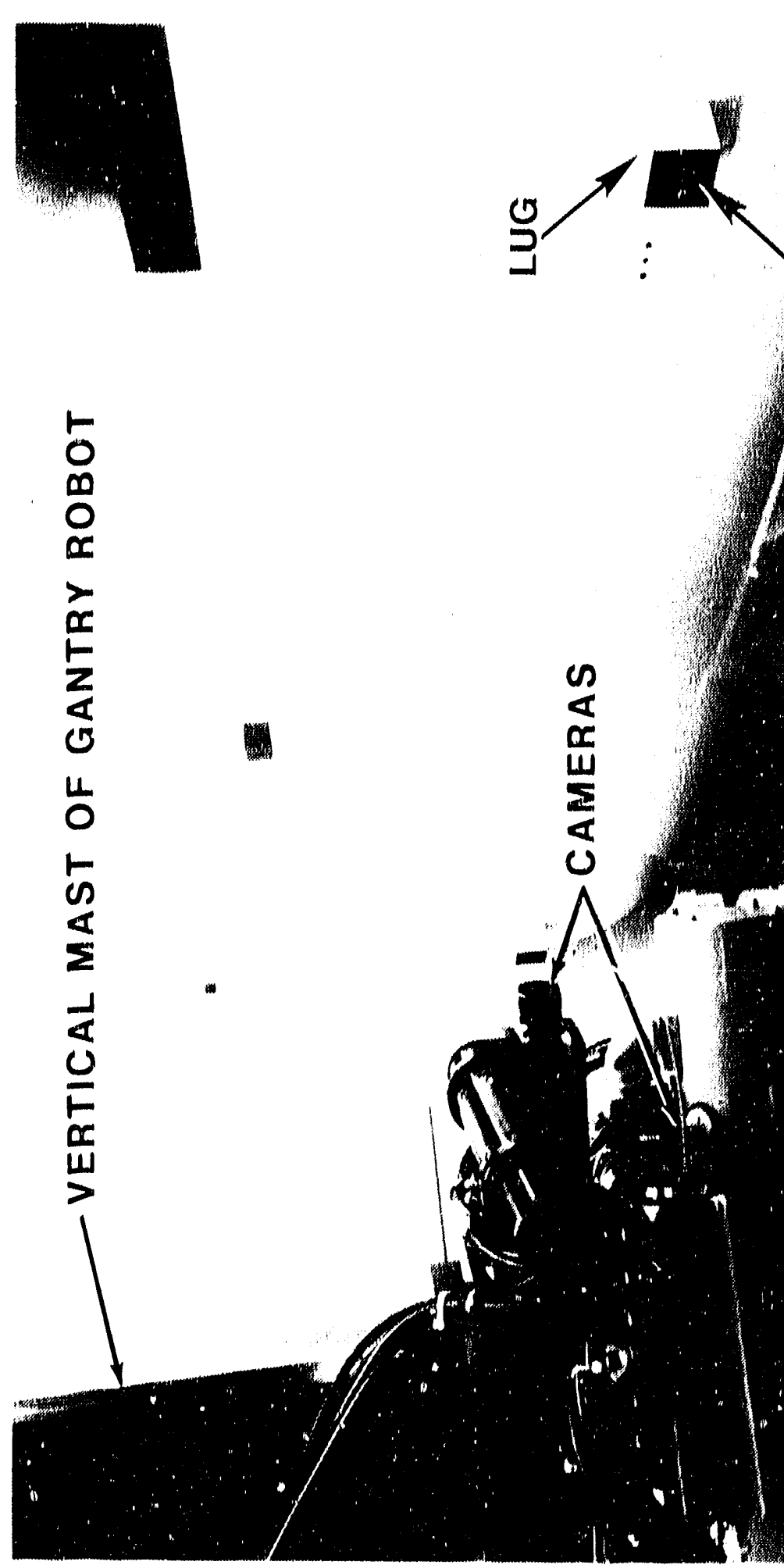


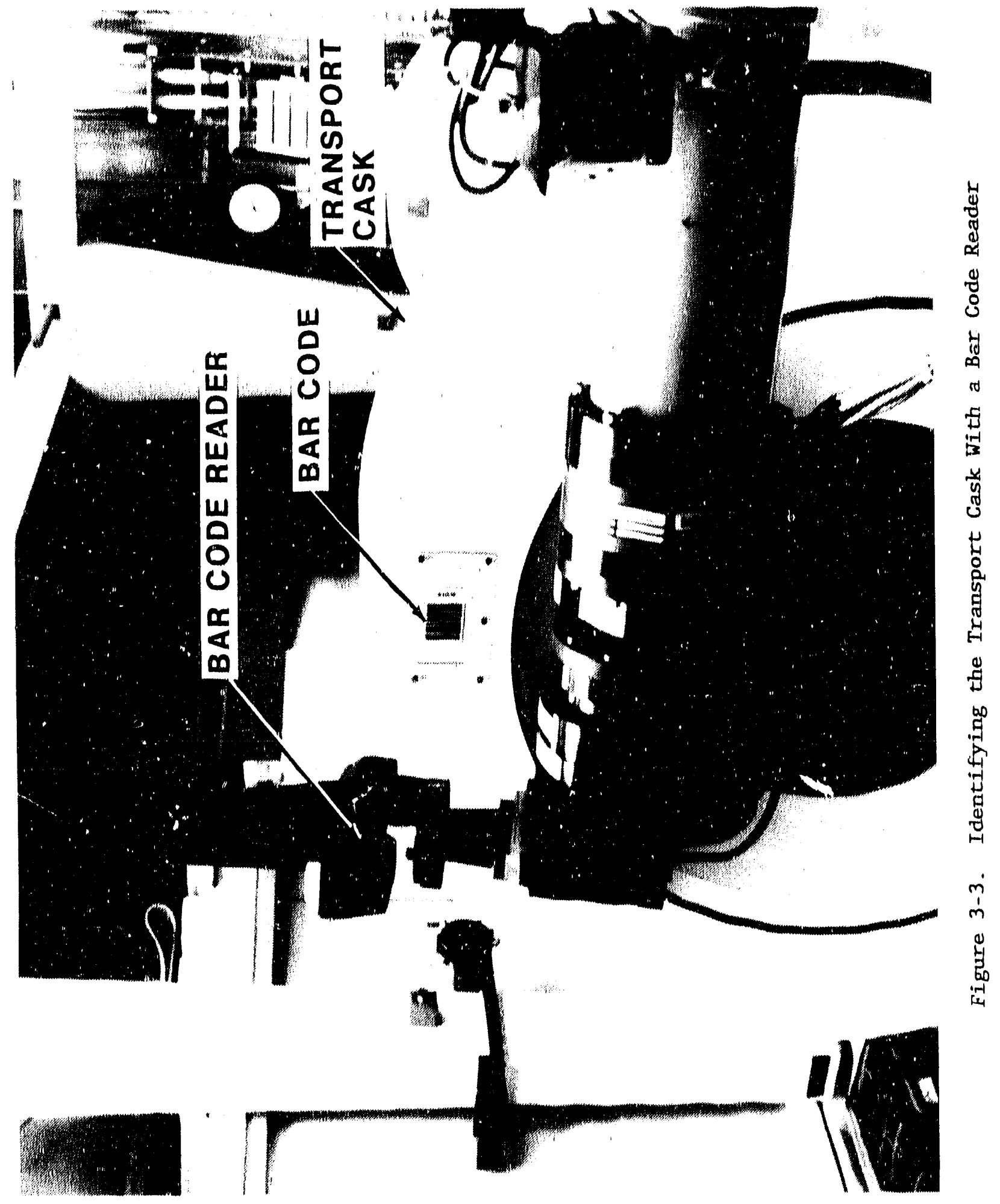




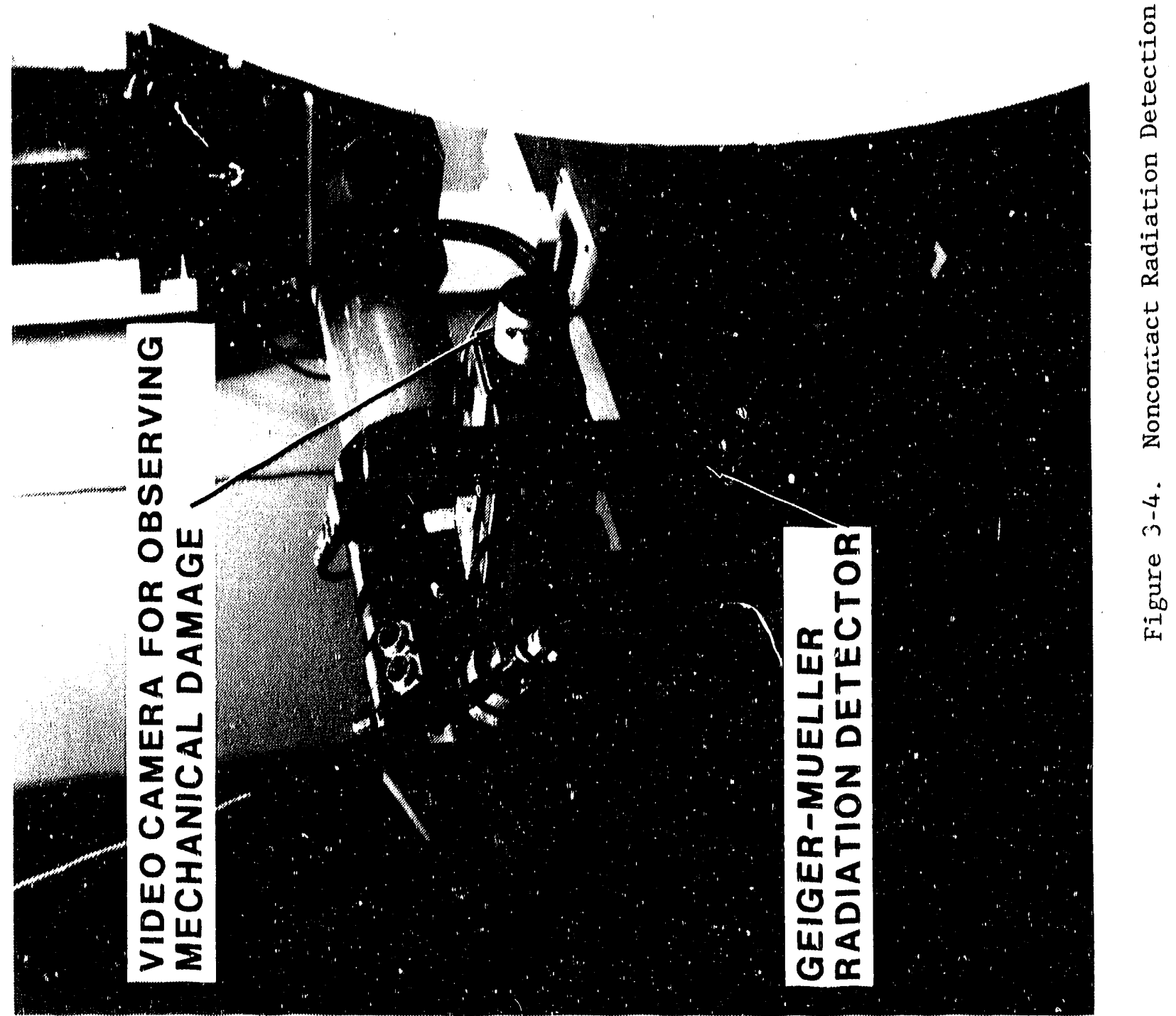




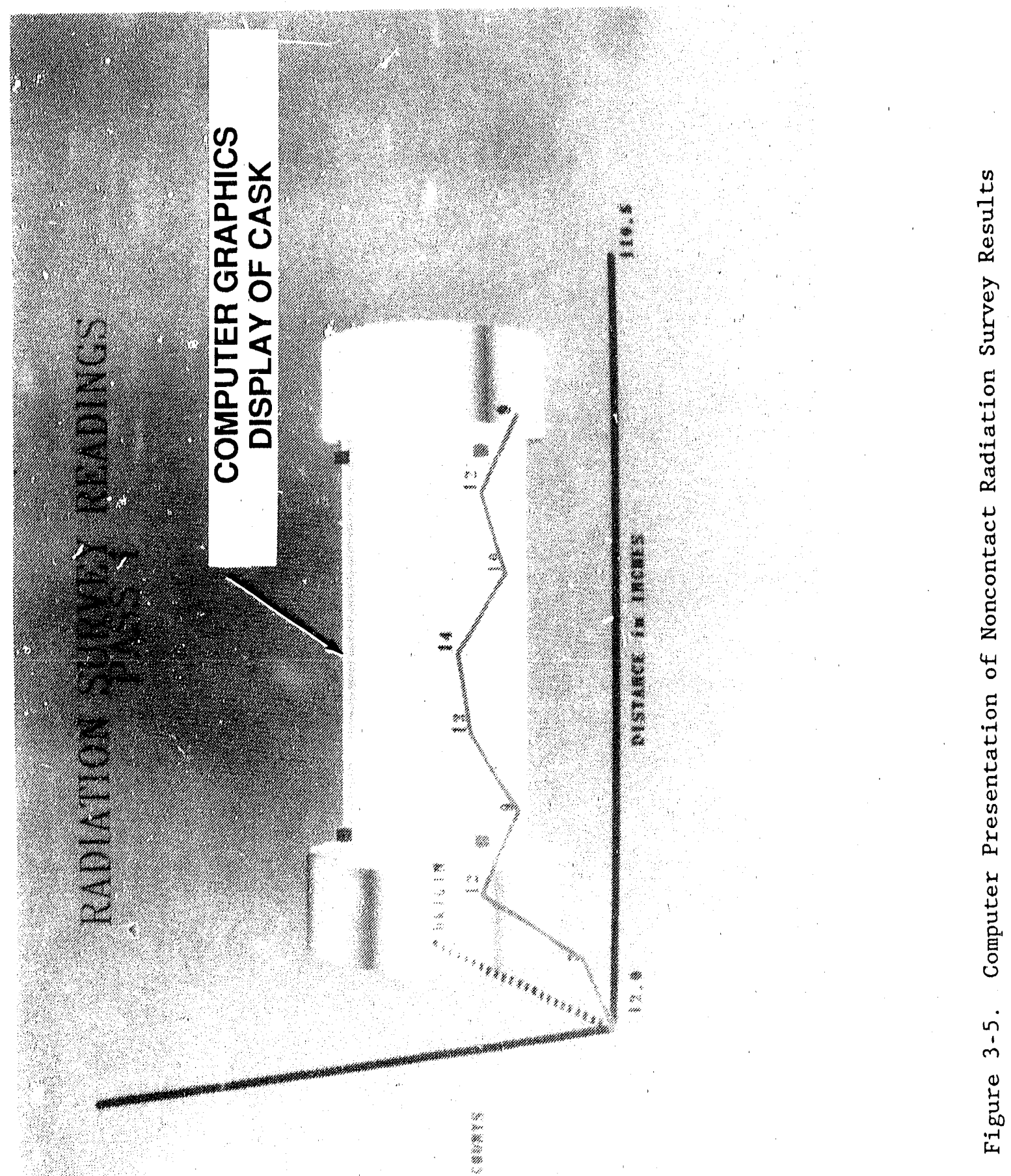


performed at seven locations around the cask to demonstrate a complete radiation survey. After completing the noncontact radiation survey and the visual inspection, the robot returns to its starting position and awaits the next step. This allows the operator to visually verify that the robot has completed the task.

When the noncontact surveys are complete, the RRSAS performs a contact swipe survey at multiple points (currently 40) on the cask surface, then analyzes the radiation emanating from the contaminated swipes. As shown in Figure 3-6, the swipes consist of filter paper mounted on semicircular plastic plates that are flat on one side. A 3/16-in.-thick piece of foam rubber between the filter paper and the plastic plate provides the passive compliance needed for active force control of the robot during the swiping process (see Section 2.5). Swipes are individually dispensed from a supply magazine (Figure 3-7, and Appendix D) mounted on the robot structure. The robot uses its gripper to pick up a swipe (Figure 3-7) and then proceeds to a cask swipe point.

Swipe points on the cask surface are randomly generated by the supervisory computer using the CAD model of the cask. Computer graphic displays are used to show the operator which point will be swiped (Figure 3-8). The operator can then visually verify that the robot is moving to the proper location. The computer automatically programs the robot arm movements, or trajectoiles, through space to prevent collisions with cask features such as the lifting trunnions. The computer also automatically positions the swipe normal to the surface being surveyed and determines the pruper direction to move during the swiping process. For example, during swiping of the top of the simulated lifting trunnion, the computer directs the robot to approach the trunnion in a manner that avoids collision with the impact limiter (Figure 3-9). The swipe is automatically oriented so that the flat edge (Figure 3-6) fits into the joint formed by the square lug and the cask body. Finally, the computer directs the robot to move to the right during the swiping process, avoiding collision with the impact limiter.

The RRSAS swiping process is performed using force control. The system uses a commercial force sensor mounted near the end of the robot arm (Figure 3-8). During a swiping operation, the robot approaches the cask's surface to within 1 in. under position control and then makes contact with the cask under force cortrol.

Position control, under which the RRSAS robot is commanded to move to positions in space, is the normal operational mode for most commercial robots. This type of control is inadequate for making contact with the cask's surface, due to small inaccuracies in the RRSAS. If, for example, the RRSAS robot is commanded to move to a position believed to be on the cask's surface, and it is, in fact, 0.01 in. above the surface, swiping cannot be accomplished, since the swipe is not touching the surface. Because of this, force control, which is used when the RRSAS robot is commanded to press with a specified force on the cask's surface, was developed by SNL for the RRSAS project (see Appendix A).

Once contact has been made, robot control is partitioned. Force control provides for movement normal to the cask's surface to maintain a desired contact force, i.e., stiffness control, and position control provides for 


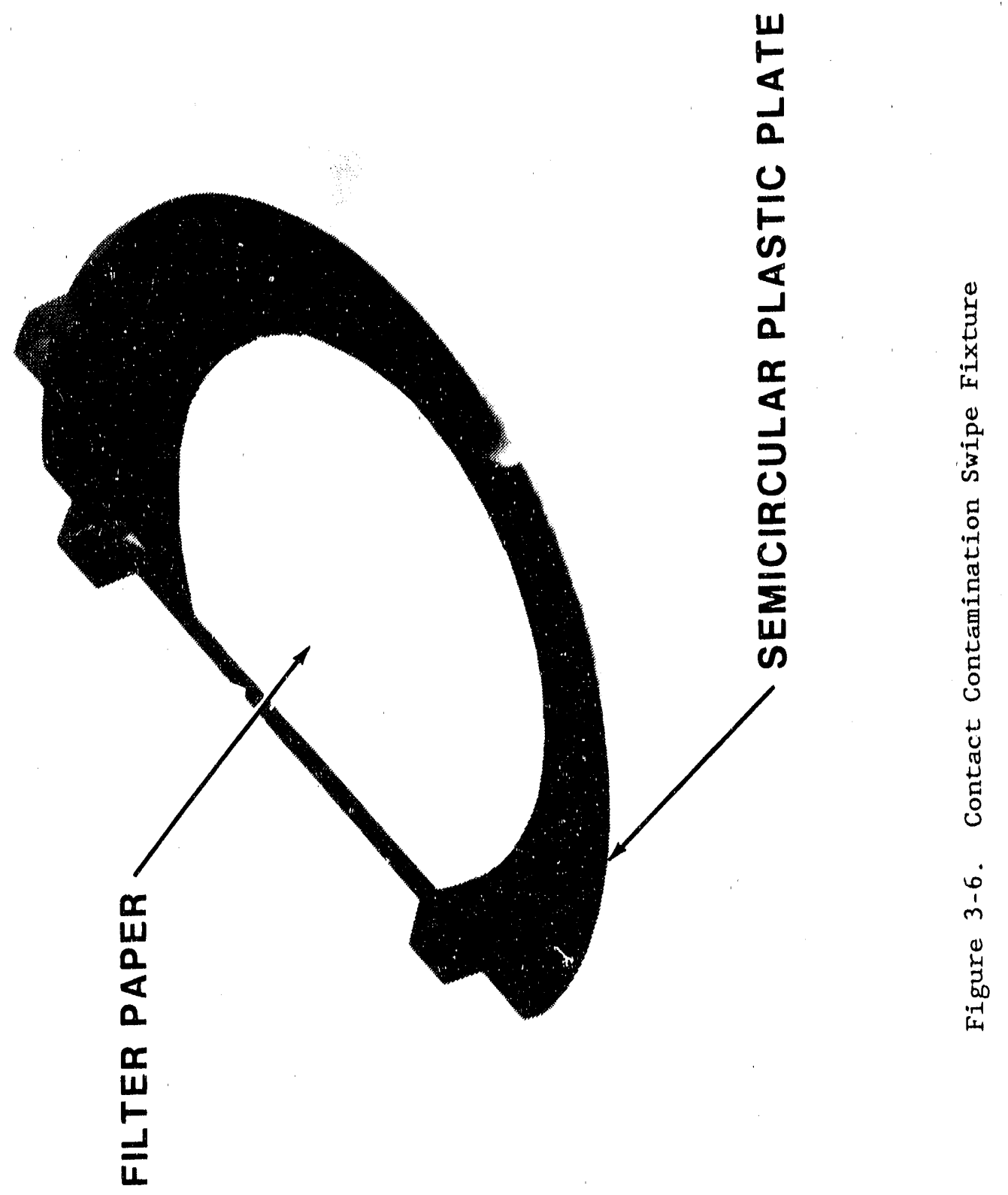




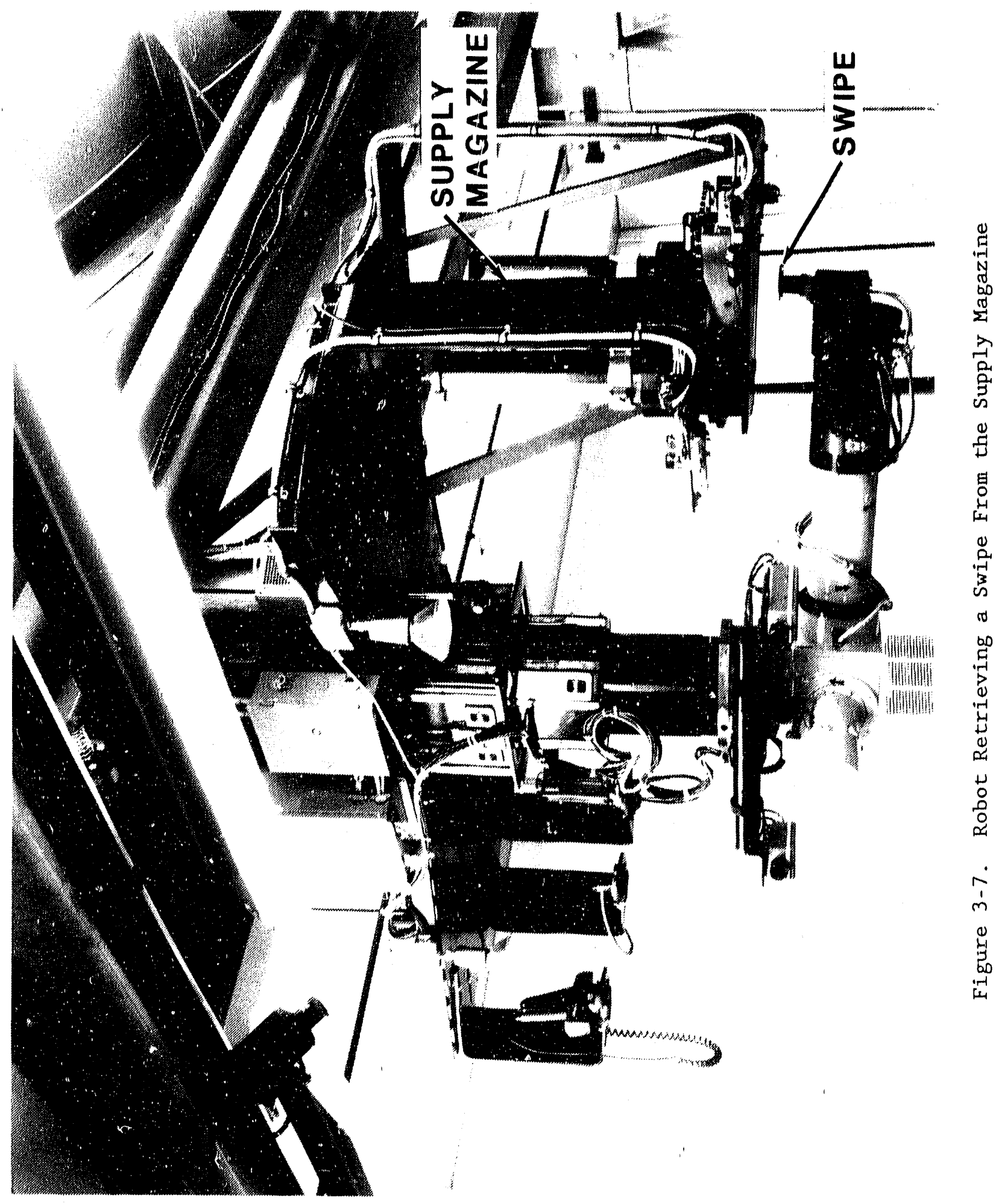




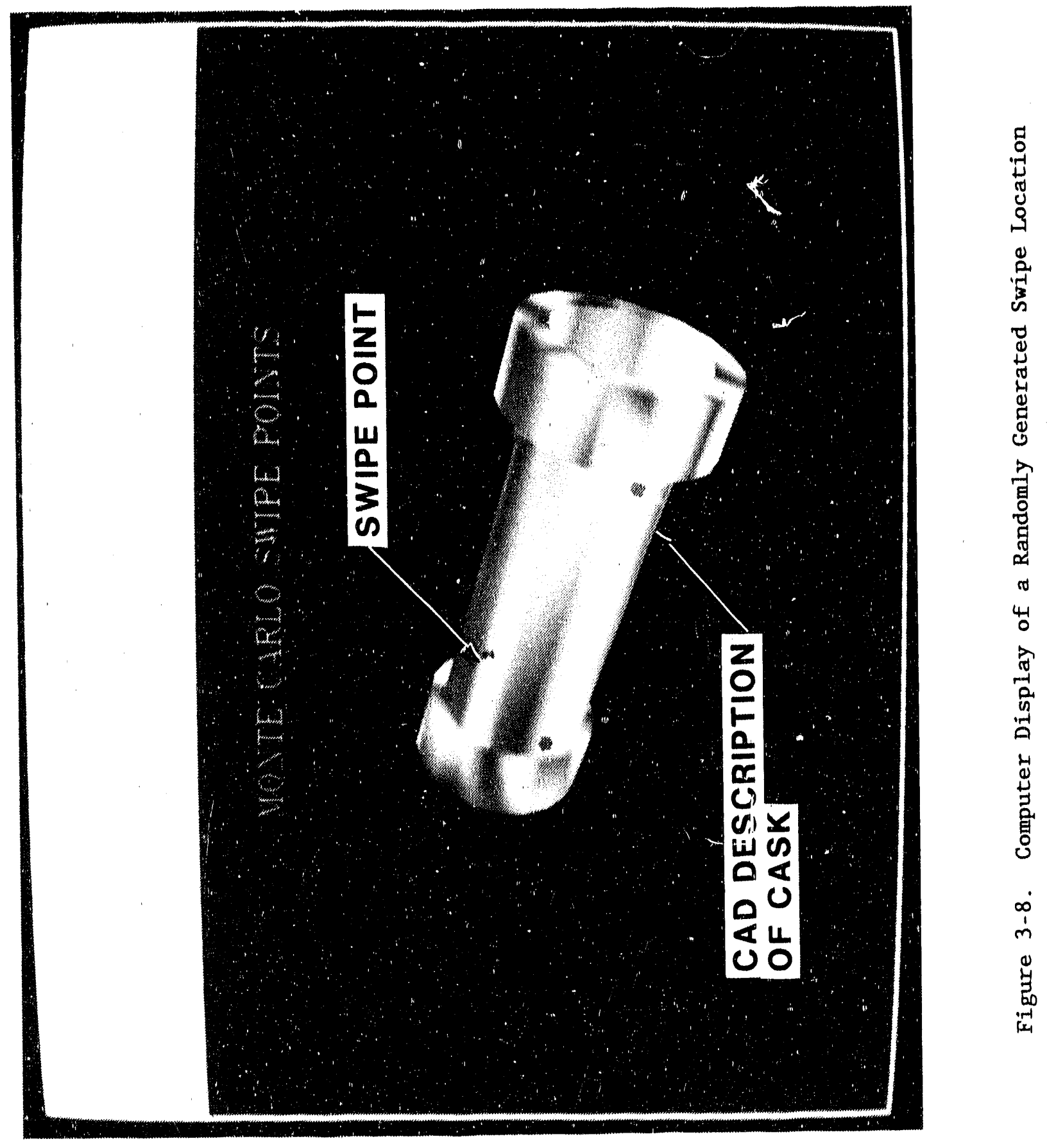




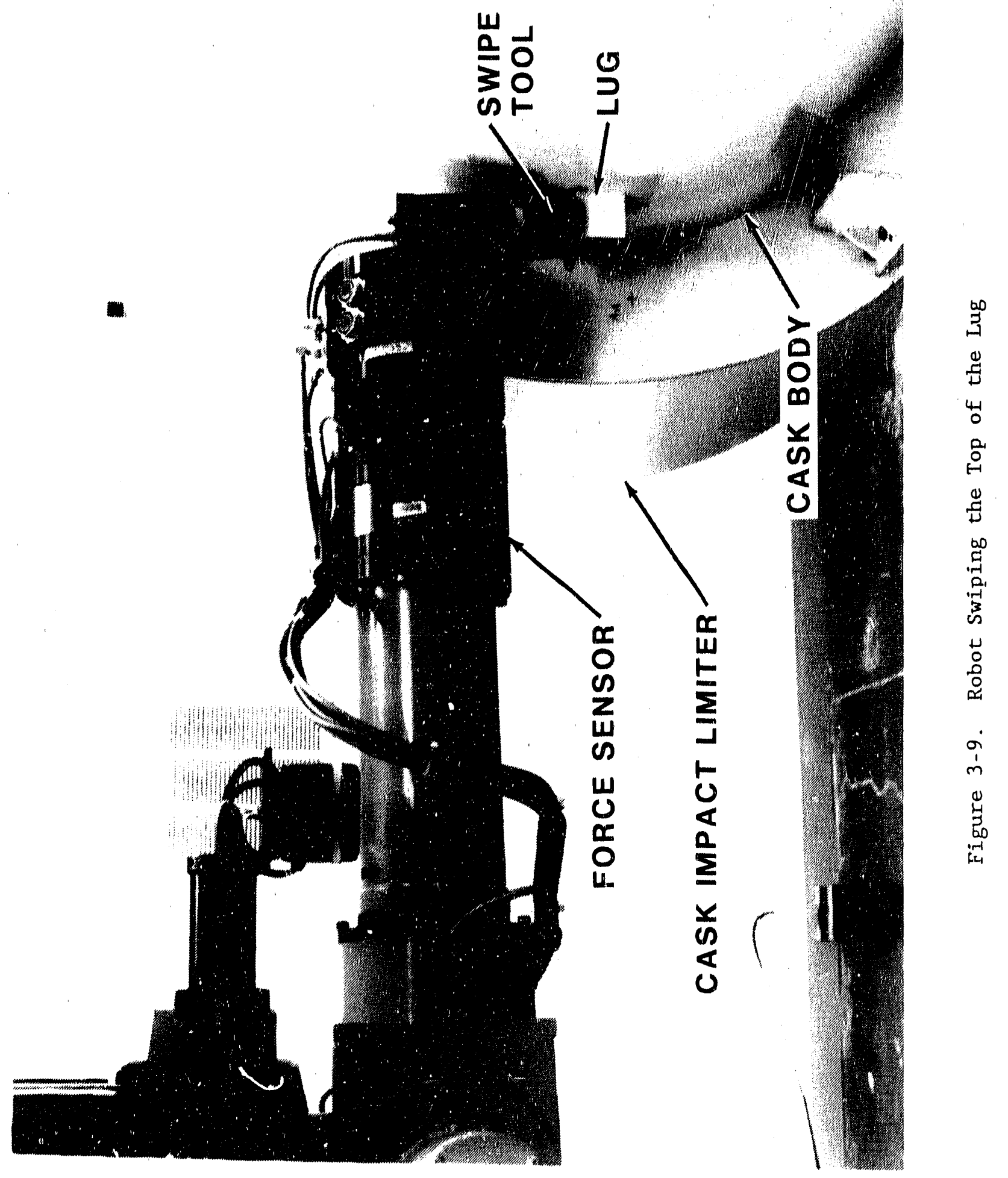


movement along the cask body. This type of dual hybrld force/position control allows swiping of the cask surface while malntaining a constant contact force. As shown in Figure 3.10, the inltial contact force of 7 to 8 lb is reduced to $4 \mathrm{lb}$ within $1 / 2 \mathrm{~s}$, and the robot maintains this reduced force ( $\pm 1 \mathrm{lb}$ ) during the $4 \mathrm{~ms}$ swipe. Extenslve development at SNL in hybrid force/position control technology, together with robot-controller modiflcation, have been required to allow the $4,500-1 \mathrm{~b}$ robot to achleve this precise level of control.

When a swiping process is complete, the used swipe is placed in a storage magazine. Upon completion of the entire contact swipe survey, the robot picks up the storage magazine and delivers it to a Canberra swipe reader (Flgure 3-11). This reader was modifled by SNL engineers to provide for computer control and automatic swipe feeding. Once the magazine is delivered to the raader, it is locked into place, and the reading process begins.

Contact survey results are displayed to the operator on a computer terminal. The operator is alerted to all contamination survey results higher than predetermined specifications. Contaminated locations, should they occur, are indicated by a blinkirig light on the graphic display of the cask. All high-radiation readings are associated with the sample location on the cask surface, and provisions are made for automatically returning the robot to that location for resurvey, if desired. The time required to accomplish the radiation and contamination survey test for 40 randomly generated swipe locations is approximately $29 \mathrm{~min}$. Manual surveys typically require approxi. mately $1.20 \mathrm{~min}$ to perform all swiping, detector, counting, and ar!elysis operations (Schneider et al., 1987). Further systems analysis indicates that this total swiping time could be reduced by 2.5 to 50 percent by reducing electronic delays within the robot controller, thus allowing the robot to operate safely at higher speeds.

\subsection{RRSAS Control Concept}

The RRSAS supervisory control system is the integrating agent for the entire robotic isstem. Robot system control may be either manual or auto. matic. Manual control is used for error recovery situations when the operator must move the robot under teach pendant control. The gantry robot teach pendant is shown in Figure 3-12. The operator commands the robot to move by pushing the appropriate buttons on the teach pendant. When using the teach pendant, the operator must provide all the detalled robot motion commands required to accomplish a given robot task.

Under programmed control, the operator serves in a supervisory capacity only, verifying that the system is operating correctly. The RRSAS supervisory control environment supports both computer reasoning about robot actions, such as planning of collision-free robot movements, as well as serenr-based control, e.g., force control. In addition, supervisory control provias for recovery from error situations and integrates the diverse RRSAS subsystems with a reliable functioning system (see Appendix C).

The st icture chosen for the control system is shown in Figure 3-13. This structure is similar to that of many human organizations in which a supervisor controls the activities of several subordinates with specialized 


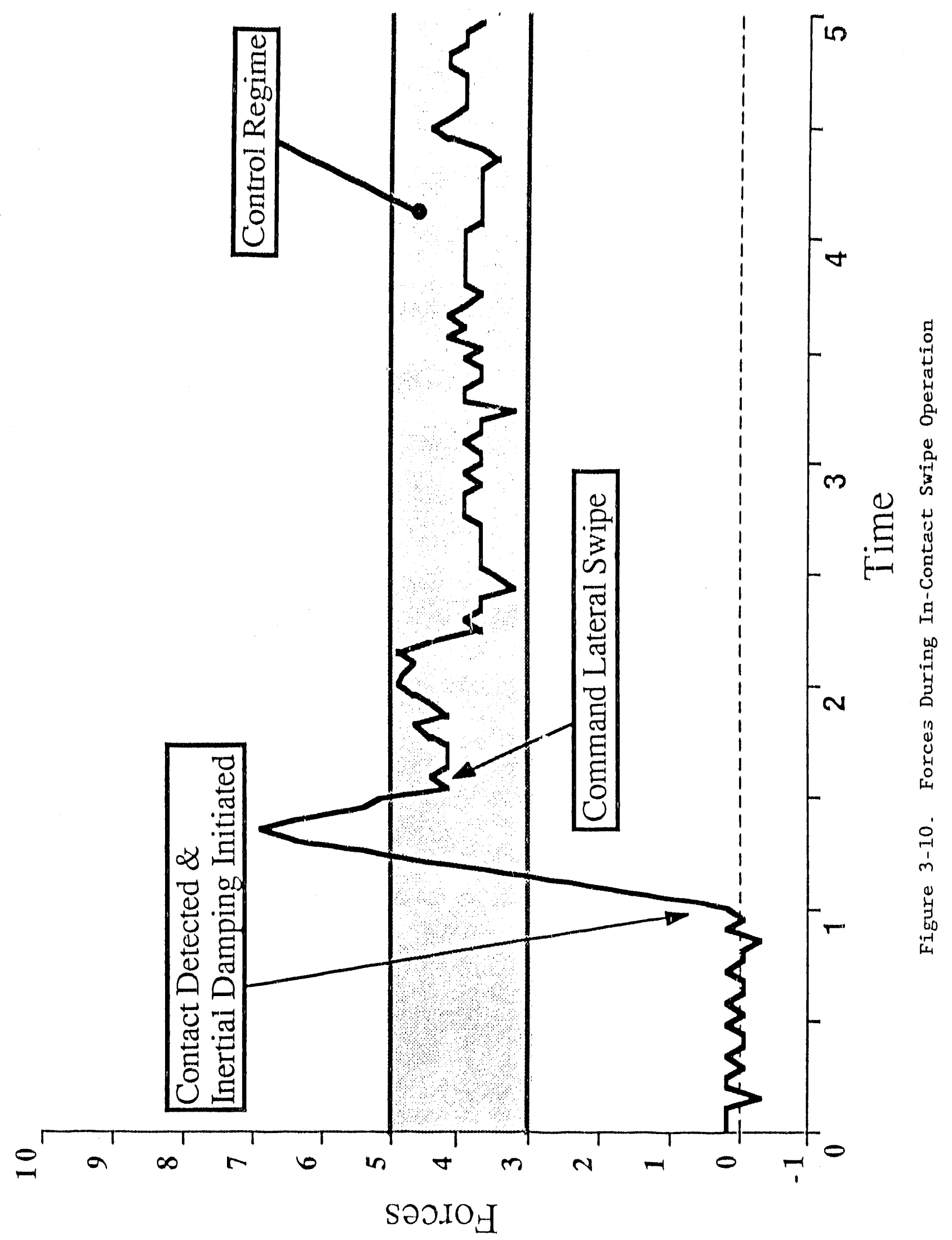




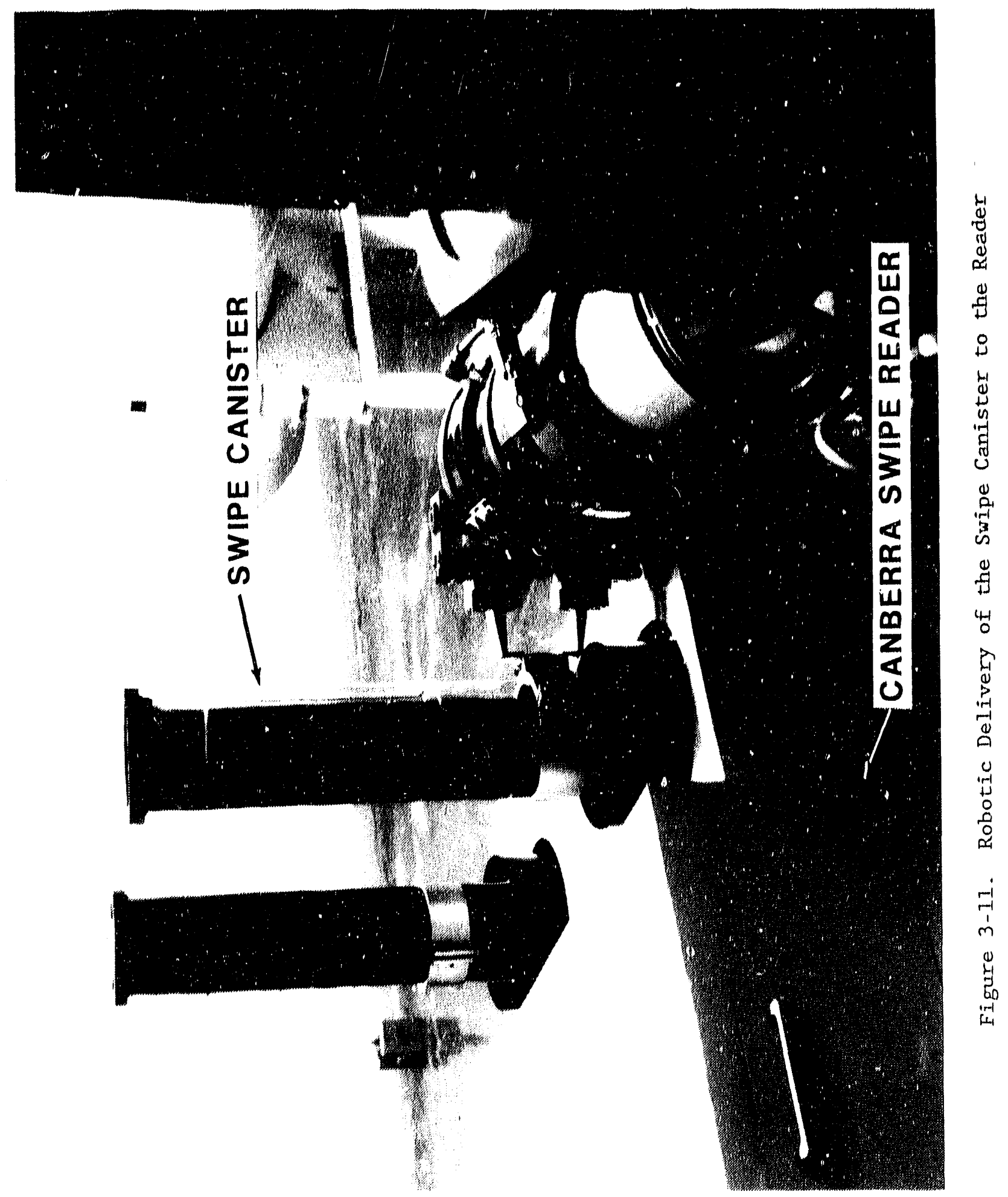




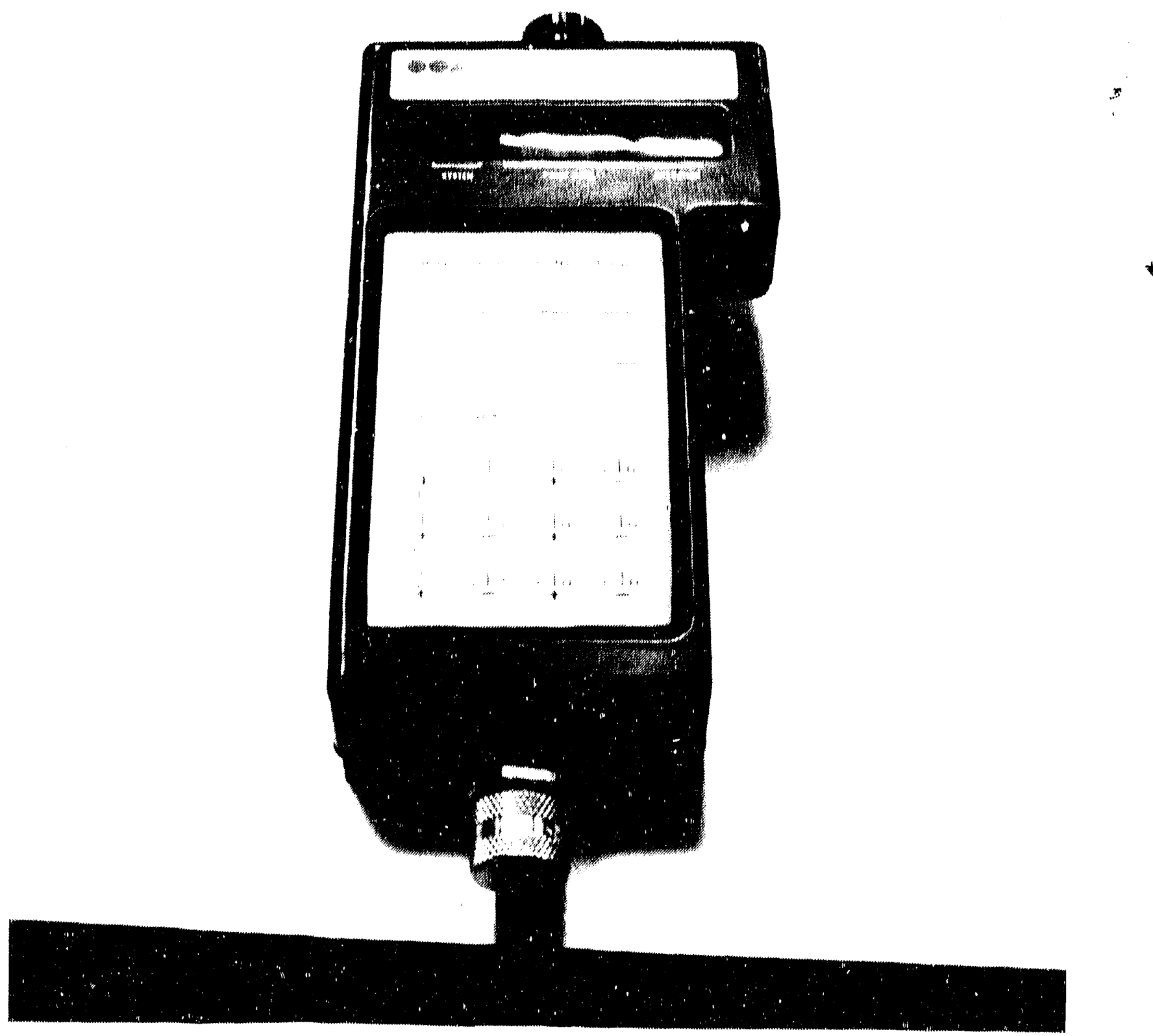

Flgure 3-12. The Cantry Robot: Teach Pendant 


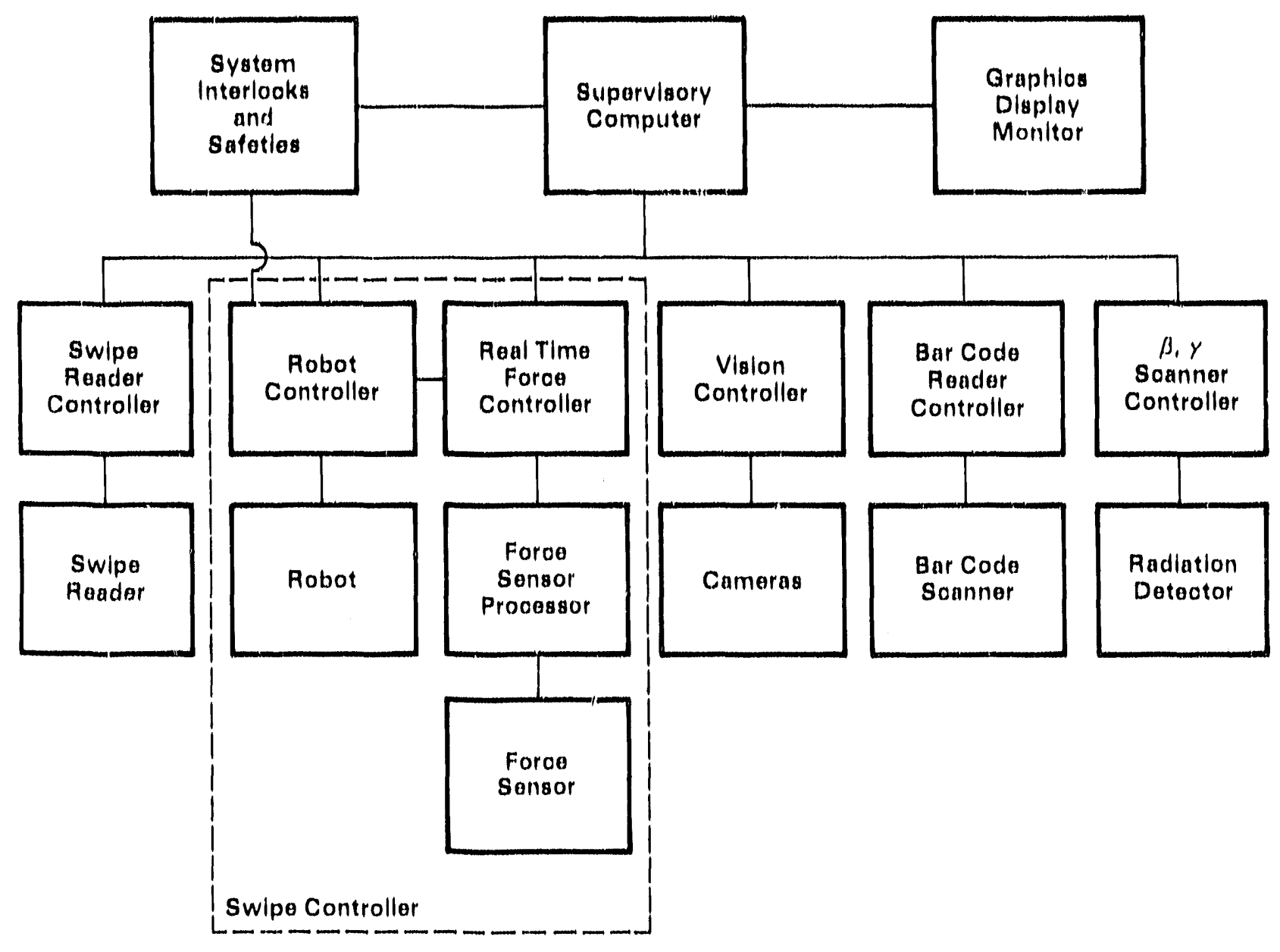

Flgure 3.13, The RRSAS Control System 
abilitias, In such an organdation, tha suparedsor talis tha subordenatas

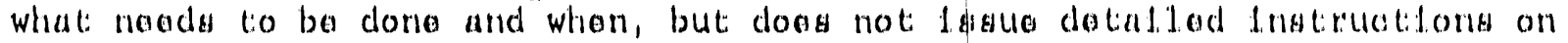
how to pertorm a task; the subardinates have speodal knowladga on how lio perforin the tasks for which thay aro rosponstbla, In addititon to glving task Instruations, the supervisor also coordinates the subardinates autivities to

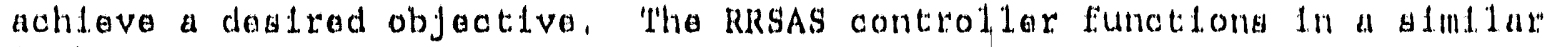
fashion.

A Sun Microsystems modal $3 / 160$ computer sarvas as the suparvisory computer. 'Ihis computar monftors and schedules the hotivities of six aubaystem controliars; the swlpa rader, robot, rad-time forco control for swlplug, vlaton, bar code readar, and noncontact radlation acanar. In addition, the supervisory computer provides an operator interface that: Includes hlgh-speed graphlos display, thls display, as dlocussod above, serves two primary functions. Firat, the radiation survey resultis are displayed to the system operator to allow him of her to deterinlne whether:

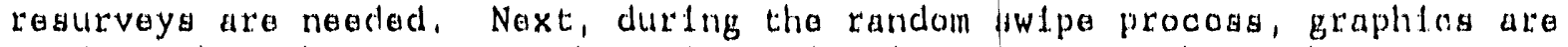
used to show the operator the swipe polnt location, so that robot movementis can be mondtored. Although the RRSAS has proven to be extramely rellable, safe oporation procedures dictate operator verdfleation that tha robot is indead moving to the correct location on the cask.

The supervisor comblase clata from the computar viston subsystem with the mathematical description of the cask, or CAD description, to bulld a model. of the robot and cask world. This model consists of the robot's location as woll as the cask's location with respect to the robot. Procedures for axe. cuting specifle tasks are also intograted with this model of the robot world, The requlred tasks, e.g., swlpling the cask surface, are analyzed within the context of the model. to develop commands that must be communfated to Indi. vidual subsystem controllers, such as the swlpo controller, for exocution. Each subsystem controller is renponstble for axacuting tha suparvisory commands and returning messages that indicate successful or unsuccessful completion of the command, plus any requlred data resulting from command execution, as in the vision system.

The primary reason for aclopting the control architecture shown in Figure $3.13 \mathrm{ls}$ to allow control distribution throughout the system to support the requirements for different types of control, facllitating real atine sensorbased control. and model-based high.level control. This control archltecture is similar to methods used in human organizations to provido afflctent use of subordinates' sk111.s. The RRSAS 1.a comprised of many spectallzed subsystems. The structure represented in Figure 3-13 allows the use of multiple computing enviroments, adapted to the particular neads of each task, e.g., viston, and all coordinated by a single supervisor. Dotalis of the supervisory control are presented in Appenclix $C$.

In addition, the control archltecture in Figure $3-13$ provides a structure within which to construct the requlred system control algorithms in a modular fashion. Software development ls based on a modular bullding-block approach with single-page, slingle-purpose routines bullding on one another to

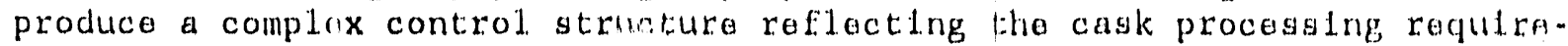
ments. 


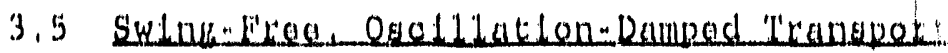

Durling the clevelopment of the RRSAS project, personnel assoolated with

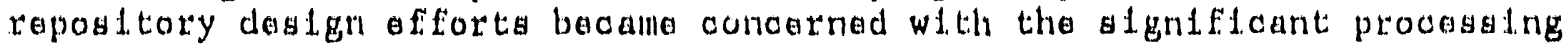
times predictad for heavy materlal movement using standard bridge crane technologles, The RRSAS prov!das an excollent expertmental anviroment for exandnlng altornative materlal movement strategles, Earlier work at SNL aluggested tha feaslbility of traneporting objects susponded by a cable whthout doveloping signfficant pendulum motion. The gantry robot in the RRSAS has boen used to slmulate a computer-controlled bridge crano. Cantry acceleration 1 s controlled using a mathumatical model of a pendulum. Proper accelaration control of the gantry brldge allows damplng of any restdual. swlngling of suspended objects in one swing porlod. Thls resulte in signifl. cant decreases in material transport times (sae Appendix E).

The approach adopted to move objects without residual. swinging is shown In Figure 3-14. While suspended from a bridge crane, an object such as a spent fuel assembly that is initally at rest, will begin to swing if the bridge crane moves. The motion of the obfect will be slmllar to that of a simple pendulum, To move these objects without resldual swing ing, SNL uses the charactetistics of pendulum motion in 1 tes approach.

Consfder an object awingling 1 ike a pendulum about a flxed polnt. At the two extremes of 1 ts swlng, the object must stop momantarlly to change direction. Now consider Figure 3-14, where the polnt about which the object swings la contfauously moving. Note that in Figure 3-1.4 the object suspended from the briclge crane continues to move at the two extremes of 1 ts swing. Howaver, the object's motion with respect to the bridge crane stops for its direction of motion to change. Therefore, at the two extremes of 1 ts swing, the object suspended from the bridge crane in Figure 3-14 momentarily moves at exactly the same velocfty as the bridge crane.

If the acceleration of the bridge crane is constant, as in the constant brldge acceleration example in Flgure 3-14, the two posltions where the swinging object will come to rest are somewhere to the left of and directly beneath the moving bridge crane. Oscillation is the polnt at which the swinging object returns to a polnt directly beneath the moving bridge crane, If, after one period of osclilation, the bridge crane acceleration is instantly set equal to zero, the obfect will no longer swing as the crane continues to move, because the crane and the object now have exactiy the same velocity, The net result, as in the constant velocity of bridge and object: example in Flgure 3-14, is that the obfect travels directly beneath the bridge crane without swingling.

As shown in the bridge and object-at-rest example In Figure 3-14, the bridge crane can be brought to a complete ytop with zero resultant swing of: the object. Here, a constant rate of deceleration for the bridge crane is selected. The rate of deceleration ls selected so that the bridge crane cones to a rest after exactly one perfod of suspended object osclilation. As the crane slows, the object swings out in front of the moving crane. As discussed above, however, if the rate of deceleration is constant, the swingling object w11.1 return to a polnt directly beneath the crane after one osclilation period. At that time, the object's velocity will be equal to the 


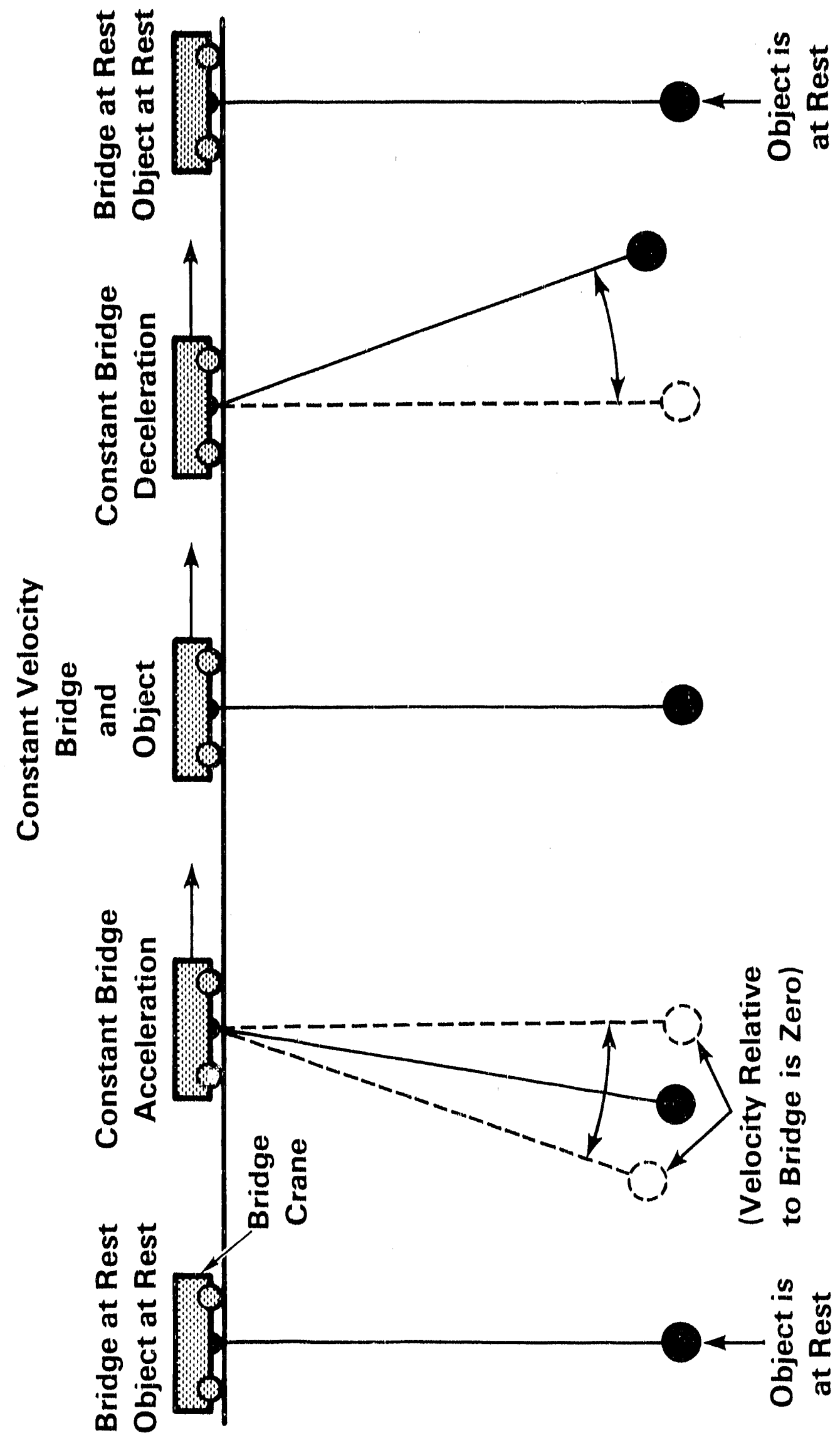


bridge crane's velocity. Thus, if the deceleration rate was selected so that the bridge crane's velocity was exactly zero after one period, the object's velocity would also be zero; the object would be stopped without swinging.

\subsection{Summary}

Robotic execution of nuclear waste shipping cask radiation and contamination surveys offers potential for significantly reducing personnel exposure to radiation. Technology developed during the RRSAS project demonstrates that large, heavy robotic systems can operate under real-time force control to perform contact swipe surveys. This technology not only allows healthphysics surveys of nuclear waste shipping casks to be done remotely, but provides enhanced rejeatability of the process. Automated data collection and analysis piuvide improved evaluation of the survey results and automatically generate archival data for tracking cask histories and quality assurance purposes.

The RRSAS project was successfully completed in August 1987 and is currently operational. The computer vision system can locate a shipping cask with an accuracy of $1.5 \mathrm{~mm}$ (0.06 in.) in two dimensions and $2.5 \mathrm{~mm}(0.10 \mathrm{in.})$ in range. This is better than the gantry robot's worst-case measured accuracy of $0.56 \mathrm{~cm}(0.22 \mathrm{in.})$. Thus, the robot's accuracy dominates the safe approach distance of the robot to the cask surface.

Hybrid force/position control, described in Section 3.3, allows swiping of the cask surface with $4 \mathrm{lb}$ of force, $\pm 1 \mathrm{lb}$. This force is maintained during the swipe process. The entire swipe process from moment of contact to end of swipe requires $5 \mathrm{~s}$.

Operational times for completing all RRSAS tasks under programmed operation by the supervisory computer are shown in Table 3-1. The time for reading the swipes is indicated as variable because each swipe is measured for a length of time sufficient for proper counting statistics. Thus, the time of counting is a function of the contamination level. Recent experiments in which the effect of electronic delays within the force control system have been reduced show that total swiping time can be further reduced by approximately 25 to 50 percent.

Oscillation-damped movement of objects using a computer-controlled bridge crane, as simulated by the $X R^{\circledR} 6100$ gantry robot, is feasible. Tests with the RRSAS robot have shown that a simply suspended object can be transported approximately $15 \mathrm{ft}$ in $2 \mathrm{~s}$ with a residual oscillation of less than 0.1 degrees. Such movements not only greatly reduce the time for material transport, but also allow for obstacle avoidance because the suspended payload is not swinging.

The RRSAS project has identified many cask design features that significantly impact the feasibility of robotic cask handling, e.g., clearances for overhead approach, high-contrast unique visual reference points, and provisions for lifting points directly over the object's center of gravity to allow swing-frie transport (Griesmeyer and Thunborg, 1988). Of particular importance are cask designs that can be efficiently represented and modeled by a computer. The RRSAS is strongly model-driven because it must operate in an unstructured environment, select random cask swipe locations, and 
Table 3-1

RRSAS Operation Times

\begin{tabular}{|c|c|}
\hline Process & Time Required (min) \\
\hline System Initialization & 1.10 \\
\hline Visual Location of Cask & 1.2 .5 \\
\hline Read Bar Code & 1.00 \\
\hline Radiation Survey (Beta/Gamma) & $\begin{array}{l}\text { On-Line } \\
\text { Operations }\end{array}$ \\
\hline$\beta, \gamma$ Data Processing/Display & 0.75 \\
\hline Take Contamination Swipes (40) & 23.40 \\
\hline Load Swipe Reader & 0.75 \\
\hline Total Radiation Survey Time & 29.75 \\
\hline Read Swipes and Display Results & $\begin{array}{l}\text { Off-Line Operation of } \\
\text { Variable Duration }\end{array}$ \\
\hline
\end{tabular}

determine the appropriate robot movement for executing swiping operations based on a CAD model of the cask. In addition, the RRSAS must efficiently respond to sensor inputs, not orily to directly control robot movements such as force-controlled swiping, but to detect and respond to error situations. Cask designs based on simple geometric shapes greatly simplify computer modeling and the model used for controlling robot actions. In addition, design symmetry greatly facilitates both modeling and subsequent reasoning processes. 


\subsection{CONCLUSIONS}

\subsection{Technical Achievements}

The RRSAS was successfully completed in August 1987 and is currently operational. Over 200 demonstrations have been performed since that date. The RRSAS achieves fairly high reliability (for a laboratory system) by using models of the robot and its environment to automatically program the needed, robot trajectories without human intervention. This significantly reduces the potential for human error. In addition, should an error occur, the model-based controller can frequently recognize the error situation and recover automatically. Integration of such error recovery strategies into the knowledge base of the robotic system significantly increases the system success. A common error, for example, is misinterpretation of shadows by the computer vision system for visual reference features during the cask location operation. However, since the computer model directing the robot incorporates knowledge of the visual reference features, an error is typically detected and the robot system automatically reevaluates the visual reference feature from a slightly different vantage point to overcome the effects of the shadows. Automatic programming of robot trajectories from models also allows swiping of randomly selected locations on the cask's surface. Without automatic model-based prograraming of the robot's movements, swiping of randomly selected cask surface locations would not be possible.

The incorporation of force control into the robotic system allows controlled interantions of the robot with its environment, even in the presence of errors in the models. Force control is essentially a perturbation on the trajectories automatically determined from the models. Force control essentially corrects for slight differences between the real world and the models of the robot and its environment. High-speed force control allows contact swiping of the cask quicker than can be accomplished hands-on by an operator. The reliability of the swipe data is higher than manually achieved data because each swipe operation is identical to all other swipe processes.

Incorporation of computer vision into the RRSAS allows automatic location of objects, e.g., a nuclear waste shipping cask, within the workspace of the robot. This eliminates the need for expensive fixturing devices and allows a single robot system to deal with many different cask designs. Essentially, the computer vision system is used to update the model of the workspace environment which forms the basis for robot trajectories.

Finally, the model-based control philosophy incorporated in the RRSAS also allows swing-free transport of suspended objects, such as bridge crane transport of casks and cask components. In this case, models of object oscillatory behavior are used to determine acceleration profiles which transport simply suspended objects without residual oscillation. Such model-based control strategies greatly reduce the time required for materials transportation operations. 


\subsection{Feasibility of Using Integrated Robotic Systems for HLW Shipping Cask Operations}

While the RRSAS project concentrates mainly on survey-type task performance, the successful integration of diverse components required to accomplish those tasks convincingly demonstrates that all percelved caskhandling operations can be accomplished using a total robotic system. In particular, the success of a model-based control approach in RRSAS operations provides a necessary alternative to both traditional remote-handling methods, based on master/slave manipulation, and man-in-the-loop automated concepts, based on repetitious teach operations. As noted previously, current commer. cially available robot control technology is restricted to repetitious movements among previously taught locations. Teaching, the most common mode of robot programming, involves manually moving the robot manipulator's end point to a location in the environment and storing that position in the robot's computer memory. With restricted personnel access to the robot workspace and the need to deal with off-normal conditions, this manual approach to robot programming is difficult. Thus, robot system control must be accomplished using a supervisory computer and models of the robot and its environment. Significant progress in model-based supervisory control has been demonstrated by the RRSAS.

\subsection{Cask and Handling System Design Implications}

Via RRSAS evaluations, Griesmeyer has thoroughly documented what has been determined to date regarding the impact of cask design features on robotic handling capabilities (Griesmeyer and Thunborg, 1988). Some of the major points are summarized here for completeness.

Critical to the success of model-based supervisory control is the computer model of the robot's world. This model allows the supervisory computer to interpret sensory data and automatically direct robot motions based on this sensory information. Simple cask geometries greatly facilitate task planning and supervisory control. Thus, cask designs should employ geometries that are as simple as possible, without compromising cask functionality. The RRSAS swipe operation depends on model-based control of a commercial robot and a single sensor (force). This technical approach, combined with a simple cask geometry, has allowed the RRSAS to perform a wide range of contact-based manipulation tasks not previously demonstrated such as mechanical assembly and radiological swiping. In fact, the radiological swiping operations can likely be performed faster robotically than manually. simplified cask geometry will also allow easier manual swipe operations.

Given the restrictive capabilities of currently available robotic systems, design of the robot's work environment is extremely important to the success of applying robotic systems to remote-handling tasks. Experience with the RRSAS indicates that modest design changes that do not change the functionality of major cask components can significantly affect the ability to robotically execute various cask operations. Symmetries and alignment tapers for self-guiding assembly, which reduce requirements both for accurate alignment of components and the complexity of robot control algorithms, can reduce the time for such robotic operations by up to two orders of magnitude over designs without these features. 
Other limitations of current robotic systems exist but are expected to be overcome in the near future. While not yet commercially avallable, sensor-based controls exist. Force-control capabilities have been demonstrated with the RRSAS, but the vision system is still limited to location tasks only (1,e., vision servo control has not been demonstrated).

Limited degrees of freodom and the need for special end effectors, or tools to perform various tasks, require that clearances be provided on a cask for the approach of the often bulky end effector and changer mechanism. straight-line approaches should be used. The expense of robotic systems provides incentive to employ only one multifunction robot in a given workspace. Overhead gantry robots are likely candidates and, thus, clearances for straight-line overhead approaches are desirable.

Other design features could limit RRSAS survey operations. Obstructions could interfere with radiation and visual scans of the cask and transporter exterior surfaces. Uneven surfaces and recesses are difficult to access in a robotic swiping operation. Al1 component surfaces should be comprised of simple, mathematically definable shapes.

Many more specific cask design implications based on RRSAS experience with other operations are summariztd by Griesmeyer and Thunborg (1988). Griesmeyer and Thunborg concluded that cask interface design and operational features can be defined to facilitate robotic cask handing with minimal impact on a cask's functional requirements.

\subsection{Transportation System Impacts}

Operations with the RRSAS clearly illustrate that robotic handling of nuclear waste shipping casks at receiving facilities will significantly reduce occupational exposures. The experience gained from the development and operation of the system has been used to evaluate an automated handling system alternative to the postulated reference system of the ALARA analysis (Schneider et al., 1987). Conceptual details of the system have been developed by a team of SNL and Westinghouse Hanford Company personnel based on both RRSAS operations and earlier proof-of-principle experience (Berger et al., 1986). Two cases have been considered: a totally remote system and a partially remote system; neither optimized for remote operations.

The resulting integrated dose to cask-handling workers at a repository has been estimated to be reduced from 418 person-rem/yr for the postulated reference system to 5 person-rem/yr for the totally remote automated system. With an estimated total crew of 80 people, the average dose to individual workers in the totally remote system would be approximately 60 personmrem/yr, well within ALARA guidelines.

Estimates of the operational times for this alternative have indicated that remote operations should not take longer than manual operations. In the ALARA comparison, the operational and turnaround times for the automatedhandling concept are estimated to be equal to the postulated reference case. More recent experience with the RRSAS indicates that the time estimates used in the ALARA analysis for swipe surveys and moving large objects could be further reduced with a corresponding reduction in turnaround times. Changes 
in operational times of the remote automated alternative, however, would only slightly impact the dose to workers since workers would not be near the casks, but rather would be located in control rooms with low background dose rates. Therefore, operational times for alternative remote automatedhandling concepts are not of major importance to doses recelved by workers. However, changes in operational times could have important effects on system costs. Regardless of time considerations, the automated concept has been found to be the only alternative that could decrease the annual doses to repository workers to the level desired by DOE design objectives.

The costs of using robotics in the repository cask-handling system have also been estimated for the ALARA analysis (Schneider et al, 1987). The capital cost for the totally remote system is estimated to be nearly $\$ 19$ million (1987). Using a totally remote automated system at the receiving and handling facility would result in an estimated staff reduction of 31 persons by reducing requirements for operators, maintenance-craftsmen, quality control persons, crane operators, and radiation monitors. Reducing the reposi tory labor force by the above amount would result in an estimated labor coist decrease of $\$ 1.3$ million per year.

As noted, the original handling times estimated for the advanced remote concept of the ALARA analysis are of the same range as the postulated manual operational reference case. Optimization of the facility for robotic operations would reduce those times considerably (Yount and Berger, 1984). Also, more recent RRSAS experience indicates the time required for many cask operations could be reduced by another factor of two or more below that required for manual operations. This could result in a reduction in the number of handling bays at a repository, as well as a possible reduction in the number of individual casks in the system due to the reduced turnaround time requirements. Thus, a fully optimized robotic system could achieve a benefitbenefit situation; dose reduction with cost savings.

As noted, minor design modifications significantly impact the feasibility of robotic cask handling. The design process becomes one of attention to detall rather than radical alteration of concepts (Griesmeyer and Thunborg, 1988). Handling simplicity also results in designs more easily handled during manual operations, and thus lower exposures at repository facilities.

Operations reliability and quality are also significantly improved since all procedures are conducted in a prescriptive, software-directed manner. Quality assurance is provided by a continuously updated data base that determines when an operation is completed by comparing feedback data to limits. This imprcved quality will result in significant reductions in error probabilities commonly dominated by human error rates on the order of $10^{-3}$ to $10^{-5}$ per task (Sanders et al., 1987).

In summary, experience gained from the development and operation of the RRSAS provides proof of the technical feasibility of a fully robotic caskhandling concept. Little design impact on transport casks is required for most operations. Exposure levels of repository operations can be reduced significantly with improvements in processing rates, task reliability, quality and verifiability, and general occupational safety. These benefits could occur with cost savings, resulting in a benefit-benefit situation. 


\section{REFERENCES}

Berger, J, D., B. C, Gneiting, and T', L. Sanders, 1986. "Use of Robotics for Radioactive Waste Shipping and Receiving," Proceedings, PATRAM'86, Davos, Swltzerland, 2:485.

DOE (U.S. Department of Energy), 1981. "Requirements for Radiation, "Order 5480:1A, Washington, D.C., Chapter 11.

DOE (U.S. Department of Energy), 1986. "Development of From-Reactor Casks," DE-RP07-861D12625, Idaho Operations Office, Idaho Falls, ID.

Griesmeyer, J. M., and S. Thunborg, 1988, "Remote Cask Handling and Impli.. cations for Cask System Design," SAND87-2670, Sandia Nationa1 Laboratorles, Albuquerque, NM.

Madsen, M. M., W. L. Uncapher, D. R. Stenberg, and E. E. Baynes, 1.987. "Testing the Half-Scale Model of the Defense High-Leve1 Waste Transportation Cask," SAND86-1130, Sandia Nationai Laboratories, Albuquerque, NM.

NWPA, The Nuclear Waste Policy Act of 1982, as signed by the President on January 7, 1983 (Pub1ic Law 97-425, 96 Stat. 2201, 42, U.S.C. 10101).

Sanders, T. L., R, M. Westfal1, and R. H. Jones, 1987. "Feasibility and Incentives for the Consideration of Spent Fuel operating Histories in the Criticality Analysis of Spent Fuel Shipping Casks," SAND87-0151, TTC-0713, Sandia National Laboratories, Albuquerque, NM.

Schneider, K. J., W. A. Ross, R. I. Smith, P. M. Daling, R. B. Grinde, C. J. Hostick, R. W. Peterson, D. L. Stiles, S. A. Weakley, and J. R. Young, 1987. "Analysis of Radiation Doses from Operation of Postulated Commercial Spent Fuel Transportation Systems," DOE-CH/TPO-001, Pacific Northwest Laboratory, Richland, WA.

Shirley, C. G., 1983. "NWTS Transportation Interface Technology Development Priority Report," SAND82-1804, TTC-0336, Sandia National Laboratories, Albuquerque, NM.

Strip, D. R., 1987. "Robotic Handling of Spent Fuel Shipping Casks: Preliminary Assessment of Cask Design Impacts and Technology Development Needs," SAND86-2470, Sandia Nationa1 Laboratories, Albuquerque, NM.

Winson, G. H., et a1., 1980. "Opportunities to Increase the Productivity of Spent Fuel Shipping Casks in the United States," PNL-3017, TTC-0078, Pacific Northwest Laboratory, Richland, WA.

Yount, J. A., and J. D. Berger, 1984. "Conceptual Design Report for a Remotely Operating Cask Handling System," HEDL-7376, TTC-0449, Rev. 1, Hanford Engineering and Development Laboratory, Richland, WA.

Zimmer, A., and M. M. Madsen, 1985. "A Defense High-Leve1 Waste Shipping Cask Design," Proceedings, Waste Management 85, Tucson, AZ, 3:337.

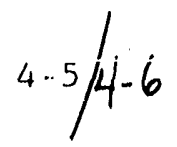


APPENDIX A

FORCE SERVO CONTROL OF A COMMERCIAL GANTRY ROBOT*

Ben J. Petterson

and

James F. Jones

Sandia National Laboratories**

Albuquerque, New Mexico 87185

\begin{abstract}
Sandia National Laboratories is investigating robotic handling of spent nuclear fuel shipping casks for proposed geologic waste repositories. Robotic handling will impact not only transportation cask design, but also the overall design of the waste repository. A goal of robotic handling is the reduction of personnel radiation exposure. One of the major technology development areas has been the integration of sensors into the robot control. system to allow operation in semistructured environments. In particular, a multiaxis force sensor is used to make robot trajectory corrections based on the contact forces between the robot and cask. This force feedback system allows contact swipes (smears) to be made on the cask. urface in a safe, repeatable manner.
\end{abstract}

*Paper presented at Robots 12/Vision 188 Conference, sponsored by the Society of Manufacturing Engineers, Detroit, Michigan, June 6-9, 1988.

**Work supported by the U.S. Department of Energy at Sandia National Laboratories under Contract DE-AC04-76DP00789. 


\section{IN'TODUC'TION}

As part of a project to investigate the lmpact of robotic handiling on the design of nuclear waste shipping casks, Sandla National Laboratorles (SNL) is developing a force-controlled robotic system to perform radiation surveys of nuclear waste shipping casks (Thunborg, 1987). This appendix discusses the approach to the force-control problem and implementation of a force-controlled robotic system. The approach to force control inclucies not only theoretical considerations, such as control algorlthms and control space partitioning, but also semiempirical considerations, such as system compliance and servo gain determination. Flnally, results obtained with the inftial and improved implemented robotic system at SNL are revlewed.

Recent work has demonstrated that force feedback can allow a commerclal robot to work in semistructured environments (Starr, 1986; Thunborg, 1986; Petterson and Jones, 1987). The objectives of the work described here are to determine if robotic radiation and contamination surveys of nuclear waste shipping casks in semistructured environments are feasible, and to evaluate the impact of robotic handling on the design of these shipping casks. Robotic execution of cask surveys offers distinct advantages over manual execution of these tasks. These advantages include reduced human radiation exposure (DOT, 1984), high repeatablifty of radiation survey procedures (Westinghouse Hanford Company, 1986), and accurate correlation of radiation survey data with sample locations on the cask surface. In short, for a robotic survey to be feasible, the robot must accurately collect data while maintaining safe, reliable operation, and must produce process flows consistent with the desired facility throughputs.

\section{APPROACH TO FORCE CONTROL}

Commercial robots typically provide only position control and no force control. Thus, an existing robot controller must either be replaced or modifled to provide force control for a commerclal robot. SNL's approach was to modify a CIMCORP XR ${ }^{\circledR} * 6100$ gantry robot controller to provide hybrid force/position control by developing a force-control loop around the position-control loop of the existing controller.

The position-control servo loop used in the $\mathrm{XR}^{\circledR} 6100$ controller is shown in Figure A-1. The servo loop consists of a proportional/differential controller where the position error, $X_{e}$, is used to generate the error signal that drives the robot arm to the desired position, $\mathrm{X}_{\mathrm{d}}$ (Craig, 1986). The robot's velocity, $X$, is monitored to provide damping for stable operation. As with most commercial robots, the control system for the $X^{\circledR}{ }^{\circledR} 6100$ control. ler is significantly overdamped to prevent position overshoot.

Figure A-2 shows the force-control strategy developed for this work. The contact force between the robot and the workpiece is measured by a force transducer mounted between the wrist of the robot arm and the end effector. The contact force, $F$, and its derivative, $F$, are the feedback parameters supplied to the proportional/differential force-control loop as shown. The force error $F_{e}\left(F_{e}-F-F_{d}\right.$, whore $F_{d}$ is the desired contact force) generates

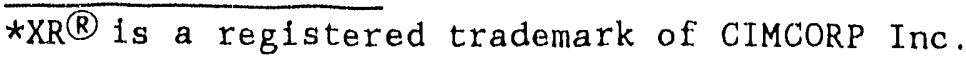




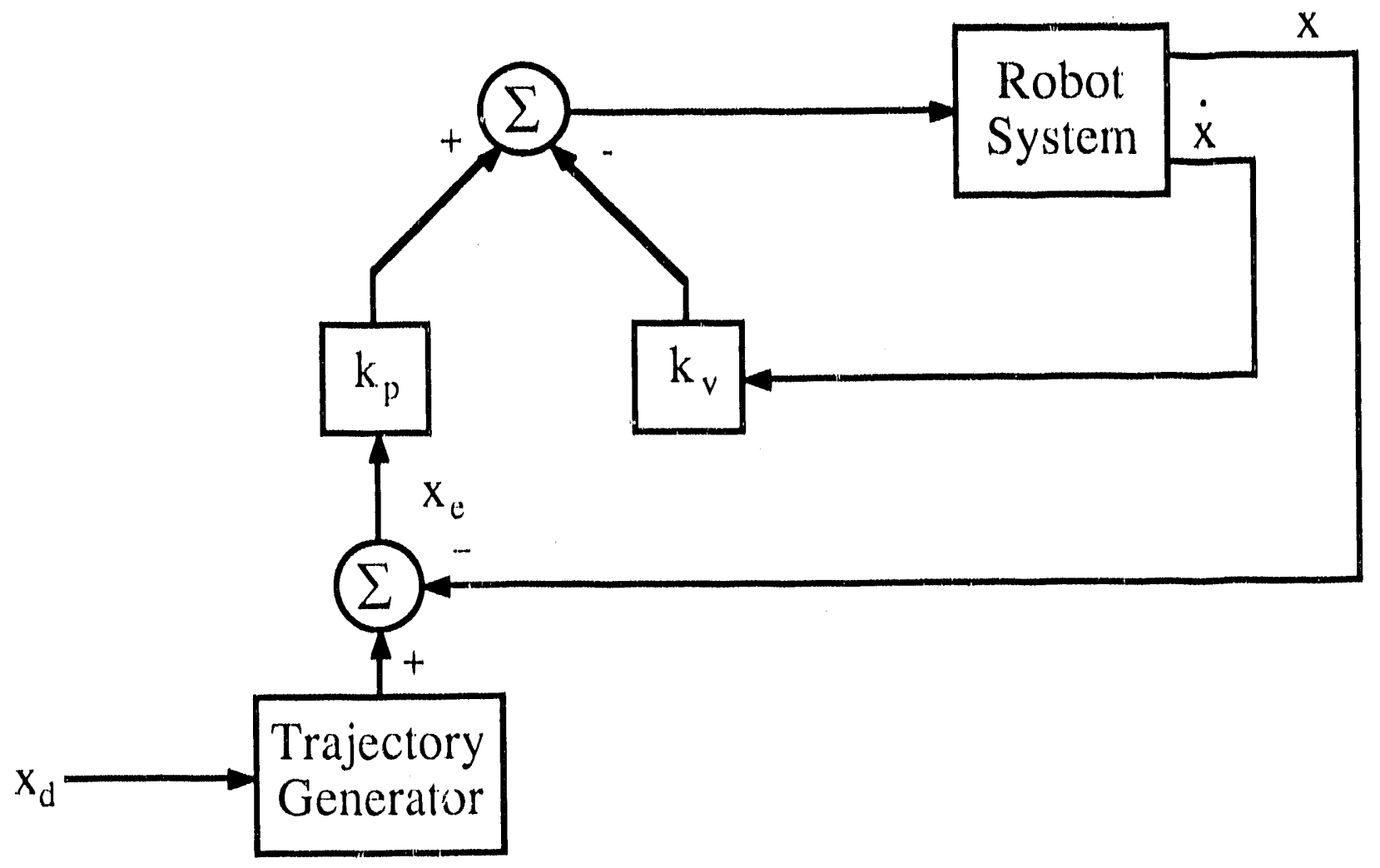

Figure A-1. Position Control Servo Loop Used in the $\mathrm{XR}^{(B)} 6100$ Gantry Robot Controller 


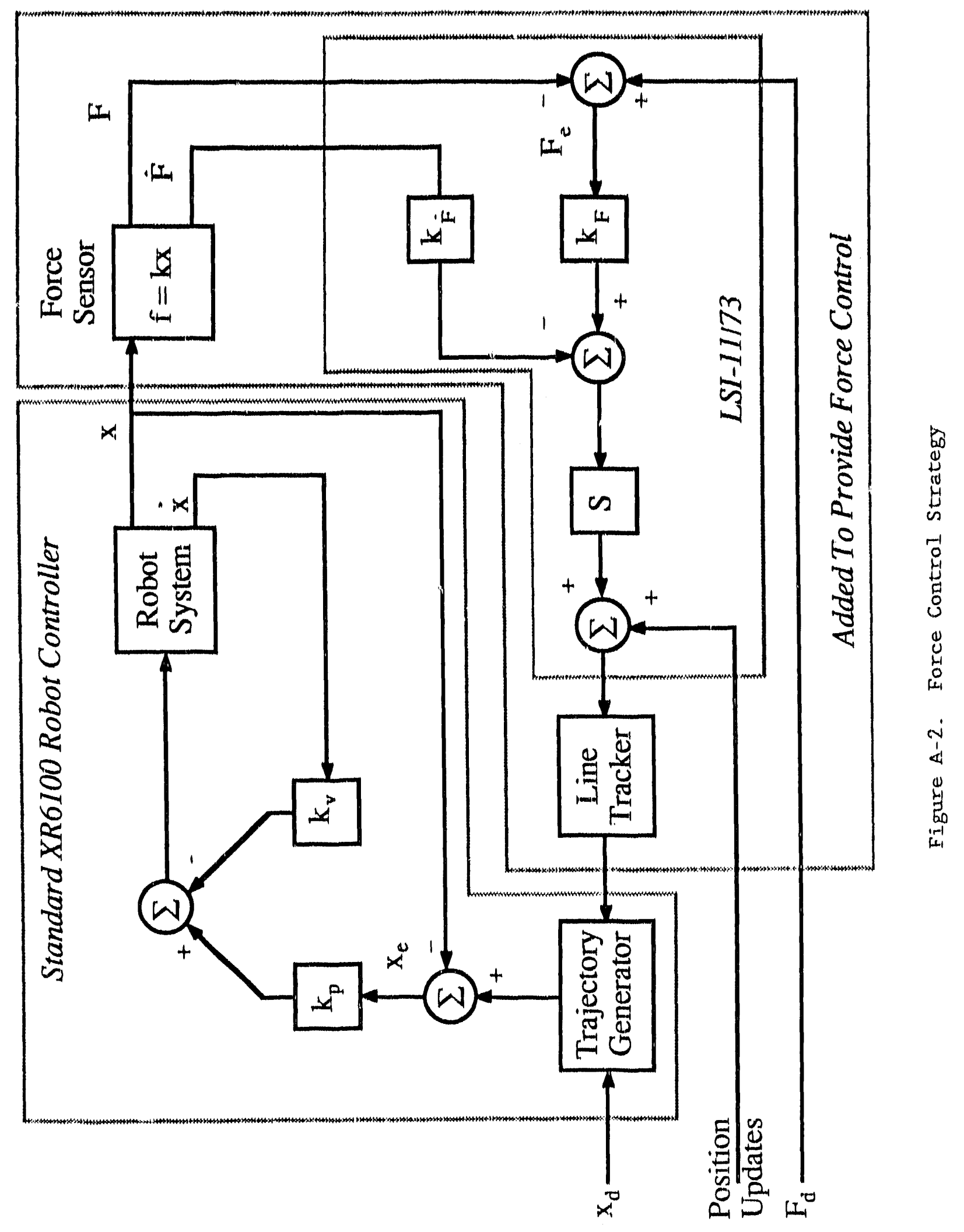


an arror sleral to drive the forca artor to zoro. The rate of change of the

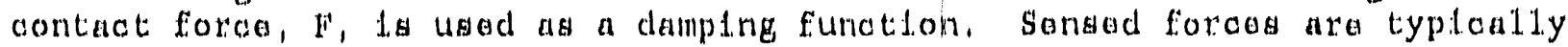
notay, and difforontiation for control purposes 1 s usualiy liluadvisad (Cralg, 1986). However, the slow response of the large electromechandeal syatem used in this work affectively fliters the force sensor nolse.

Because the robot's postetion oontroller provides the driving slgnal to the robot, a postetion command must be generated by the forceroontrol loop. Ihus, the damped force error is multipllad by a stiffness matrix, $s$, which relates force to incramental. displacoment using the sprling rate of the robot system (Saldsbury, 1980). The resulting fncremental displacement 1s commund. rated to the robot position controller and added to $X_{d}$ to generate a new desilred robot position. The robot's position controlier then drives the robot to this new, destred position.

Due to the large spring rates (high stiffness) of most industrial robot mantpulators, passive compliance mut typlca. ${ }^{1} \mathrm{v}$ be added to the system to provide stable force control. The added compliance must be compatible with the robot's position-control characteristics. If the robot's finest resolution move results in large force varlations due to excessive system stiff. ness, stable control will be difflcult to achleve. However, if excessive compl lance is added to the system, small changes in force will require large robot movements, maklng the system appear overdamped and upresponstve. Thus, the tradeoff 1 s to reduce the robot system stlffness, which increases system dampling, while maximizing system responsiveness to allow high-resolution force control. In addition, any compliance added to the robot system should be as close to the polnt of applied force as possible. Tools, or end effectors, mounted onto a compliant: device may sag, Lnduclng tool postetoning errors.

Hybrid force/position control is accomplished by partitioning the robot's control space into force and position subspaces to simultaneously satisfy force and position constraints (Rabert and Cralg, 1981). The strategy is to control selected robot degrees of freadom by force control, while using position control for others. In terms of Figure $A-2$, the stiffness matrlx, $S$, is a diagonal matrix in robot tool coordinates, with zeros everywhere but the degrees of freedom under force control. Forcecontrolled robot trajectorles are generated by summing the incremental. position updates, $x_{1}$, derived from the stiffness matrix, with the position commands defining the desired robot motion along the surface. This allows the robot to follow the contour of a surface while malntaining a prescribed force normal to the surface.

Finaliy, the control of any robot must be tured to the characterlstics of that particular robot. As discussed above, most commerclal robot position controllers are significantly overdamped to elfininate position overshoot. However, force control is best implemented in a slightly underdamped position-control envlronment to provide fast response to changes $\ln$ force. Thus, the values of $k_{p}$ and $k_{v}$ in Flgure $A-2$ should vary depending on whether. that particular degree of freedom is force or postition controlled. 
FORCE, CON'TROL, IMPLIEMIN'IA'TION

\section{Hardware}

The hybrld force-control system discussed above $1 \mathrm{~s}$ Implementad on a CIMCORP XR(B) 6100 robot at SNL. The $\mathrm{XR}^{\left({ }^{(B)}\right.} 61.00$ system cons1sts of a $2,0454 \mathrm{~kg}$ $(4,500-1 b)$ gantry mantpulator arid a digltal sixuaxts robot controlier, fiorce control using the $X \mathrm{R}^{(\mathcal{B}} 6100$ robot requlres that three additional components be added to the standard robot: a force tranaducer, to inonter contact forces; a force-control computar, to perform forca-control loop calculations; and a CIMCORP line tracker, to allow high-spead communlcation with the robot: controller.

The force transducer is a JR3 force/torque sensor capable of converting forces along three orthogonal axes and the corresponding moments. The JR3 has an analog-to-digital converter and a inicroprocessor that convert the force and torque slgnals to digltal readings and transmit the readings to the force-control computer.

The force-control computer is a Dlgital Equipinent Corporation LSI-11/73(B)

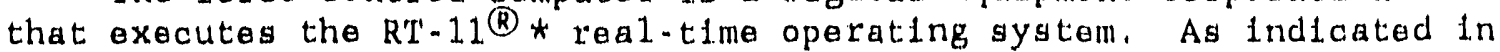
Flgure A-2, the force-control computer monttors the force sensor, computes required position updates using the proportional/differential force-control algor thm, and communicates these updates to the line tracker. The IIne tracker provides the interru, from the force-control computer to the robot position controller.

\section{Compldance}

In addition to the force sensor and computing hardware, passive compliance has been added to the robot arm. Experiments with the $\mathrm{XR}^{\circledR} 6100$ robot arm have revealed spring rates of 53,000 to $120,000 \mathrm{~N} / \mathrm{m}$ (300 to $700 \mathrm{lb} / \mathrm{In}$.) depending on the a rm configuration. The smallest commandable position change of the $\left.X^{(}\right) 61001 \mathrm{~s} 0.025 \mathrm{~mm}(0.001 \mathrm{in}$.$) . This position$ change would result in a minimum change in force of 1.3 to $3.1 \mathrm{~N}(0.3$ to $0.7 \mathrm{lb}$ ), depending on arm conflguration. Because the goal of this arm modification is to control the applied force to within $\pm 4 N( \pm 11 b)$ of the $18-\mathrm{N}$ (4-1b) specifled force during the swlplng process, compliance is added to the robot system to improve system stability.

A $2,4-\mathrm{mm}(3 / 32-1 \mathrm{n}$,$) foam pad has been placed between the contact swipe$ and the robot end effector, reducing the effective spring rate to about $21,900 \mathrm{~N} / \mathrm{m}$ ( $125 \mathrm{lb} / \mathrm{in}$.$) . This decreased spring rate yields the desired force$ resolution while maintaining robot responstveness.

\section{Software}

The force-control computer (Figure A-2) recelves task information from a supervisory computer (Thunborg, 1987). This Information Includes controller gains $\left(k_{p}, k_{f}\right)$, applied force magnitude $\left(F_{d}\right)$ and direction, and lateral swipe distance and direction. The force-control algorlthm ts then implemented on

*LSI-11/73(B) and $\left.\mathrm{R}^{\prime}-11^{(}\right)$are registered trademarks of Digltal. Equipment Ciorporation. 


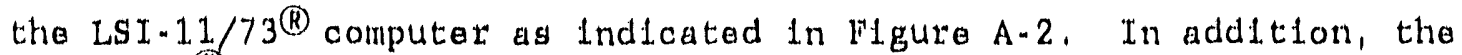
LSI $1.1 / 73^{(B)}$ provides intertuptudriven communications to the robot position controllex through the line tracker.

The JR3 force sensor communicates digltal. force data serially to the force-control computer. After the force-control computer recelves a complete data set, the data are stored for use by the force-control algorlthm.

Communication from the force controller to the robot posttion controller is through the line tracker. The 1ine tracker issues a synchrontzing pulse to the force-control computer every $47 \mathrm{~ms}$. After recelving a pulse, the force-control computer transmits a position update to the line tracker and then computes the next robot position update using the proportional/ differential force-control algortthm with the most recent force data set. After the next position update is calculated, the forcencontrol computer walts for the synchronizing pulse from the line tracker before beginning the cyole again.

\section{Synchronlzation and Timing}

Force control must yleld smooth, repeatable, and responslve motion of the robot arm to minimize force overshoots. Synchronizing the force-control. routine with the update rate of the robot controller helps ensure smooth, repeatable, and responslve motion of the robot arm by allowing consistent experiments to accurately determine the force controller's parameters. In addition, the delay between changes in contact force and robot arm response must be minimized for responsive and stable force feedback control.

Reducing the delay between application of the force and the robot arm response is difflcult because a large part of this delay occurs within the commercial hardware and software. In the inftial implementation of force control on the $X R^{\circledR} 6100$ system, the time delay between force application and robot response is about $0.5 \mathrm{~s}$. Approximately $0.22 \mathrm{~s}$ of this delay is due to the electronics between the force transducer and the robot servos (Table A-1), while about $0.28 \mathrm{~s}$ of the delay is due to the electromechanical system response.

Table A-1 shows the minimum delays found betwecr the force transducer and the robot servos. Asynchronous operation of several of the components can introduce additional delays totaling 10 to $20 \mathrm{~ms}$. The potential improvements isted in Table A-1 show the minimum delays obtainable without major system redesign for each component.

A significant delay results from a $16-\mathrm{Hz}$, fourth-order Butterworth filter used in the JR3 force amplifier (Step 1). The fllter causes a phase shift in the force signal. that delays the analog data by $40 \mathrm{~ms}$. This delay can be reduced to $4 \mathrm{~ms}$ by using a $163-\mathrm{Hz}$ filter supplied by JR3. Step 2, the analog-to-digital conversion of the force signal, takes $2 \mathrm{~ms}$.

As initialiy set up, the JR3 samples the force signal every $10 \mathrm{~ms}$ (Step 3). This $10-\mathrm{ms}$ delay can be reduced to $4 \mathrm{~ms}$ by requesting a faster sampling rate. But, because the JR3's force sampling runs asynchronously to 
Table A-1

Electronic Delays Between Force Transduce and Robot Servos

\begin{tabular}{|c|c|c|c|c|}
\hline \multirow[b]{2}{*}{ Step } & \multicolumn{2}{|c|}{ Shortest Delay } & \multirow{2}{*}{\multicolumn{2}{|c|}{$\begin{array}{l}\text { Component } \\
\text { and Process } \\
\text { Causing Delay }\end{array}$}} \\
\hline & $\begin{array}{l}\text { Unmodified } \\
\text { Equipment } \\
\text { (ms) }\end{array}$ & $\begin{array}{l}\text { Potential } \\
\text { Delay } \\
\text { (ms) }\end{array}$ & & \\
\hline 1 & 40 & 4 & (JR3) & Butterworth Filter \\
\hline 2 & 2. & 2 & (JR3) & Force $A / D$ \\
\hline 3 & 10 & 4 & (JR3) & Update Rate \\
\hline$\Leftrightarrow$ & 20 & 0.5 & (JR3) & Buffer \\
\hline 5 & 11 & 5.5 & (JR3) & Serial Communication \\
\hline 6 & 0 & 0 & (LSI) & Data Age \\
\hline 7 & 3 & 3 & (LSI) & Calculations \\
\hline 8 & 43.875 & 10 & (LSI) & Synchronization \\
\hline 9 & 12 & 12 & (LSI) & Serial Communication \\
\hline 10 & 81.75 & 23.4375 & $(\operatorname{Tr} a j)$ & ) Internal Computations \\
\hline
\end{tabular}

Totals

223.625

64.4375

the rest of the system, the actual delay due to force sampling could be twice that reported in Table A-1, if data were requested by the JR3 buffer just after the start of sampling, rather than just after sampling completion.

The data buffer in the JR3 produces a significant delay as well (Step 4). The JR3 has a first-in, first-out buffer that stores a minimum of 20 bytes of force information. At 9,600 baud, the time required for force data to pass through the buffer is $20 \mathrm{~ms}$. Reducing the buffer size to 1 byte and increasing the baud rate to 19,200 , reduces the buffer delay to $0.5 \mathrm{~ms}$. Also, increasing the baud rate to 19,200 reduces the time required to transmit one force data set (11 bytes) to the force control computer from 11 to $5.5 \mathrm{~ms}$ (Step 5).

Step 6 indicates that the force-control computer will always use data that is zero ms old; however, zero $\mathrm{ms}$ is a minimum delay. If the force computer begins its calculations before it receives a complete data set from the force sensor, the computer will use the previous data set recelved from the sensor. Depending on when the force computer begins its computations during the force data set transmission, the force computer may be using data that is up to $11 \mathrm{~ms}$ old ( $5.5 \mathrm{~ms}$ in the improved case).

Computation of a position update using the force-control algorithm on the force-control computer takes $3 \mathrm{~ms}$ (Step 7). However, a 44-ms delay is introduced while the force computer waits for the synchronizing pulse from the line tracker to begin transmitting the position update (Step 8). With a better synchronization scheme between the force computer and the line tracker, the $44-\mathrm{ms}$ delay could be reduced to an estimated $10 \mathrm{~ms}$. Finally, 
the serial communication of the position update to the line tracker takes an average of approxisately $12 \mathrm{~ms}$ (Step 9).

Once the line tracker receives the position update, the robot position controller takes approximately $82 \mathrm{~ms}$ to compute the appropriate motor drive signals (Step 10). CIMCORP is investigating changes to their controller that could reduce this delay to approximately $24 \mathrm{~ms}$.

In addition to the improvements in digital implementation, increasing the servo gain (Figure $A-1$ ) reduces the time constant of the electro. mechanical system by approximately $60 \mathrm{~ms}$. Also, the JR3 offers a parallel communications option that could potentially eliminate nearly all delays associated with Steps 4,5 , and 6 . U1timately, CIMCORP may be able to synchronize all processes in Step 10 to eliminate approximately an additional $12 \mathrm{~ms}$.

\section{RESULTS AND. DISCUSSION}

Figure A-3 shows the forces developed during a typical swiping operation. The goal is to move $10 \mathrm{~cm}$ ( $4 \mathrm{in}$.) along the cask surface while maintaining $18 \pm 4 \mathrm{~N}(4 \pm 1 \mathrm{lb})$ normal contact force.

The solid line in Figure A-3 shows the forces generated using the initial implementation (see the Synchronization and Timing Section). The maximum applied force is $39 \mathrm{~N}(8.8 \mathrm{lb})$. Stable force control is established after approximately $1 \mathrm{~s}$, after which the hybrid controller executes the required robot lateral movement to generate the swipe trajectory while main. taining the specified normal force. From time of initial contact, total swipe execution requires approximately $5 \mathrm{~s}$.

Figure A-3 also displays system compliance characteristics. Immediately after contact (zero s), the force curve shows significant curvature due to the compliance of the foam pad in the swipe tool. As the applied force increases beyond $18 \mathrm{~N}(4 \mathrm{lb})$, the slope of the force curve steepens significantly due to compaction of the foam pad. This increase in the force curve slope represents transition of system compliance from the foam pad to the robot arm. Notice that the added system compliance provides near-optimum compliance for force control at the 18-N (4-1b) level.

To improve the response of the system, the position controller gain, $k_{p}$, in Figure A-1 can be increased in the CIMCORP controller. Also, to quickly achieve the desired contact force with minimum force overshoot, a semiempirical strategy for damping robot motion, termed jumpback, is implemented. Due to the overdamped nature of the robot position controller, the robot requires approximately $1 \mathrm{~s}$ to complete a move on the order of 1 to $100 \mathrm{~mm}$. Thus, if immediately after contact the robot is commanded to stop, the robot remains in motion for a full second until the last commanded move is fully. executed. To cancel this residual robot movement, the robot is issued a new position command $1.5 \mathrm{~mm}$, or approximately half the thickness of the foam pad, back from the previously commanded position. This new position goal creates a smaller position error, $X_{e}$, in Figure $A-2$, which slows the arm's movement. The force controller then servo controls the robot to the desired contact force. 


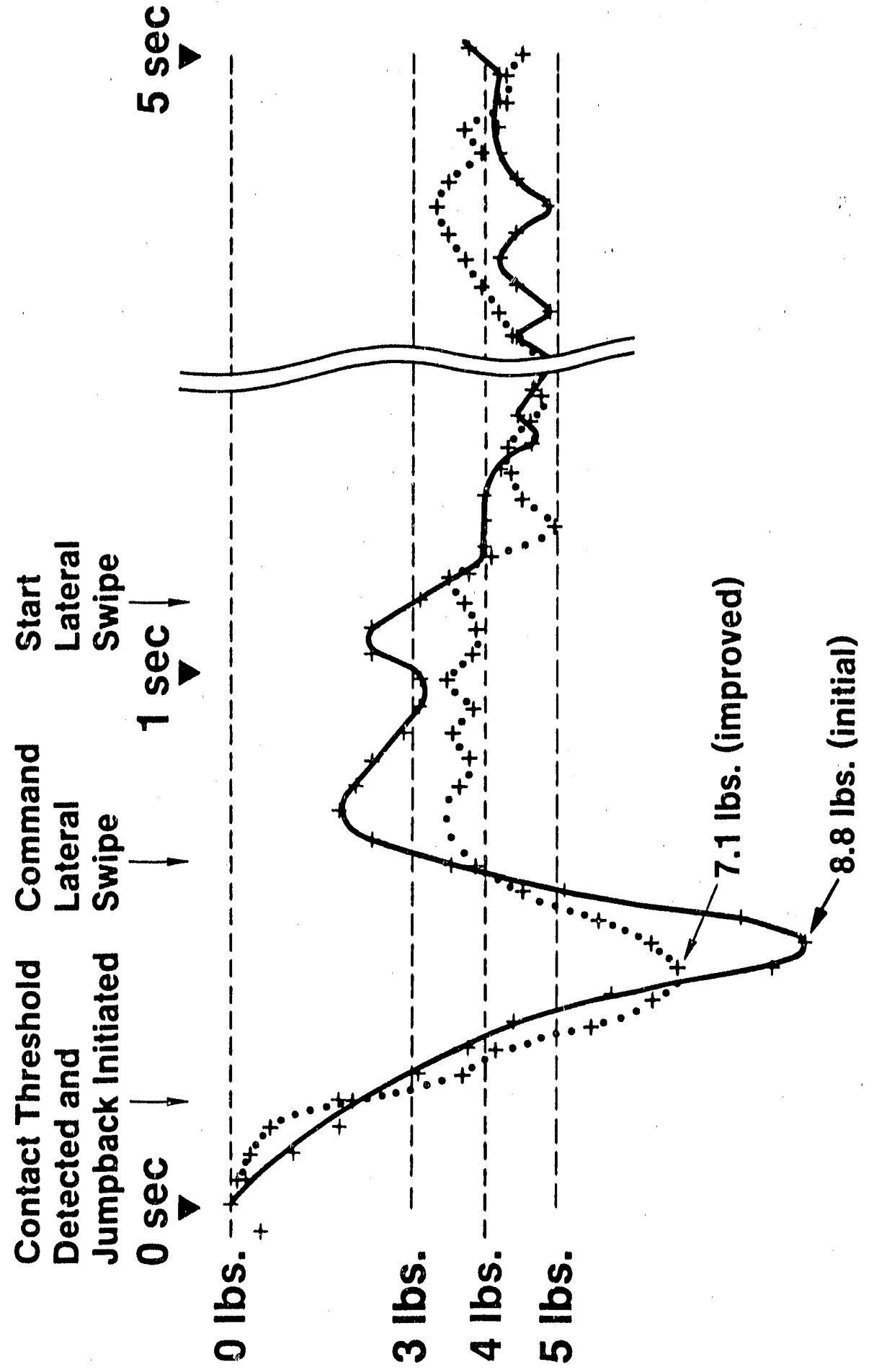

D 
Robot controller delays can also be observed at the start of the swipe trajectory. Although the command to initiate lateral robot movement is issued by the hybrid controller approximately $0.75 \mathrm{~s}$ after initial contact, lateral movement does not actually begin until approximately $0.28 \mathrm{~s}$ later.

The dotted curve in Figure A-3 shows an improved force-control implementation. By reducing the controller delays associated with Steps 1 through 5, as shown in Table A-1, the force overshoot is reduced to $31 \mathrm{~N}(7.1 \mathrm{lb})$ and stable force control is established sooner. Therefore, if the remainder of the delays could be reduced, as noted in Table A-1, it is reasoriable to assume that further improvement could be obtained.

\section{CONCLUSIONS}

Hybrid force/position control can be implemented using commercially available robot controllers through the addition of a force-control loop around the existing position-control loop. The addition of hybrid force/ position control greatly increases the utility of commercial robots by allowing them to make controlled contact with objects in their environment, and to perform force-directed manipulations, such as swiping the cask surface. It is possible to perform contact swipe operations consistently maintaining $18 \pm 4 \mathrm{~N}(4 \pm 1 \mathrm{lb})$ using a standard robot arm weighing $2,045 \mathrm{~kg}$ $(4,500 \mathrm{lb})$ by employing the hybrid force/position technology developed in this project.

For a given mechanical system, the hybrid force/position controller response is directly related to the responsiveness of the system electronics. Currently, commercially available equipment can cause long delays, from the time initial contact occurs to the time the robot arm begins to react to the contact. These delays are typically due to large buffer sizes in asynchronous communications, asynchronous component operation, slow update rates of synchronous components, and overdamped position control of commercial robot systems. By reducing these delays, improved performance of forcedirected tasks is obtainable. SNL is working with CIMCORP and JR3 to develop more responsive systems to allow more effective force control.

Robotic contact contamination surveys are feasible, and the time it takes to execute such surveys appears to be competitive with human performance. In addition, superior data collection, storage, reduction and presentation, and correlation between radiation survey data and sample location on the cask surface can be obtained using computer-based systems.

Hybrid force/position control partitions the robot control space into force- and position-control subspaces. This requires knowledge of the cask geometry for efficient control, particularly with overdamped robotic systems. If the surface geometry is not well known, and the commanded tangential move results in either breaking contact with the surface or pushing the robot strongly into the cask surface, the force-control subsystem will create large variations in applied force. The net result will be inconsistent force application during the swiping process and a much slower swiping process. Thus, smooth, well-defined surfaces that lend themselves easily to computer modeling greatly facilitate force-controlled robotic processes. 


\section{REFERENCES}

Craig, J. J., 1986. Introduction to Robotics Mechanics and Control, Reading, MA: Addison-Wesley, pp. 223-252.

DOT (U.S. Department of Transportation), 1984. "Hazardous Materials Regulations," rev. ed., 49 CFR 100-177, Sec. 173.442.

Petterson, B. J. and J. F. Jones, 1987. "Force Control of a Robot for Surface Contamination Detection," Remote Systems Technology Division Proceedings, American Nuclear Society Winter Meeting, pp, 140-143.

Raibert, M. H, and J. J, Craig, 1981. "Hybrid Position/Force Control of Manipulators, Transactions of the ASME, 102:126-133.

Salisbury, K. J., 1980. "Active Stiffness Control of a Manipulator in Cartesian Coordinates," paper presented at the 19 th IEEE Conference on Decision and Control, pp. 1-6.

Starr, G. P.,.1986. "Edge-Following with a PUMA 560 Manipulator Using VAL-II," Proceedings of the 1986 IEEE of the International Conference on Robotics and Automation, 1:399-383.

Thunborg, S., 1987. "A Robotic Radiation Survey and Analysis System," Remote Systems Technology Division Proceedings, American Nuclear Soclety Winter Meeting, pp. 133-139.

Thunborg, S., 1986. A Robotic System for Remote Maintenance of a Pulsed Nuclear Reactor," Proceedings, 34th Conference on Remote Systems Technology, pp. $181-186$.

Westinghouse Hanford Co., 1986. "Preliminary Design Report for a Remotely Operated Cask Handling System," Hanford, WA. 


\section{ACKNOWLEDGMENTS}

The authors would like to thank Bill Davidson of Sandia National Laboratories for writing all the interrupt-driven software for communication between the LSI-11/73 ${ }^{\circledR}$, the JR3 force sensor, and the $X^{\circledR} 6100$ robot controller. In addition, we would like to thank the engineering staffs of CIMCORP and JR3 for their cooperation. 


\section{APPENDIX B \\ COMPUTER VISION FOR SHIPPING CASK LOCATION}

Larry P. Ray

Sandia National Laboratories

Albuquerque, New Mexico 87185

ABS'TRACT

This appendix discusses a robot vision system developed to locate shipping casks. The system uses arm-mounted stereo cameras for close-up views of handling lugs, or trunnions, on the cask, enabling location of an 8-ft-long cask model to within 0.2 in. The system operates with ambient 1 ight, accommodating wide variations. It also detects and attempts to recover from error conditions. 


\section{INTRODUCTION}

The Remote Radiation Survey and Analysis System (RRSAS) project at Sandia National Laboratories (SNL) is intended to examine the impact of robotic handiing on nuclear waste shipping cask design (Thunborg, 1988). Since the casks would be delivered by truck or rail and since they are quite massive (20 to 125 tons), it is not feaslble to position them with great accuracy at delivery. The robot vision system described in this appendix determines the position of a prototype shipping cask to within 0.2 in., allowing subsequent robotic handling. The cask model is roughly cylindrical and measures approximately $8 \mathrm{ft}$ long and $30 \mathrm{in.}$ in diameter, approxinately one-half the size of a full-scale truck shipping container.

\section{TASK DESCRIPTION}

The robot used for cask operations is a CIMCORP XR ${ }^{\circledR} \star 6100$ six-degreeof-freedom gantry robot (Figure B-1). The cask location is specified by determining the three-dimensional position in the robot's base coordinate system of each of three handling lugs or simulated trunnions on the cask. Since the lugs are not colinear, their locations uniquely define the cask position. To make the lugs readily identifiable, they have been painted flat black fur high contrast with the white exterior of the container. The center of each lug is to be located within 0.25 in.; location accuracy should not degrade for full-scale containers. It is assumed that the vehicle carrying the cask has been parked within $18 \mathrm{in}$. of a specified nominal position. Skylights in the demonstration facility result in wide variation in the ambient lighting; the vision system should accommodate this variation as much as possible to minimize special lighting requirements. Based on the required throughput, approximately $2 \mathrm{~min}$ are avallable for the location operation.

\section{RRSAS VISION SYSTEM}

The RRSAS vision system uses two Sony XC-37 charge-coupled-device (CCD) RS-170 video cameras mounted on the robot arm at a position allowing four degrees of freedom: three degrees of translation and one degree of rotation. The camera resolution is 384 pixels horizontal and 480 pixels vertical. The cameras are mounted for stereo viewing, with a baseline of $24 \mathrm{in.}$ This configuration allows close-up views of lugs and rotation to view lugs on both sides of the cask. The rotation also allows a particular lug to be viewed from many positions.

Using cameras mounted in fixed positions, rather than on the robot, has also been considered. If such cameras viewed the entire workspace, better than half-pixel accuracy would be required for the lug location in the image, and the lugs would be only about 8 pixels across--an undesirably small target. In addition, the larger field of view required for fullscale casks would have reduced location accuracy. Alternatively, fixed cameras could have viewed the smaller area of interest, the area where the lug is expected to appear, using one pair of cameras for each lug. This would have given a similar field of view to that presently in use.

$\overline{* X R^{\circledR}}$ is a registered trademark of CIMCORP Inc. 


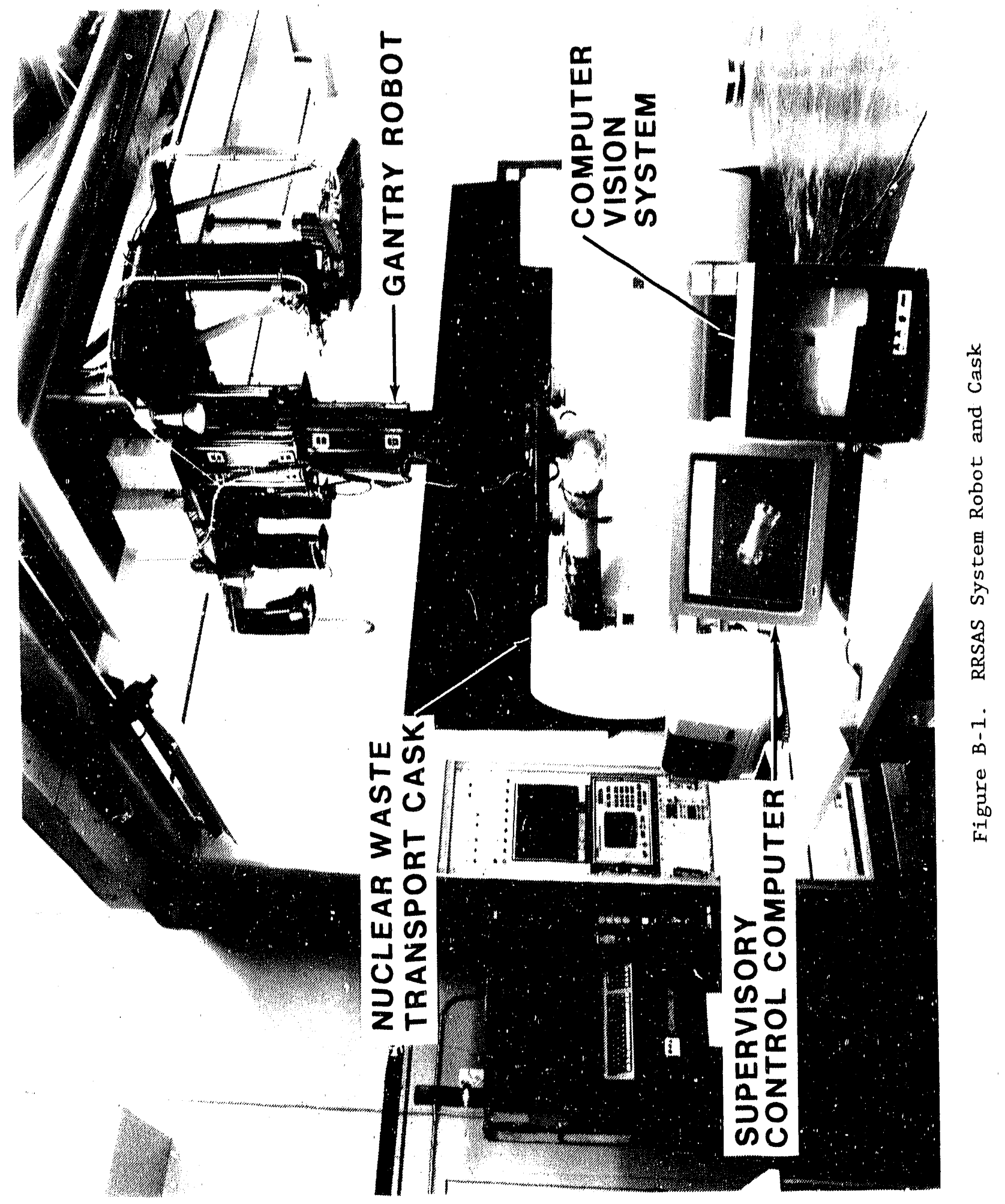


However, the arm-mounted cameras ate preferred due to thelr greater flexibility. The arm-mount position enables easler view position selection and facilitates modifications, such as locating additional lugs or averaging multiple-1ug vlews. In addition, the movable cameras more readily support future vision tasks. The ablifty to change view positiors is useful in the error recovery procedure,

Another: configuration considered has been a single, arm-mounted camera moved by the robot for stereo views. This conflguration has been rejected because robot position errors would not simply add an offset to the measured lug position, but would affect the stereo baseline, leading to much larger errors.

\section{SYSTEM DESCRIPTION}

Figure B.2 shows an overview of the vision system. The RRSAS vision process requires coordinated activity by the robot and an image-processing subsystem in response to commands from the RRSAS supervisory program. The main vision program runs on the host computer, a Sun Microsystems $3 / 160$. This program, the vision server, provides computer vision services for the RRSAS supervisory program, or the client. The server accepts commands from the client and directs the image-pracessing computer and robot operations. The vision server can control the position of the robot with requests to the RRSAS supervisory program. Image-processing operations are performed by a Machine Vision, Inc. Genesis 4000 computer vision system (MVI, 1986). This unte, called an Image Flow Computer (IFC), serves as a vision peripheral to the host computer; communication is via RS-232 lines. The IFC is programmable in the $C$ language, so, in principle, any algorithms can be implemented. However, in practice, only operations supported by specialized hardware run at acceptable speeds for RRSAS purposes. These include both binary and gray scale morphological operations (dilations and erosions), thresholding, and simple arithmetic (Serra, 1982).

\section{CASK LOCATION}

When commanded to locate the shipping cask, the vision system moves the robot arm to a position allowing both cameras to view the nominal position of the first handling lug with a $40-\mathrm{in}$. field of view. The system then acquires images from botl: left and right cameras. Each image is processed to determine, if possible, the two-dimensional location in the image of the target, the center of a dark area surrounded by a bright area. If the target is successfully located in both images, previously determined camera calibration coefficients are used in a triangulation process to find the three-dimensional coordinates of the lug center in the robot base coordinate system. If the lug center is not successfully located in both images, an error recovery procedure is invoked. The position of each of the three lugs is found in this way. If checks on the lug locations are satisfactory, the three lug positions are sent to the client program with a status code indicating successful location (see the Error Detection and Recovery section below). 

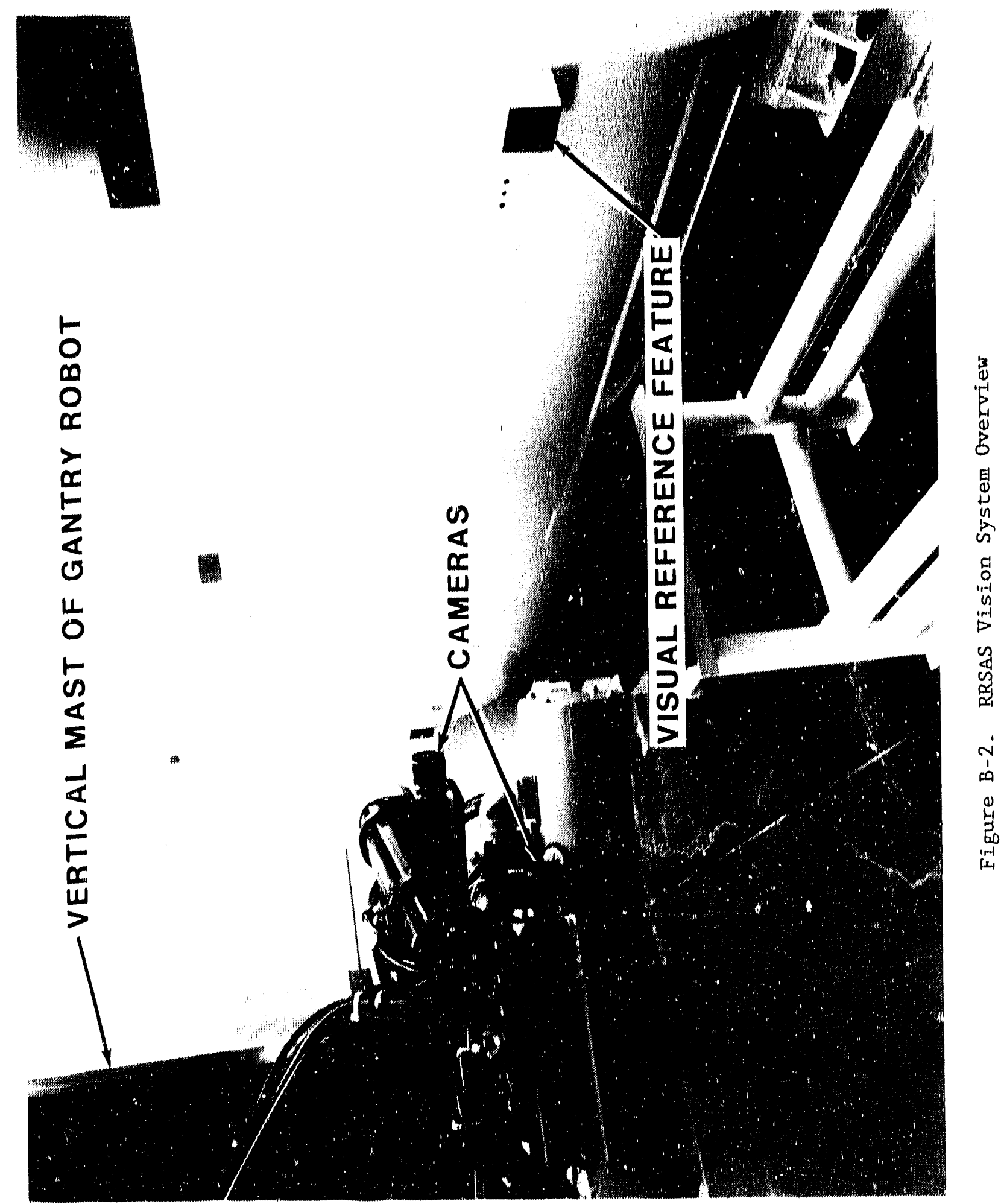


\section{CALITBLA'LION}

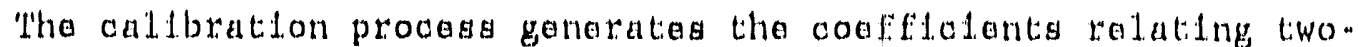
dimenstonal. Lmage locations to threadimeneforal locations in the world, Calibration requires a serles of cata sets; each data sat conelates of tho throendimans lonal coordinates of a point and the position of the point in the left and right camera lmages, A lug, like those on the oask, is mountad on a white wall to serve as a oaldbration target. Durlng calibration, tha vision systam moves the robot to a start position at which the target is approximately centarad in both camera lmagos, 'the system then moves the arm to a serles of postefons displaced from the stat: position by varylng distanoes in $x, y$, and $z$. ('the fourth degroo of: freadom, theta, is not exarcised,) At each position, the vistonsystam acquires a palr of limages and locates the lug center fon each lmage. 'The coordinates of the lug denter at oach position are the $x, y$, and $z$ displacements in robot base coordinates, from the center of jolnt four, which ls the robot's elbow, to the lug center. 'The resulting data are passed to the calibration routine, which fincls the camera callbration coeffictents by performing a least-squares-error fit to a set of linear: equations contalning the calibration data.

The resulting frame of reference has $1 \mathrm{tg}$ orlgin at jolnt four, rotates with folnt four, and 1 s allgned with the robot base fralle when folnt four Is at the calibration position. Subsequent triangulation operations fin the IFC Find the location of a point in this frame. The host computer: transforms points from the camera coordinate system into the robot base coordinate systam.

\section{IMAGE ACQUISITION AND TARGET LOCATION}

Both cask location and callbration depend heavily on locating the lug center in Images. The following procedures are used to acquire images that compensate for lighting varlation and to isolate the lug center.

As part of the Image acquistition process, the gain of the image digitizer is adjusted so that the histogram of plxel intensitios is well. distributed over the possible range, In an iterative process, the system acquires an Image, examines the histogram, and modifies the digftizer gain unt11. the acquired lmage is acceptable. After digltizer settings are selected for both cameras, Images from each camera are acquired in quick succession. Because the robot is slowly hunting around a nominal position, 1.t is necessary to obtain the left and $r$ lght camera linges with minimum time difference to minimize the possible change in stereo baseline.

The first Image processing step is to convert the gray scale lmage to a binary image. A threshold is selected by processing a histogram of the pixel intensity in the area of interest; confining the processing to this area eliminates the background clutter above and below the cask. The handling lug is the darkest object in the area of Interest; the linge histograin is bimodal. The process searches the histogram for the minlinum value between the intenstites corresponding to the lug and those for the cask body. The lug group must include at least as many plxels as the minimum expected lug size. The finge is binarized with this threshold. 
The Image las also Lnvertad, 1.a., dark plxals becone foreground, atrice the objact of Intorast ds dark.

The next processing step is lug loolation from other foreground pixels, A dilation operation fills in ary small holes in the foreground grouplngs. Then, an eroston operation oliminates grouplngs much smalier than the expected lug slae, Finally, another dilation returna any remalning groups to thele orlglnal slze, Normally, only one group remalns in the area of Interast. If this group 1 s within accoptablo slze 11 intes and 1 ts shape 1 s approximately square, tis center is denteled as the lug conter. If there are no groups, or more than one of the rlght slae and shape, the routine reports a fallure to locate the lug; this leads to atempted error recovery.

\section{ERROR DE'TEC'TION AND RECOVERY}

The RRSAS vision system can detect several indlcations of error. If the lug center ls not successfully located in both 1mages, the system moves the robot slightly and repeats the lmage acquisition and analysis process. If not successful after throe tries, the system reports a fallure to the c. lent process. In the early phases of vision development, the system has been occasionally confused by shadows on the cask body; often this shift in viewing position has allowed the lug center to be located. The current viston algorlthms described above have eliminated the shadow problem.

In addition, each lug position is checked to confirm that it lies within $18 \mathrm{ln}$, of the nominal position and within $3 \mathrm{ln}$, of the nominal helght. As a further check, the distances between lugs are calculated to ensure that they are approximately correct. These verification steps minfinize the probability that the robot will be directed to begin operations in an incorrect location. Hoilever, no automatic recovery is attempted if lug locations are Invalid.

\section{RESUL'TS}

The RRSAS vision system has been operational for approximately 1 yr and has achleved the requlrements identified in the Task Description section. The system rellably locates the mock-up cask, determining the position of each lug within 0.2 in. Seventy-five percent of the locations are within $0.1 \mathrm{in}$. No signiflcant difference in performance is observable under lighting variation. Time required for cask location $1 \mathrm{~s} 1 \mathrm{~min}, 15 \mathrm{~s}$. As a result of the error detection procedures, the vision system has never reported a successful cask location whlle ceturning an incorrect cask location. With the current algorithms, the vision system has located the cask 112 times; the only fallures resulted from an inage digltizer hardware fallure.

Over a 10-wk perlod, the cask has been left in one position to allow evaluation of vision repeatablifty and stablilty. The system was not recalibrated during this time. The resulting data are suminarized in Table B-1. Note that no variation in location accuracy is evident during this time. A theodolite measuring system is used as an independent check of vision accuracy; for each lug, the mean location, as measured by the vision system, agrees with the theodolite measurement to within the 
T'able B -1

Repeatability of Cask Location

\begin{tabular}{|c|c|c|c|c|c|c|c|}
\hline Lug & Pertod & $\begin{array}{c}\text { X-Axis } \\
\text { Mean }\end{array}$ & $\begin{array}{l}X-A \times 1 . s \\
\text { Sted Dev }\end{array}$ & $\begin{array}{c}\text { YoAxLs } \\
\text { Mean }\end{array}$ & $\begin{array}{l}\text { Y AxIs } \\
\text { Std Dev }\end{array}$ & $\begin{array}{c}2-A x \perp s \\
\text { Mean }\end{array}$ & $\begin{array}{l}\text { Z.Axis } \\
\text { Std Dev }\end{array}$ \\
\hline 0 & $\begin{array}{l}\text { T'en Weeks } \\
\text { First: Week } \\
\text { Last Weak }\end{array}$ & $\begin{array}{l}-101.23 \\
-101.22 \\
-101.24\end{array}$ & $\begin{array}{l}0.05 \\
0.05 \\
0.05\end{array}$ & $\begin{array}{l}-8.02 \\
-8.05 \\
-7.99\end{array}$ & $\begin{array}{l}0.07 \\
0.07 \\
0.07\end{array}$ & $\begin{array}{l}-18.89 \\
-18.89 \\
-18.88\end{array}$ & $\begin{array}{l}0.0 .5 \\
0.04 \\
0.06\end{array}$ \\
\hline 1. & $\begin{array}{l}\text { Ten Weeks } \\
\text { First Week } \\
\text { Last Week }\end{array}$ & $\begin{array}{l}-41.31 \\
-41.31 \\
-41.31\end{array}$ & $\begin{array}{l}0.04 \\
0.05 \\
0.04\end{array}$ & $\begin{array}{l}-5.07 \\
-5.09 \\
-5.04\end{array}$ & $\begin{array}{l}0.06 \\
0.06 \\
0.05\end{array}$ & $\begin{array}{l}-19.06 \\
-19.06 \\
-19.05\end{array}$ & $\begin{array}{l}0.04 \\
0.03 \\
0.05\end{array}$ \\
\hline 2 & $\begin{array}{l}\text { Ten Weaks } \\
\text { First Weak } \\
\text { Last Weak }\end{array}$ & $\begin{array}{l}-42.991 \\
-43.00 \\
-43.01\end{array}$ & $\begin{array}{l}0.05 \\
0.03 \\
0.03\end{array}$ & $\begin{array}{l}28,38 \\
28,38 \\
28,37\end{array}$ & $\begin{array}{l}0.05 \\
0.07 \\
0.05\end{array}$ & $\begin{array}{l}-19.22 \\
-19.22 \\
-19.22\end{array}$ & $\begin{array}{l}0.04 \\
0.03 \\
0.04\end{array}$ \\
\hline
\end{tabular}

theodolite accuracy $(0.1 \mathrm{ln}$.$) . Another check on the vision system's$ relative accuracy is the distance between lugs. The actual distance between Lug 0 and Lug 1 is $60 \mathrm{in}$.; the mean distance measured by the vision system is $59.99 \mathrm{in}$, with a standard deviation of $0.03 \mathrm{in}$.

After declding to use arm-mounted cameras, there has been some concern about the effects of arm motion and vibration. However, the results have been favorable: camera calibration has benn stable; and the CCD cameras have shown no adverse effects from the vibration. 


\section{REFERENCES}

Machine Vision International, 1986. "Genesis Systems Operations Manual," Ann Arbor, MI.

Serra, J., 1982. Image Analysis and Mathematical Morphology, New York: Academic Press.

Thunborg, S., 1988. "RRSAS Project: A Real Time Sensor Driven Robotic System," paper presented at Robots $12 / \mathrm{Vis}$ ion ' 88 Conference, sponsored by the Society of Manufacturing Engineers, Detroit. 


\section{ACKNOWLEDGMENTS}

The advice and technical assistance of J, Bailar, J. S. Littlejohn, D. J. Miller, B. J. Petterson, C. B. Selleck, and S. Thunborg were invaluable and are gratefully acknowledged. 
APPENDIX $\mathrm{C}$

SUPERVISORY CONTROL FOR A COMPLEX ROBOTIC SYSTEM*

David J. Miller

Sandia National Laboratories

Albuquerque, New Mexico 87185

\begin{abstract}
The Robotic Radiation Survey and Analysis System (RRSAS) investigates the use of advanced robotic technology for performing remote radiation surveys on nuclear waste shipping casks. Robotic systems have the potential for reducing personnel exposure to radiation and providing fast, reliable throughput at future repository sites. A primary technology issue is the integrated control of distributed, specialized hardware through a modular supervisory software system. Automated programming of robot trajectories, based on mathematical cask and robot models coupled with sensory feedback, enable flexible operation of a commercial gantry robot with the reliability needed to perform autonomous operations in a hazardous environment. Complexity is managed using structured software engineering techniques, resulting in the generation of reusable command primitives that contribute to a software parts catalog for a generalized robot programming language.
\end{abstract}

*Paper presented at Robots 12/Vision 188 Conference, sponsored by the Society of Manufacturing Engineers, Detroit, Michigan, June 6-9, 1988. 


\section{INTRODUCTION}

This appendix discusses the supervisory software environment of the Robotic Radiation Survey and Analysis System (RRSAS). Of particular importance is the development of software to support the automatic programming of detalled robot trajectories based on models of the robot and its environment. Sensors are used to correct for errors in the models. Model-based robot control is critical for such application, since personnel access to radiation enviroriments for manual programming of robots will be severely limited.

In the following sections, the problems associated with developing complex software environments are explored, particularly as they relate to the model-based control of robotic systems. The characteristics of quality software and the goals and principles of software engineering that have been used in the RRSAS development process are discussed. This is followed by a description of the software design methodology and 1ts application across all levels of programming, ranging from modeling of the shipping cask and automatic programming of robot motions at the highest task leve1, to realtime force control at the lowest robot level. Finally, it is shown that the resulting implementation may be considered a paradigm for controlling any complex robotic system.

Evolution of complex computing environments has led to hierarchical distributed systems with multiple heterogeneous computers. These computers execute specialized concurrent functions, often in real time, while communicating with one another in a coordinated fashion. Such architectures lend themsel.ves to robotic systems containing diverse devices that must be integrated with a manipulator to perform specific tasks. The RRSAS is an example of a hierarchical distributed computing system that addresses five well-defined operations for handling nuclear waste shipping casks at repository sites:

- Cask location using vision,

- Cask identification using bar code labels,

- Video survey for mechanical damage,

- Geiger counter survey for beta/gamma radiation analysis, and

- Contact swipe survey at random cask surface locations for alpha/beta/gamma radiation analysis.

A large 20 -ft $\times 40-\mathrm{ft}$ gantry robot performs these operations. Each operation possesses a set of control requirements (Thunborg, 1987) that must be handled by a supervisory computing system. The supervisory computer communicates with specialized hardware, e.g., a robot coniroller, vision system, force sensor, bar code reader, Geiger counter, and swipe reader. Communication occurs by passing messages of command primitives to each system component. A11 subsystem activity is initiated by the host computer, which may communicate with several devices simultaneously, thus providing a parallel control architecture.

The technical challenge associated with developing a supervisory software environment for the RRSAS results from the software, which is the integrating agent for the system. Software complexity could not be avoided, due to the innate complexity of the RRSAS environment and the requirement for 
model-based automatic control. Therefore, an approach that resulted in controlled complexity was adopted, and high system reliability was achieved through error detection and recovery. In addition, the hierarchical modularized approach to the software architecture employed in this research produces selected system-independent software modules reusable in other robotics projects. This represents the beginning of a system-independent library of software modules. One goal of robotic systems development at Sandia National Laboratories (SNL) is the generation of a parts catalog for robotic systems software to facilitate the development of future advanced robotic systems. The supervisory software development associated with the RRSAS contributes to that goal.

\section{COMPLEXITY ISSUES FOR ROBOTIC SOFTWARE}

The special nature of robotic systems presents unique, complex software problems. First and foremost, robotics software must interact with a richer variety of intelligent subsystems than most application environments. The RRSAS configuration illustrates this with five different external devices, including a vision system, bar code reader, Gelger counter, swipe reader, and force sensor. This diversity poses difficulties for software development, particularly when all of the subsystems must be integrated. New software is usually needed for each piece of new hardware. Therefore, the software designer must become intimately familiar with many different types of hardware or treat them as black boxes, relying on proprietary vendor firmware and documentation. If the firmware does not function as advertised, the software designer must determine the true capabilities of each device and compensate for poor hardware and inadequate firmware. Interfacing with other incompatible subsystems requires a communications code that must handle protocol and timing differences. Frequently, the software design cannot be completed or implemented until the hardware is installed and physically networked together. The software developer must first experiment with uncertain device behaviors before committing to a design that has only been worked out on paper.

Another unique aspect of robotic systems is the physical interaction between the robot and its environment to perform tasks normally done by humans. This interaction requires that the software models the world in which the robot exists to automatically program appropriate robot motions. This model includes geometric and physical knowledge of the objects in the robot's workspace, as well as a kinematic model of the robot itself. In the RRSAS, a mathematical model of the shipping cask and a model that relates the kinematics of the gantry robot to its approaches and to each cask surface are critical in performing the random swipe survey.

Motion and grasp planning are key tasks of robotics software that require a good world model. Generated plans must deal with issues such as safety, stability, reachability, speed, accuracy, and joint limits.

Trajectories must be coordinated with knowledge of the environment to achieve correct arm position and orientation while avoiding obstacles. Different types of motion must also be handled. If a planned path has no known obstacles, and the robot is not interacting with other objects, free motion can be used to take the quickest and most direct route available toward the destination. If the robot interacts with other objects, guarded motion that mây be slowed or terminated on the basis of sensory data should be usod to 
facilitate proper contact with these objects. In the RRSAS, guarded motion occurs during the contact swipe survey to move in and touch the shipping cask. When a certain amount of force has been detected between the swipe and the cask's surface, the motion is terminated. Finally, compliant motion is used to swipe the cask's surface. This type of motion must conforrn with forces encountered between the swipe and the cask to maintain constant pressure on the surface. Using guarded and compliant motion implies the need for real-time sensory information and feedback. These are dynamic aspects of the world model. The software that controls such real-time physical processes performed by the robot cannot be suspended and later resumed while the computer is servicing other programs. All of these modeling issues contribute to complexity when designing software for an integrated robotics system.

A third aspect of robotic systems that contributes to software complexity is the need for extensive error detection and recovery procedures. When the system architecture contains many distributed components that interact with one another, the number of different system states can be large. The software design must anticipate these states and provide appropriate responses to each. The strong interaction between the software and the physical system it controls makes error recovery for robotic systems difficult to implement. It requires the most current knowledge of the stateof-the-world mode1, which must be dynamically updated during each robotic operation. Error handling is particularly critical for applications like the RRSAS, where the robot is performing remote surveys in a hazardous environment. However, the quantity of code implemented to achieve high reliability can equal or exceed the code that performs the actual system tasks. Approximately 50 percent of the code in this module performs error detection or recovery operations.

Aside from these unique aspects, robotic software design also inherits the problems associated with any complex software system. Most systems are initially poorly specifled and, thus, the software must be designed for extensibility, adaptability, and maintainability. Using operating system software, e.g., a kernel, compiler, or window manager, to handle code generation, computer resource and device management, graphics, or communications may introduce errors that are difficult to find and work around. Real-time control often demands special hardware and system software support, which requires expertise in interrupt-driven programming and assembly languages. User interfaces are time-consuning to implement and require extensive coding to be flexible enough for all levels of usage, yet robust enough to prevent accidental or deliberate damage to the system.

Finally, the software designer must have a mechanism for dealing directly with complexity. Designing and implementing thousands or possibly millions of lines of code to solve complex problems requires intellectual and physical capacities that exceed those of a single person, unless the solution is broken down into manageable parts. A divide-and-conquer strategy is the only way to successfully bulld a complex system. Software design methodologies can provide a formal mechanism for implementing this strategy and for ultimately controlling complexity. 


\section{MANAGING COMPLEXITY}

Designing the complex software environment needed to control the numerous intelifgent devices comprising the RRSAS has posed a challenge. The concept of embedded intelligence has resulted in the development of many systems whose distributed computing potentials have not been fully utilized, because the resulting complexity has outgrown the ablilty to manage the system. This inability to develop software that effectively manages subsystems integration required to perform complex tasks is part of a dilemma commonly referred to as the software crisis (Pressman, 1982). The development of software tools has not kept pace with the development of computer-driven hardware, making it difficult to cope with the diversity and complexity of large-scale systems like the RRSAS.

A major requirement for the RRSAS is high reliability to prevent personnel exposure to radiation in hazardous environments where such robotic systems must perform. However, uncontrolled complexity results in unreliability. To develop the complex yet rellable software system required by the RRSAS, software development has been patterned after the development of complex hardware systems, in which relatively simple components are combined to achieve complex behavior and desired functionality. This enables isolation of related functions, simplification of their interfaces, and thorough testing of individual components. System complexity is ultimately achieved through a linear combination of simple subsystems with verifiably correct behavior.

Four primary software engineering principles are generally regarded as critical to good design: modularity, locality, abstraction, and information hiding (Pressman, 1982). Modularity refers to purposeful decomposition of software into distinct elements that are integrated to satisfy problem requirements. Modularity is the software attribute that allows a program to be intellectually manageable. Locality is directly related to modularity in that it determines the degree of module independence. Locality is defined as achieving a high degree of independence by developing modules that perform single-purpose functions and require minimal interaction with other modules. Applying the principle of locality, therefore, results in modules with strong internal cohesion and loose coupling.

The principles of abstraction and information hiding refer to extracting essential properties while omitting inessential details. In the context of software development, abstraction and information hiding permit the software designer to concentrate on a problem solution at one level of generalization at a time while delaying consideration of lower-level details. Each step in the software engineering process is a refinement in the level of abstraction of the software structure. At the highest level, the software system structure is described in broad terms, using the language of the problem environment. At lower levels, a more procedural orientation to software structure is taken, where problem-oriented descriptors are coupled with implementation-oriented descriptors to define algorithmic solutions. Finally, at the lowest levels, the software structure is described in the direct implementation terms of data structures and programing language primitives. Such stepwise refinement (further discussed below) is closely aligned with modularity, because it results in a factored structure that distributes levels of control and decision making into modules. 
Information hiding suggests that procedures and data contained within a module should be inaccessible to other modules that have no need for such information. The term "hiding" implies that effective modularity can be achieved by defining a set of independent modules that communicate only the information necessary to achieve software function. Thus, abstraction helps to define the procedural or informational entities that comprise the software, and information hiding defines and enforces access constraints to both procedural detail and local data structures contalned in each module.

Numerous methodologies have been proposed (Pressman, 1982; Wirth, 1971; Yourdon and Constantine, 1979) for software development. These methodo1ogles, if properly adhered to, encourage and enforce the application of the four software engineering principles: modularity, locality, abstraction, and information hiding. They also help produce detalled code documentation, which is necessary for the proper coordination, control, and management of complex software environments.

\section{THE RRSAS SOFTWARE DESIGN METHODOLOGY}

The RRSAS is a complex robotic system with a distributed multiprocessor computing environment capable of model- and sensor-based control. The RRSAS achieves high system reliability by detecting subsystem errors and recovering from those errors. A software environment that uses procedural knowledge to plan actions is important to the consistent operational behavior of the RRSAS. The RRSAS anticipates the consequences of actions to uncover and deal with error situations.

To create a software environment supporting the RRSAS objectives and exhibiting the properties of modularity, locality, abstraction, and information hiding, a methodology has been developed that embodies concepts from top-down structured design (Yourdon and Constantine, 1979), stepwise refinement (Wirth, 1971), and bottom-up implementation. This approach is well suited for designing task-driven robotic systems with many intelligent special-purpose devices, which must be integrated to form a cohesive environment. Top-down structured design decomposes a system by making each action of the system a module. This leads to program modules that closely reflect system function, or a function-oriented approach. At the highest level, the modules represent the overall function of the system. For the RRSAS, the highest level is performance of remote radiation surveys on nuclear waste shipping casks. At lower levels, successively more-detailed functions are implemented that, when combined, perform this high-level. action. A low-level RRSAS primitive example would be to move the robot from point A to point B.

Stepwise refinement develops the intermediate-level modules that provide the bridge between the highest and lowest levels by successively refining additional levels of procedural detall. Initially, a software control program named supervisor is defined. Then, each task invoked by the supervisor is expanded in top-down fashion. Additional levels of refinement occur until a level of detali has been achieved that results in single-function modules which cannot be logically decomposed any further. 
Refinement is accomplished by selecting, at each step of the software system design process, the next lower-level procedural abstraction and investigating 1ts implementation by making lists of the tasks that must be accomplished in the procedure. Using these lists as a guide, and allowing the problem structure to determine software structure, further lower-level abstractions can be specifled. This process is iterated until suffictent refinement has been achieved, resulting in a hierarchy of abstractions that can be represented by a module dependency diagram, reflecting the completed design.

Bottom-up implementation of this software system design allows immediate interfacing with the system hardware. Immediate interfacing can quickly address problems associated with unprentictable device behaviors. Components not designed for compatibility and having insufficient documentation result in problems that can only be dealt with through experimental programining. This programming should be done early in the implementation phase to facilitate design changes resulting from new knowledge gained about each subsystem.

\section{Application of the Design Methodology}

Three primary objectives have guided the overall RRSAS software system design procedure. The first objective is to provide a robotic system that executed all cask radiation survey operations automatically, while keeping the operator informed of the system status and survey results, using windows, menus, and graphics. This requires a software system that provided a high degree of hardware integration. The second objective is to include robust error detection and recovery capabilities. This requirement for error detection and recovery reflects the need for high rellability and autonomous operation in a hazardous environment. The third objective is to create a generalized software development enviromment as opposed to a profect-specific control program. Future robotic tasks using the same or similar hardware could then be rapidly implemented with the software tools praduced.

Application of the top-down design and bottom-up implementation methodology discussed above has resulted in well-defined software tasks that map onto the appropriate hardware subsystems. This definition produces a hierarchical architecture that reflects the englneering principles of modularity, locality, abstraction, and information hiding. Figure $\mathrm{C}-1$ shows the distributed architecture with the software task hierarchy superimposed over the hardware.

The man-machine interface task (MMI Task) at the top of the hierarchy provides the primary operator interface to the system. This task hides the MMI data structures, or menu displays, and windowing system interfaces from the other supervisory components. It handles operator inputs through mouse button picks and communicates menu selections to the other tasks, triggering appropriate actions.

The Supervisor Task on the host computer is the primary RRSAS contro1 program. It is decomposed at the highest level of abstraction into taskoriented modules which, when properly combined, accomplish each of the five survey operations discussed above, as well as system startup and shutdown. These RRSAS function-oriented task modules-init, vision, barcode, radsurvey, 


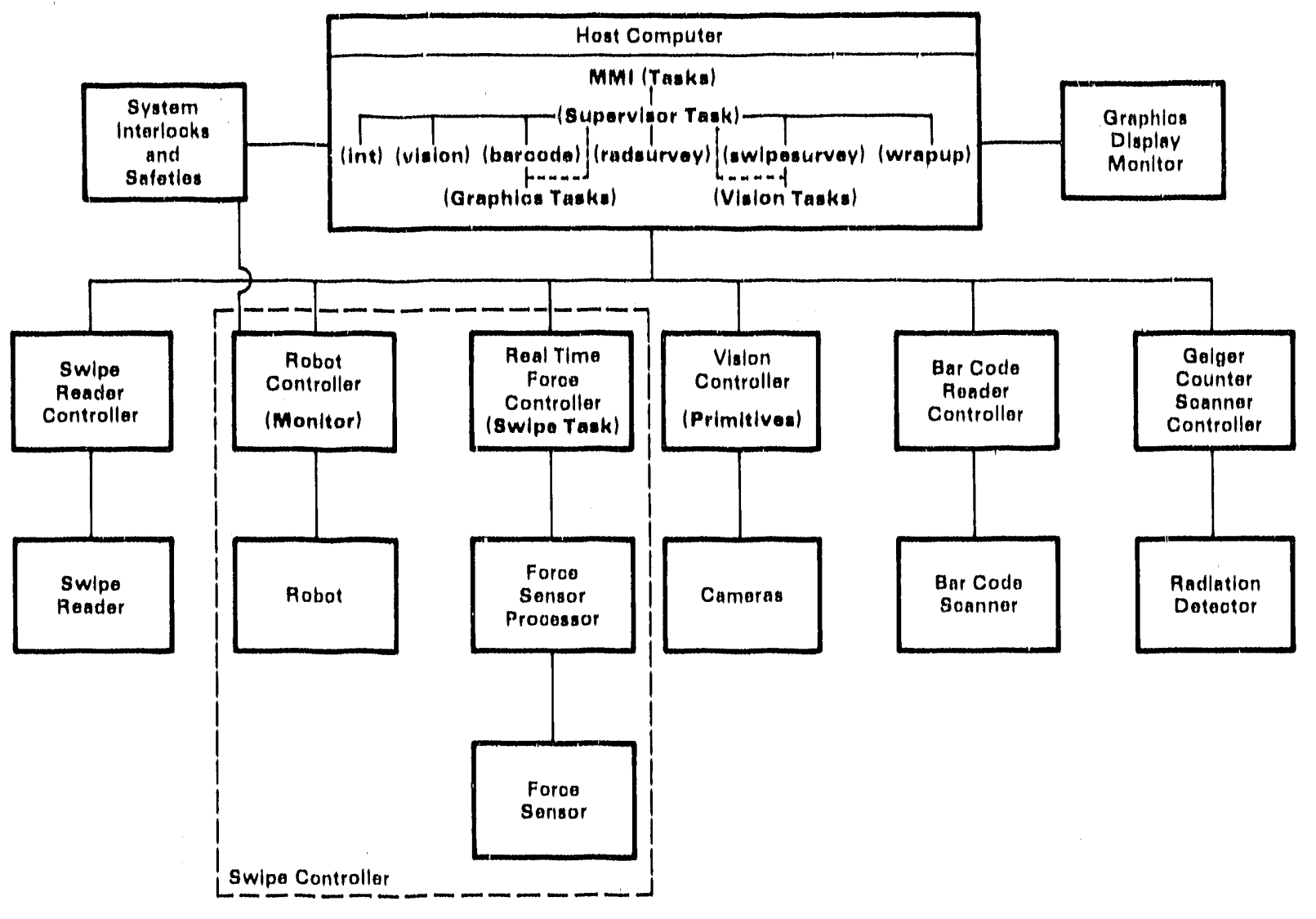

Figure C-1. RRSAS Architecture 
swlpeourvey, and wrapup are decomposed Into sucassive levels of abstraction, as described above, until a lavel. Is reached that contalns a sat of task and device-independent modules, as shown in Figure C-2. These modules contribute to the generalized software envixoment by providing reusable tools for baslc robotic functions. The generlc modulas of Flgure C.2 are decomposed further unt11, at the lowest-levels of abstraction, modules contalning devlce-dependent code result. These lowest-level modules handle operating system interfaces and communlaation protocols for the other intelligent hardware subsystems present in the overall conflguration. A detalled example of how top-down design is employed to produce a complete module dependency diagram for the random contact swlpe survey, or swlpesurvey, is discussed in the following section.

Other task modules in the software hlevarchy provlde speclalized services for the supervisor or control other subsystems, such as a Monitor program, whlch 1s downloaded by the supervisor to execute on the robot controller. The Monftor program, written in the robot language CIMPLER (CIMCORP, 1986), serves as a device driver that handles all robot primftives sent by the supervisor by parsing each command and calling the appropriate robot-control subroitines. These robot-control subroutines execute the specific CIMPLER language statements that drive the servos and move the arm.

A Swipe Task is initiated by the swipesurvey module on the host computer. It executes on a dedicated PDP/11 with RT-11 proceasor enviroment and provides force-controlled movement of the robot arm for the random contact swipe survey. This computer serves as a force servo control system, which monftors a force sensor mounted on the wrist of the robot and makes real-time trajectory corrections to the robot arm. The corrections are based on the contact force detected between the robot's end effector, or swlpe planchet, and the cask, and serve to produce a constant force swipe (Petterson and Jones, 1987). This task, therefore, hides all of the algorlthmic detalls and hardware-speclfic knowledge of force control and real-time trajectory correction from the supervisor. The supervisor simply has knowledge of a procedural level of abstraction (the doswipe module in the swipesurvey hierarchy) that commands the force control subsystem to perform a swlpe at a location and in a direction, based on the cask mode1, which is determined by the swipesurvey task module in the supervisor. This force control task, in turn, has its own abstraction hierarchy containing the necessary modules and dependencles to accomplish its specifled functions.

The Vision Task runs on the host computer in conjunction with the Supervisor Task. It provides an interface to the low-level vision functions, which are performed by a separate computer containing special-purpose computer vision hardware and software. The supervisory vision module sends high-level commands, such as "lacate cask," to the Vision Task. The Vision Task decomposes this command into a sequence of robotic actions and lmage analysis operations to ultimately accomplish the supervisor's request (Ray, forthooming, .

Finally, four other auxiliary tasks, or Graphics T'asks, reside on the host computer, as shown in Figure C-1. During the Initialization phase, the Supervisor Task activates the Craphics Tasks, which generate appropriate graphics windows when signaled to do so. They produce three-dimensional graphics representations for real-time data displays of radiation readings 


\section{Action Primitives:}
plokupeff
(). Piok up an end effector
putdowneff
(). Put down an end effector robothome
(). Send robot to a sefe home location robotmove
() - Move robot to a specified destination
robotrmove
() - Relatively move robot by specifled offsets

\section{Environment Primitives:}

checkswitch (). Check a hardware micro-switch for end effector station status cmpaltohome ()-Compare robot's current location to the home location

gripperempty ()- Determine gripper status

whateff ()- Determine what end effector is in the gripper

\section{1/O Primitives:}

$\begin{array}{ll}\text { openport } & \text { () - Open a serial port for communication } \\ \text { readport } & \text { (). - Read from a serial port } \\ \text { Writeport } & \text { (). - Write to a serial port }\end{array}$

Figure C-2, Generte Modules for a Robotic Environinent 
and random contact awlpe locations. Flgure $C-3$ lilustrates an axample of the graphtos ganorated by these tasks.

Detalled lixample - Bandoun Swlpe Suryey

The randoin contact swipe survey lin the most techndcally challengling RRSAS operation and, therefore, prevides the most comprahensive example of how a task ls decomposed, using this methodology, the spectefications for this operation can first be reformulated 1nto a description of subtasks that ldentify the subordinate abstractions required. Figure C-4 contalns this 11st of descriptions and the corresponding highest-level modules derived from 1t. Several operational characterlstics of the swipe task are captured in the task descriptions.

As shown lin Task 1, swlplng requires the use of commanded, mode1-based robot motion rather: than conventionally taught motion for path determination, because the swipe points must be selected randomly for each cask survey. In addition, 'Tasks 2, 3, and 6 show that the robot's location with raspect to the task must be known to automatically determine unobstructed travel paths, when moving from one swipe point to another with swipe-dispensing moves in between. Messages must be sent to the force control computer when the swipe planchet has been posttioned over each swipe polnt, and the force control. computer must perform the real-time constant-force swlping action. Prior to each swlpling action, graphles displays (Task 5) must: be generated showing each swipe point location on the cask. The operator can verlfy that the arm is moving to the correct location, which is unknown in advance, by observing the display and subsequent arm motion. Upon completion of the survey, the Supervisor Task directs the swipe reader to analyze the swipes in Tasks 7 and 8. Thus, to execute a swlpe survey, the Supervisor lask must coordinate the actions of the robot controller, force-control computer, swipe reader, and graphics tasks.

Figure C.5 is the module dependency diagram of the swipesurvey task module on the host computer. Each of the higher-level modules represents an abstraction level that must be decomposed tearatively using stepwise refinement to complete the diagram. Flgure $C-5$ shows the decomposition of the sulpesurvey supervisory module down to the lowest level.s. This hierarchy provides a complete structural representation for the swipe survey software.

The following section will focus on the processing detalis of each module individualily to provide procedural representation. A precise spectfication of each module includes sequence of events, exact decision points, repetitive operations, references to all subordinate modulas, and data organization and structure. Speciflcations for each RRSAS module are spelled out in the source code level files for these modules. Specifications for the highor.level modules are relatively stralghtforward because, in many cases, they conslst only of call sequences to lower level modules, The lowest levels, however, must interface with the operating system and external. devices and, therefore, require careful consideration.

The spectefcations for each of the modules in Flgure $\mathrm{C}-\mathrm{s}$ are Initially created by writing source-code-level flles contalntng only comment statements. An extended comment statement at the bogfnning of each module serves as a header containing all the information needed to understand what the 


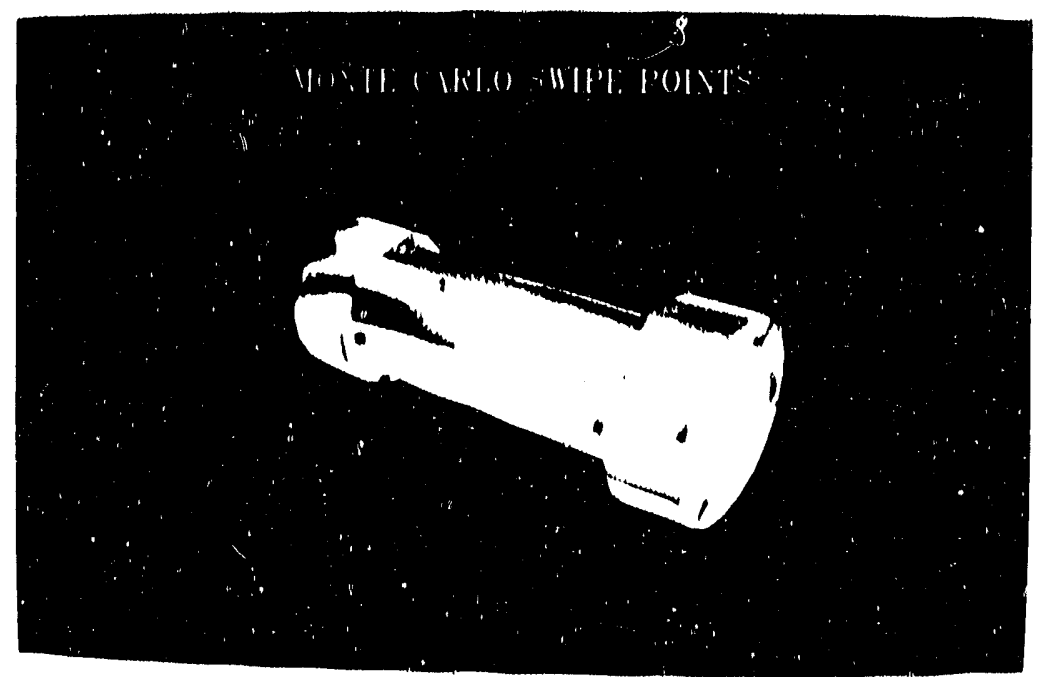

Figure C-3, Swipe Survey Graphios Display

\section{Task Description}

Module(s)

(1) Generate randorr sets of swlpe locations evenly distrlbuted over the aurfaon areas of the cask with an algorlthm whloh utillzes a mathomation modal of the cask.

(2) Generate robot appraach vectors for each swips point whloh optlmally orlent the arm and swipe tool to reash all phyaloally acoessible surfaces while avolding oollisions.

(3) Compute the inverse kinematios for the robot arm in order to transform swipe point looatlons and their oorresponding approaoh vectors into the robot's foint coordinate system, with full knowledge of robot joint limits and the cask's location through vision.

(4) Optimize the path followed by the robot around the cask as it takes swipes by sorting the points based on surfaoe looation.

(E) Graphioally display the oask and the seleoted swipe points on its surface.

(6) Retrleve a swipe from the dispenging magazine, move to a swipe looation, perform the swipe and return the used swipo to a oontamination magazine.

genswlpopts

Inlilalize

montocarlo

nddapprmats

towoh

optpath

(separate tasks)

swipestartup swlpeogquenoes awlpeop

(7) Deliver the full oontamination magazine to a swipe radiation detection system (reader).

getcaniatar

(8) Direot the swipe reader to analyze each swipe and roturn the results to the host for display and arohival purposes.

canberra 

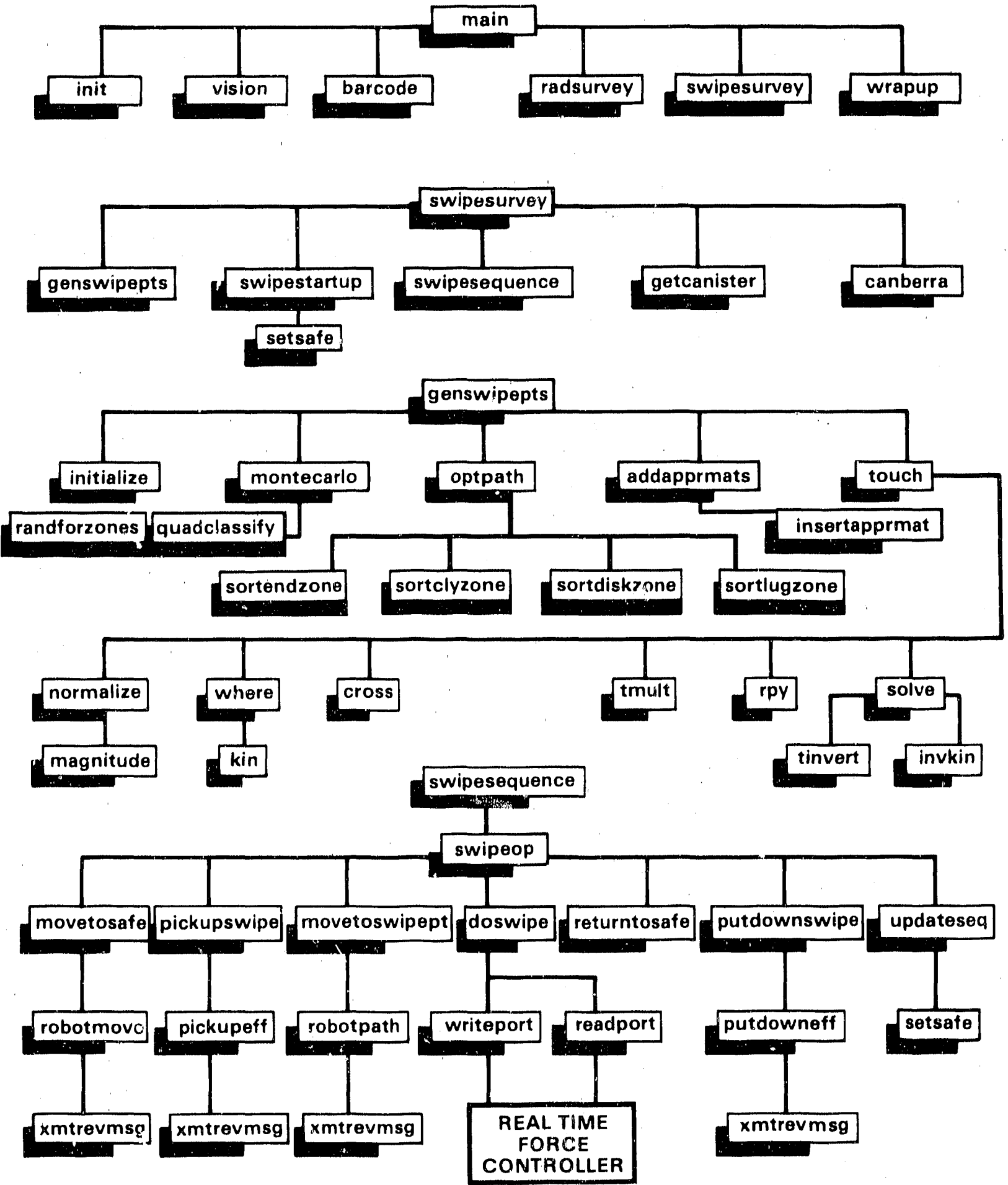

Figure C-5. Module Dependency Diagram for Swipesurvey 

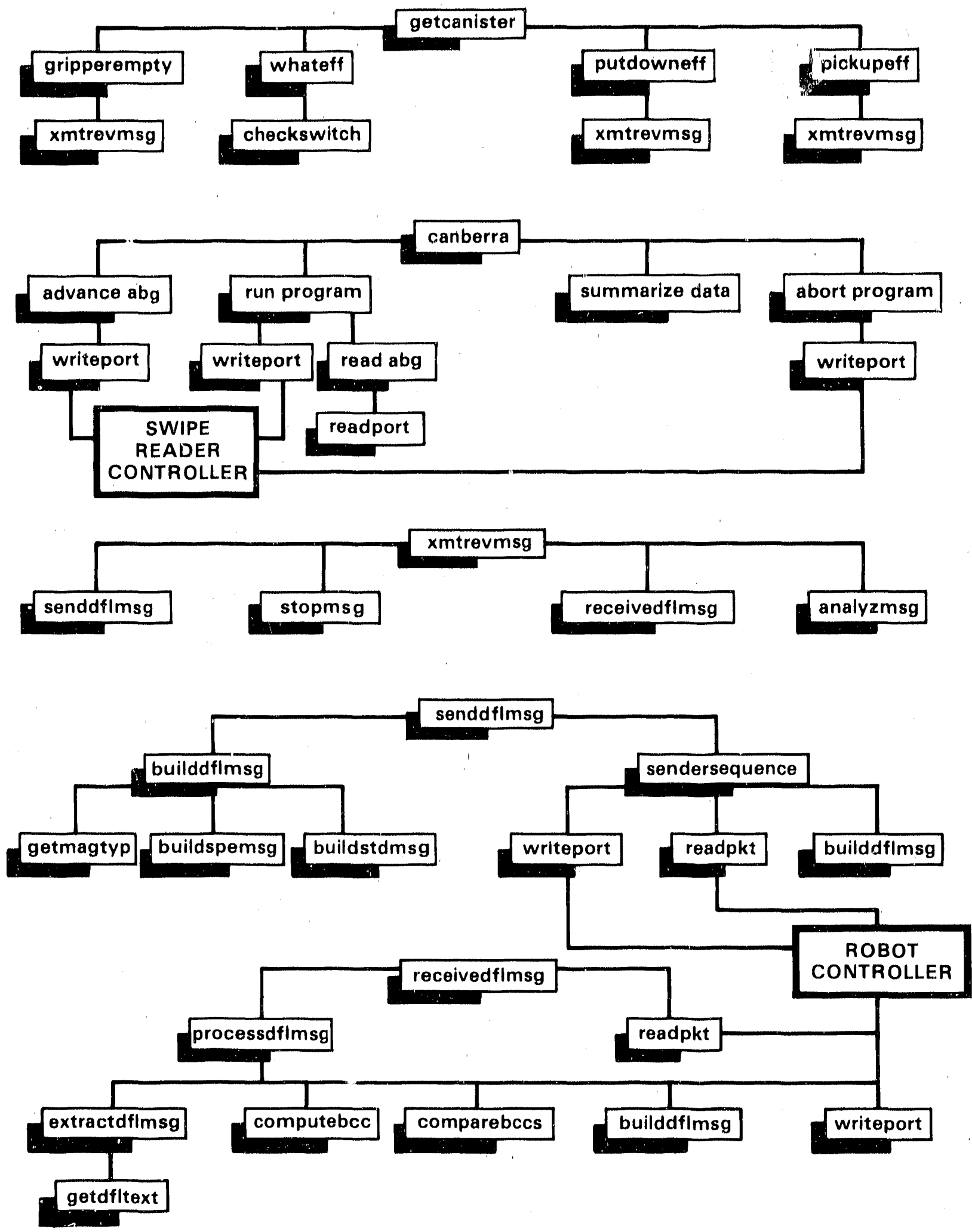

Figure C-5. Module Dependency Diagram for Swipesurvey (Concluded) 
module does and how it should be used. Then, a sequence of ccmment statements describes each step to be performed by the module, the data structures that are needed and how they are affected, and the external effects, if any, that occur when this module is executed. Once all specifications are written for each module, the data and control structures for each module are defined, using standard programming language constructs. Figure C-6 illustraces a typical RRSAS software module. Most of the implementation is performed using $C$ programing language in a UNIX environment.

The modules of Figure $C-5$ are implemented in a bottom-up fashion. This allows systematic debugging at progressively higher levels of abstraction by bullding test programs to exercise the functions of each module. Once a set of related modules has been tested individually, their dependencies and interfaces are tested. This process is iterated until the top of an abstraction hierarchy representing one of the survey operations is reached. The next operation is also debugged by starting at the bottom of its module dependency diagram and once again climbing the hierarchy. Because tasks frequently share many of the same modules at lower levels, debugging of subsequent operations has become easier, since only the higher task-specific modules required testing. In addition, milestones have been established throughout the course of development that require complete demonstrations of each operation as it is added to the system. This process results in stages of stability that eliminate the majority of software bugs by the time the entire conliguration is completed.

\section{ERROR RECOVERY TECHNIQUES}

A prinary consideration in designing and implementing the RRSAS software system has been error detection and recovery. Error detection is performed by comparing the results of module execution with models of what should have resultet, Components contributing to the error recovery environment include binary microswitch sensors monitored by the Supervisor Task to determine the state of the world. The microswitches provide the current status of endeffector stations and other critical mechanisms, 1.e., swipe dispenser, robot gripper, and pneumatic locks. In addition, an interrupt signal line from the robot controller to the host serves as a real-time alarm to alert thesupervisor Task when the robot has stopped unexpectedly. Other modules, such as those contained in the computer vision and force control subsystems, incorporate expectation-driven error detection. For example, if the computer vision subsystem executes properly, but analysis of the captured image does not contain the type of information anticipated, an error situation is signaled. Hierarchical error analysis detects failures at every level of abstraction by encapsulating modules in a control loop that checks error status after each incremental operation. This procedure provides maximum flexibility to detect error conditions at the levels where they occur, allowing for local recovery and avoiding the need to redo an entire operation when a sma11 step in its sequence has failed.

The primary sources for failure observed in the RRSAS include communication errors between the supervisor and other subsystems, unexpected stoppages due to subsystem failures (e.g., failure of the vision subsystem to locate expected visual reference features and thus not locate the cask), and microswitch signals indicating invalid system status. In many cases, the problem is caused by a minor hardware or mechanical malfunction that can be 


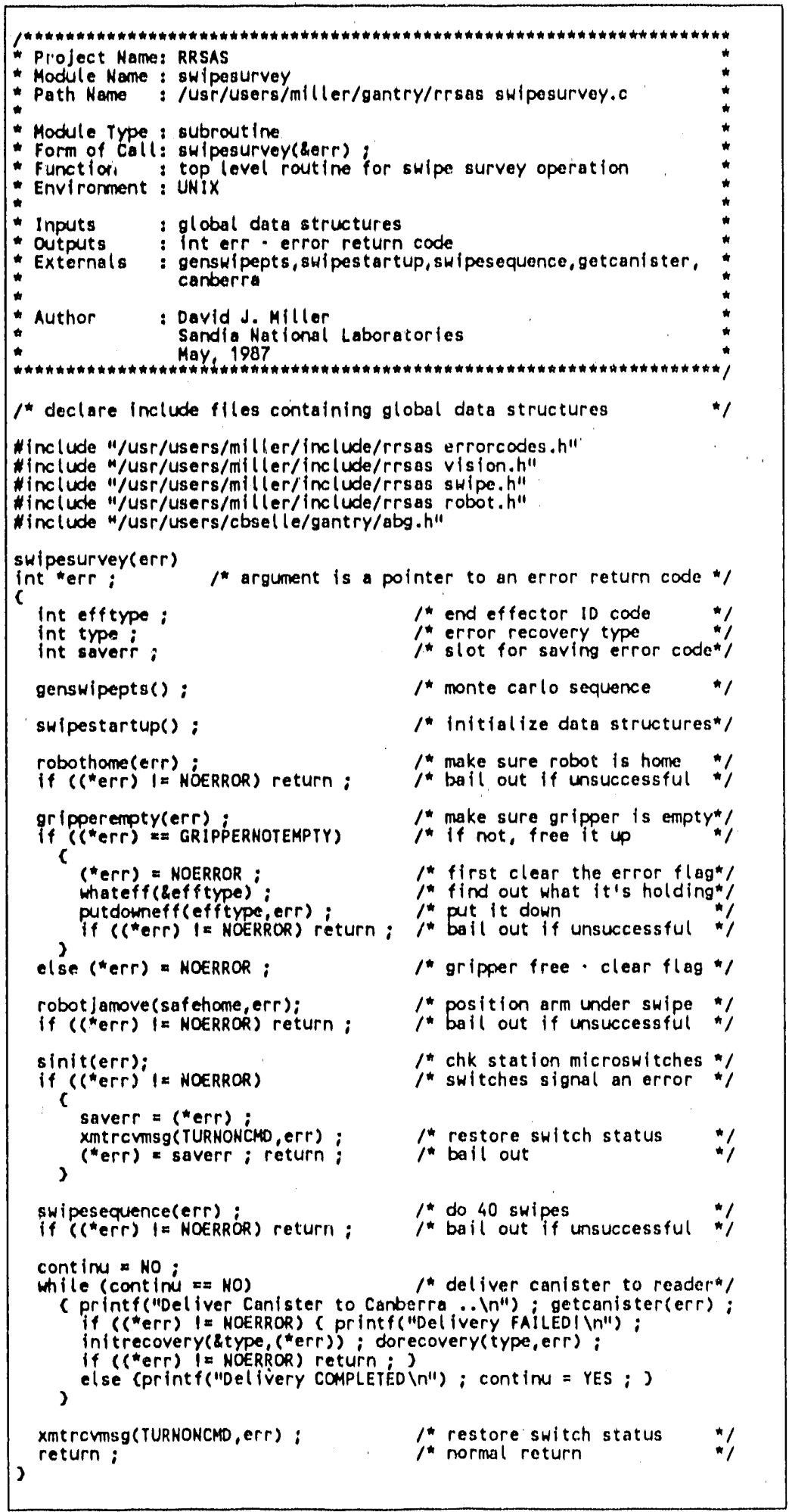

Figure C-6. Typical RRAS Module - Swipesurvey 
corrected automatically. For ex mple, if the computer vision system falls to locate an approxiate vistal reference point during its cask-finding task, the robot-mounted cameras will be automatically shifted slightly, and the vision process repeated.

Other cases, such as repeated fallure to recover automatically, would require manual intervention. A standard procedure is always invoked when an error requiring operator attention is detected. This procedure informs the operator of the cause of the fallure and provides four recovery options. The operator may choose to retry the falled operation, skip it and move on to the next operation, perform the operation manually, or abort the task. Error recovery has proven to be a powerful approach to improve system reliability. Because the system can correct fallures of individual components, it can tolerate subsystem fallures while maintaining high overall system reliability. Success is gauged by whether the operator can restore the system to normal operation without entering the hazardous environment.

\section{DISCUSSION AND CONCLUSIONS}

The RRSAS was successfully completed in August 1987 and is currently operationa1. The system successfully uses models of the robot and cask to automatically program robot trajectories to perform radiation survey tasks. While sensors provide corrections to the robot trajectories to compensate for small errors in the models, good model information is important for fast, efficient operation. The robot system can perform random swiping operations at least as fast as a human and in a far more consistent fashion, by employing good geometric information to drive the robot, and by using force sensing to make only minor trajectory perturbations and to malntain the specified contact force. In addition, error recovery has been proven to provide high overall system reliability. Since completion of the RRSAS, many system demonstrations have been performed. It is not uncommon for an ohserver to conclude that the system works without error, even though subsystem errors did occur but were detecied and corrected automatically by the system.

RRSAS software design and implementation phases were performed during the last 12 months of this 18 -month project. These phases followed six months of system specification and preliminary installation of some of the major hardware components, including the gantry robot and software development system. Additional hardware design and installation of specialized subsystem components have been performed in parallel with the software effort and were integrated on a task-by-task basis. Application of the top-down design/bottom-up implementation methodology enables software development to keep pace with hardware installation and is the primary reason that the software has been completed on schedule. The final host computer hardware configuration, a SUN $3 / 160$ work station, was not delivered until six months before the project completion date. The software has been easily ported from a DEC Micro-VAX, used for initial development. The final configuration fulfills the objectives of providing a fully automatic robot system with robust error recovery. The software satisfies design specifications and proves to be extremely reliable, with few bugs detected after the acceptance demonstration.

The rosulting supcrvisory software architecture clearly reflects the software engineering principles of modularity, locality, abstraction, and 
information hiding. The main Supervisor Task alone consists of approximately 10,000 lines of code decomposed into over 200 modules. This implies that the average module length is 50 lines of code, or a single page of printout; the ideal length for easy comprehension and modification. In addition, because the lower half of the molite dependency diagram for each of the major survey operations is rearly dofntical, decomposition has been performed in a logical and consistent fasion by teratively hiding lower-level details from successively higher levels of abstraction.

The production of generic robotic primitives also illustrates these concepts and provides building blocks for future development. In fact, the entire RRSAS hierarchy, as shown in Figure C-1, can be abstractud to a higher level that represents a generic robotic system environment. Figure C-7 illustrates this architecture, which consists of three primary components. The first layer, the Project-Speciflc Global Task Definitions, is derived from the top-down decomposition of the specifications (highest-level abstractions). An example would be the set of cask survey operations and the subtasks specific to each of these operations. The second layer, the Deviceand Task-Independent Primitives, represents functionality present in any robotic system regardless of hardware implementation or purpose. An example of these primitives would be the RRSAS modules listed in Figure C-2. The third layer, the Device-Dependent Code device drivers, is the initial result of bottom-up implementation. This device-dependent software logically represents the functional definitions of the hardware, including comuand primitives, communications protocols, and interrupt-driven, real-time sensor control. An example of this last component is the real-time force-control task used to direct the swiping operation.

With this paradigm, it should be possible and advantageous to model and build any hierarchical robotic system. Once the middle layer of generic primitives has been defined and implemented, it can be ported to any new system under development. Also, once a complete system has been implemented, adding task-orlented functionality at the top level is greatly simplified. A11 modular bullding blocks will already be avallable. They simply must be pieced together in the right sequence to produce the desired operation. This could be done interactively by a system operator by using an English-1ike command language or menu selections. Complex programming efforts could therefore be directed toward making the system more intelligent through the addition of knowledge bases, planning, and sophisticated user interfaces. Incorporating new sensors or mechanical devices at the lowest level will still involve intimate knowledge of the hardware, but this knowledge will be neatly encapsulated in modules that hide this information from the rest of the system and use consistent interface control structures a ${ }^{7}$ ready implemented for other existing devices. All of these concepts are currently being explored as an extension of the RRSAS development work, with the intent of eventually implementing them for diverse robotic environments. 


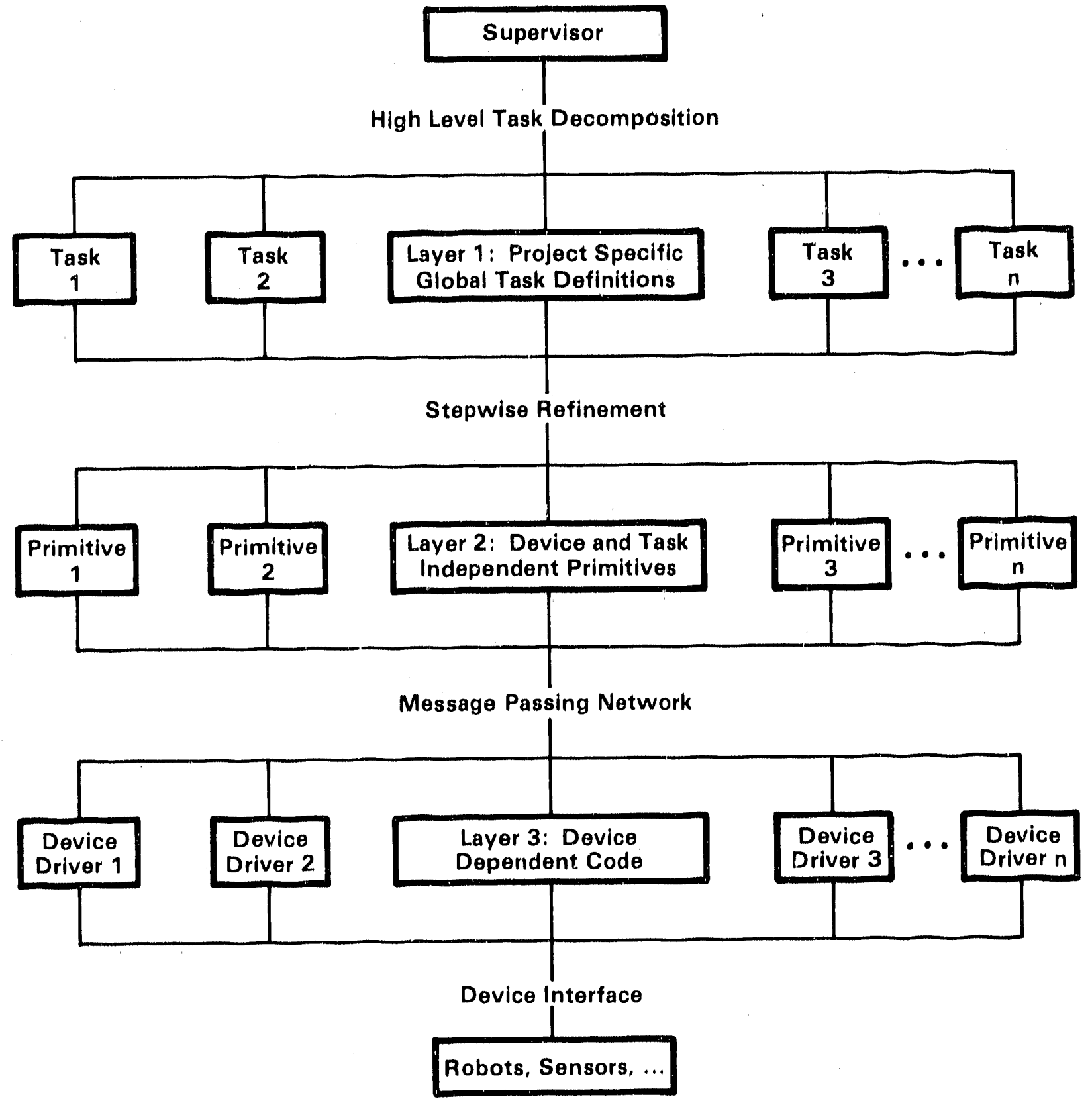

Figure C-7. Generic Hierarchical Robotic System 
REFERENCES

CIMCORP Robotics, 1986. "CIMPLER Programing Manual," Doc, Part No. 4316200, CIMCORP, Div. of Wartsila, St. Paul, MN.

Petterson, B. J. and J. F. Jones, 1987. "Force Control of a Robot for Surface Contamination Detection," Remote Systems Technology Division Proceedings, American Nuclear Soclety Winter Meeting.

Pressman, R. S., 1982. Software Englneering: A Practitioner's Approach, New York: McGraw-Hi11.

Ray, L. P., "Cask Location wfth Computer Vision," SAND87-2720, forthcoming.

Thunborg, S., 1987. "A Robotic Radiation Survey and Analysis System," Remote Systems Technology Division Proceedings, American Nuclear Society Winter Meeting.

Wirth, N., 1971. "Program Development by Stepwise Refinement," CACM, 14 (no. 4): $221-227$.

Yourdon, E. and L. Constantine, 1979. Structured Design, New Jersey: Prentice-Hall. 


\section{ACKNOWLEDGMEN'TS}

Development of the RRSAS supervisory software environment has involved a team effort. The author wishes to acknowledge the contributions of the following people: S. Thunborg, Profect Leader, L. Ray for computer vision, B. Petterson and J. Jones for robot force control, C, Selleck for swlpe reader control, and $W$. Davidson for real-time interrupt handlers and computer interfacing. 


\section{APPENDIX D \\ A DISPENSER MECHANISM FOR STACKABLE THIN-EDGED OBJECTS}

Alan Morimoto

Sandia National Laboratorles

Albuquerque, New Mexico 87185

D -1 . 


\section{INT'RODUC'TION}

The Robotic Radiation Survey and Analysis System (RRSAS) has been developed to perform radtation and contanl nation surveys on nuclear waste shlpping casks upon recelpt at geologle waste repostorten ('lhunborg, 1988). These waste contalners must be tested for surface contamination before and after shippling. Presently, repository workers survey the shipplng casks for radioactive surface contamination. The RRSAS removes repository workers from the radiation environment and improves the conslatency and rallablifty of the survey operation.

One type of radioactive contamination analyzed by the RRSAS is trans ferred radiation. Transferred radiation is radioactive contamination, in the form of contaminated particles on the cask surface, that are transforred to personne1 or objects which come in contact with the cask. To measure transferred radiation, the robot performs a serles of spot contamination checks using a tool designed for wiplng down, or swiplng, speclflc areas on the cask surface. This swipe tool, or planchet, (Figure D-1) consists of foam-backed filter paper mounted on a rigid plastic carrier. A handle on the slde of the tool opposite the filter paper allows the robot to grasp and orfent the swipe material. Planchet legs separate and provide even spacing between the planchets in the magazine, and prevent cross contamination.

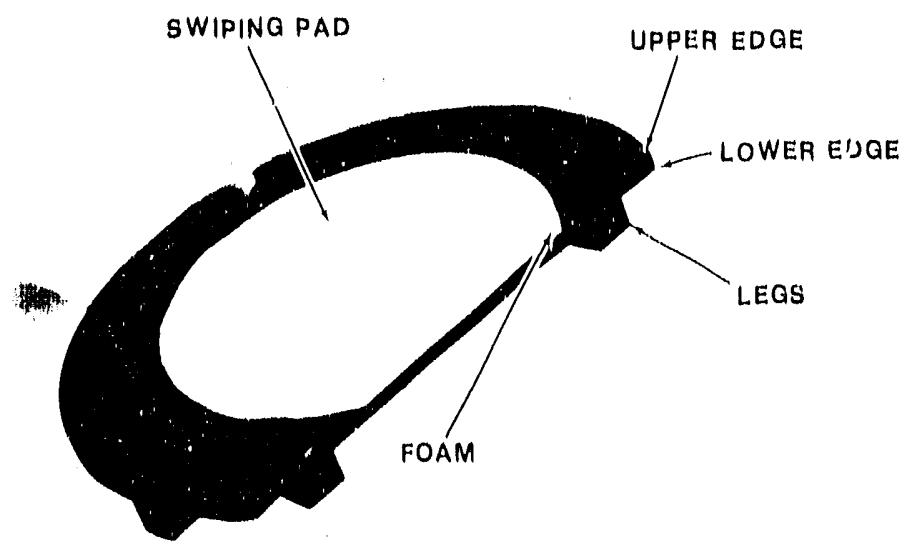

Figure D-1. Planchet Used for the Swlpe Survey 
During the swiplng operation, planchets are lindividually dispensed to the robot from a magazine contalning 40 unlts (Figure D-2). After a swipe ls performed, the robot stores the used planchet in a second magazine for future radiation analyst.s by an alpha/beta/gamma survey ingtrument. Computer corre. lation of the known location of each swlpe with lts assoclated planchet links a spacific amount of transforred contamination with a spacific point on the cask,

Existing dispensing mechanisms appropriate for use with the planchets have been found to be cumbexsome. For example, the alpha/beta/ganum detector's mechanism for dispensing planchets uses an elevating platform to $11 \mathrm{ft}$ the planchets off a retractable support and dispense them onto a turntable (F1gures D-3 and D.4). Such mechanisins, however, could not be used for dispensing the planchets, due to height and size restrictions on the robot gantry.

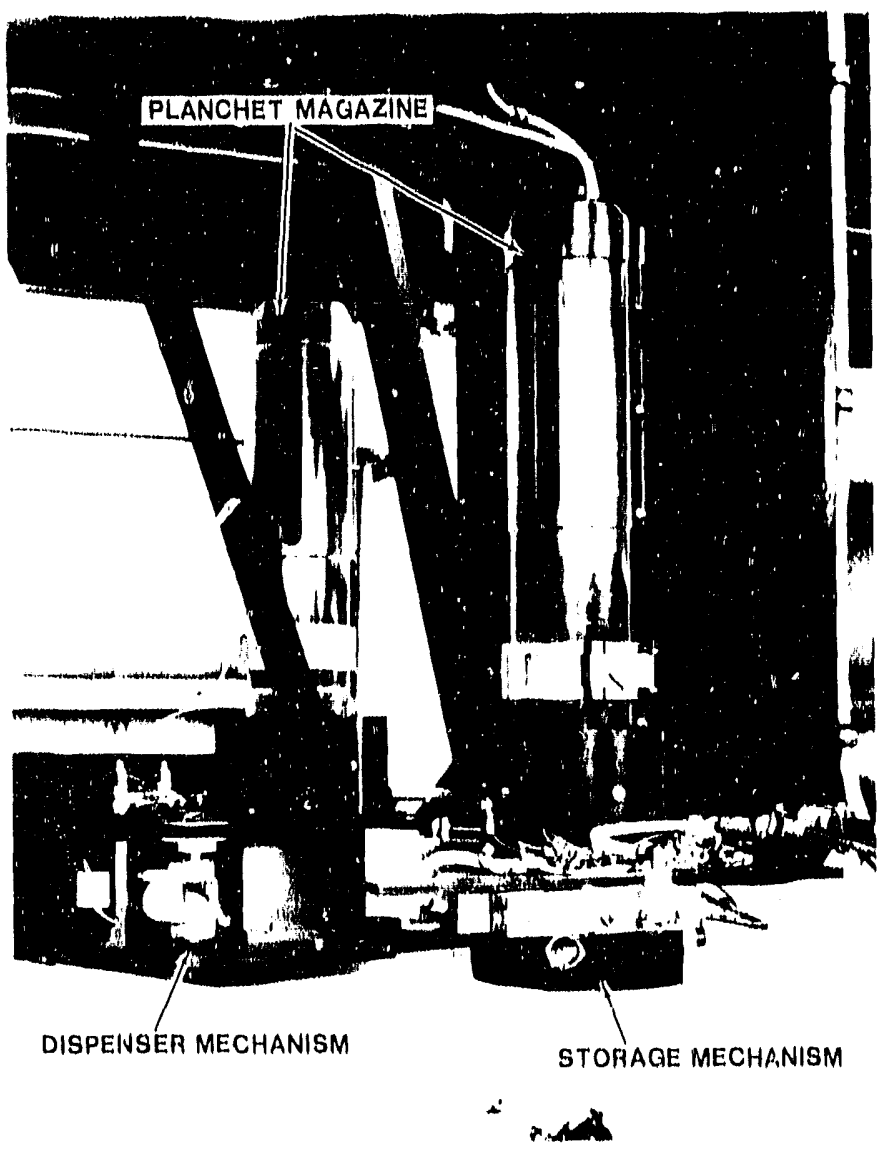

Figure D-2, Magazines Placed in the D1spenser and Storage Mechanisms 


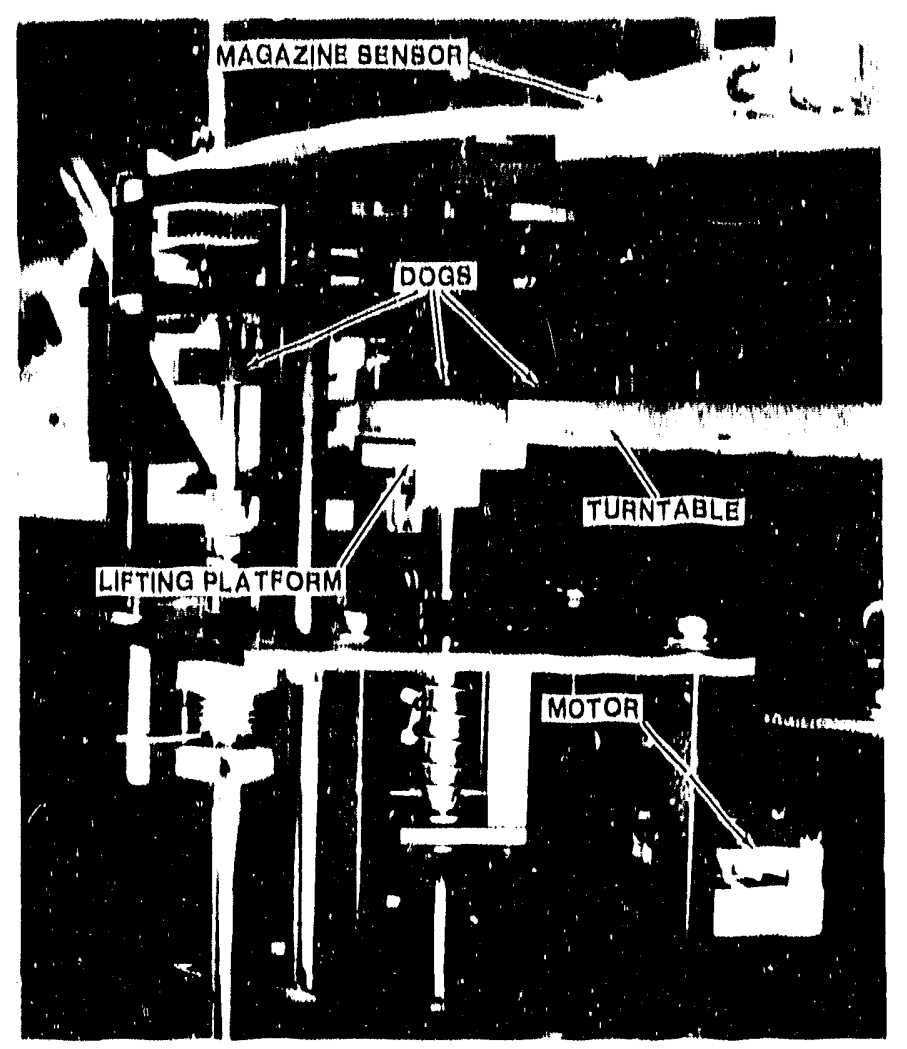

Flgure D.3. Dispenser for the Alpha/Beta/Gamana Detector

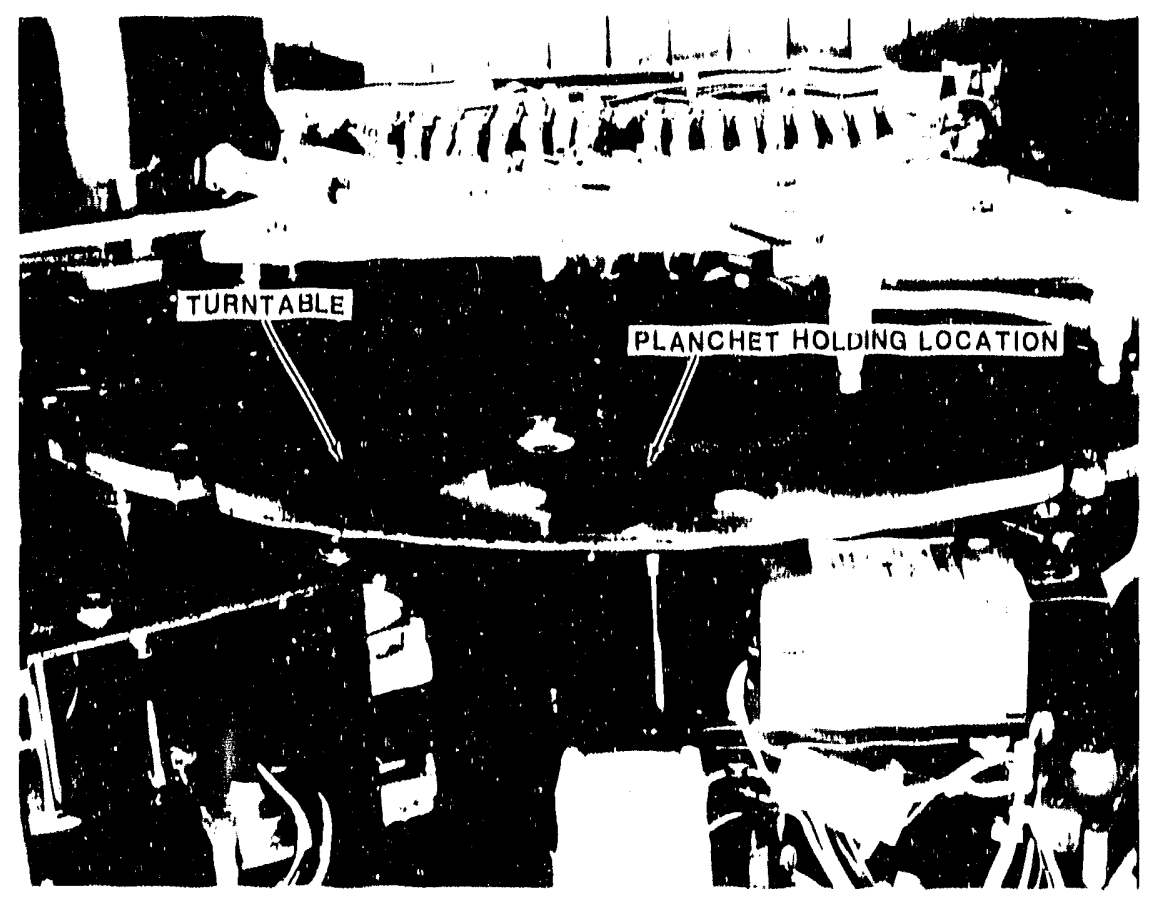

Flgure D.4. Turntable for the Alpha/Beta/Gamma Detector 


\section{DESTGN PARAMFIERS}

A stacklng/dispensling cain (Plgure D.5) has been deslgned for use with the stacked planchets. As the cam rotates in the clockwles direction, a groove catches the planchet edge and transports it upward to piovlde vertical stacking, Likewlse, countarclockwisa can rotation transports a stacked planchet downward in a controlled manner. The groove in the dispensing cam is defined by the diameter of the planchet, the distance from the adge of the planchet to the conter of the cam, and the planchet thlckriess. Three cams around the perfmeter of the disk ensure even and controlled dispensing. The diapensing rate depends on the revolution speed of the carriers.

The planchet's range of controlled motion is the vertical displacement from the polnt at which the planchet is first engaged, to the point where it is released, or the vertical distance through which the disk maintains contact with the cain. Planchet allgnment is maintained by guide ralls alongside the planchets, as shown In Flgure D-6.

The planchet-dispensing cycle consists of three phases, In the first phase, or dwell phase, the disk rides on top of the otrcular reglon of the dispensing cam. The friction between the disk and the dispensing cain's surface must be kept to a minlmum to prevent snagging or possible skipplng of the disk along the cam surface (Figure $D-6$ ). T'o reduce friction, the cam surface has been polished. Note that Figures D-6 through D-9 are photographs of a dispenser prototype that has two carriers. The final version of the dispenser has four carriers (see Flgure D-11, Items 19 and 24).

The second phase of a dispensing cycle occurs when the leading edge of the groove contacts the planchet and carries ti down in a vertical direction (Figure D-7). The leading edge of the groove is the only place where the planchet contacts the cam during this phase (Flgure D-5).

The final phasa of a dispensing cycle is the drop-off. This occurs when the leading edge of the cam rotates to the point of breaking contact with the planchet (Flgure D-7). After release, the planchet drops to a region where it sits until further action is taken (Figure D-8). In the actual dispenser, the planchet sits on a thin retaining platform until the robot grasps and removes $1 t$.

Before the drop-off polnt occurs, the tralling edge of the groove is inserted between the planchet riding in the groove and the planchet that resides above 1t. This action ensures dispensing of only one disk at a time. To facilitate this action, it is necessary to have some space between adjacent disks. This spacing is provided by the legs on the planchets.

\section{DERIVATION OF DESIGN EQUATIONS FOR THE STACKING/DISPENSING CAM}

A distinct relationship exists between the planchet and the cain geometries. The cam groove must accept the planchet edge without interference while malntalning proper planchet motion. The minimum groove is defined by the curve traced by the upper and lower edges of the planchet during its vertical travel. During dispensing, the cam rotates counter. clockwlse with the reference frame, $u$, fixed to the carrier and the disk resting on the unit: vector, u2 (Figure D-5). 


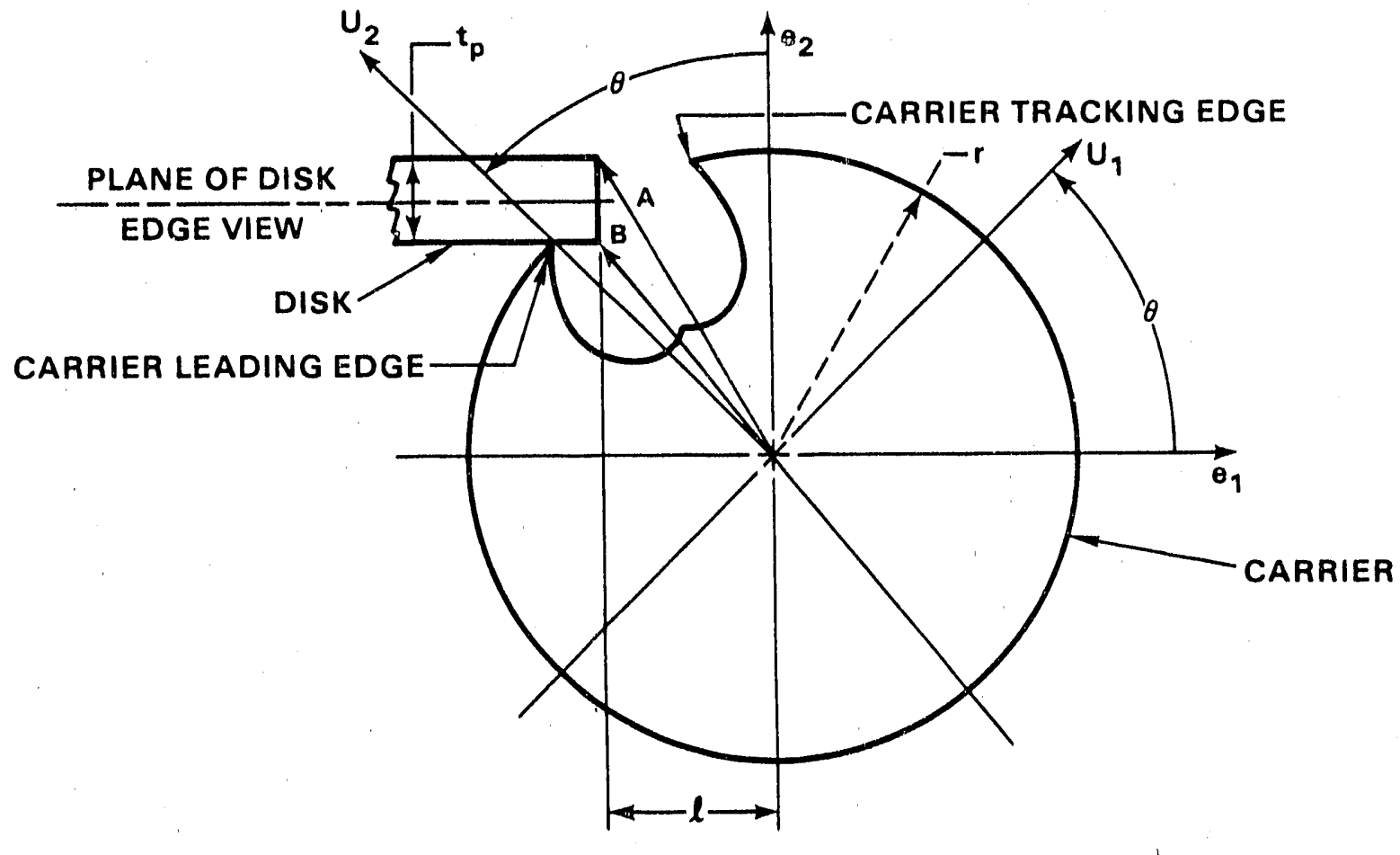

Figure D-5. Diagram of Disk and Reference Frames 


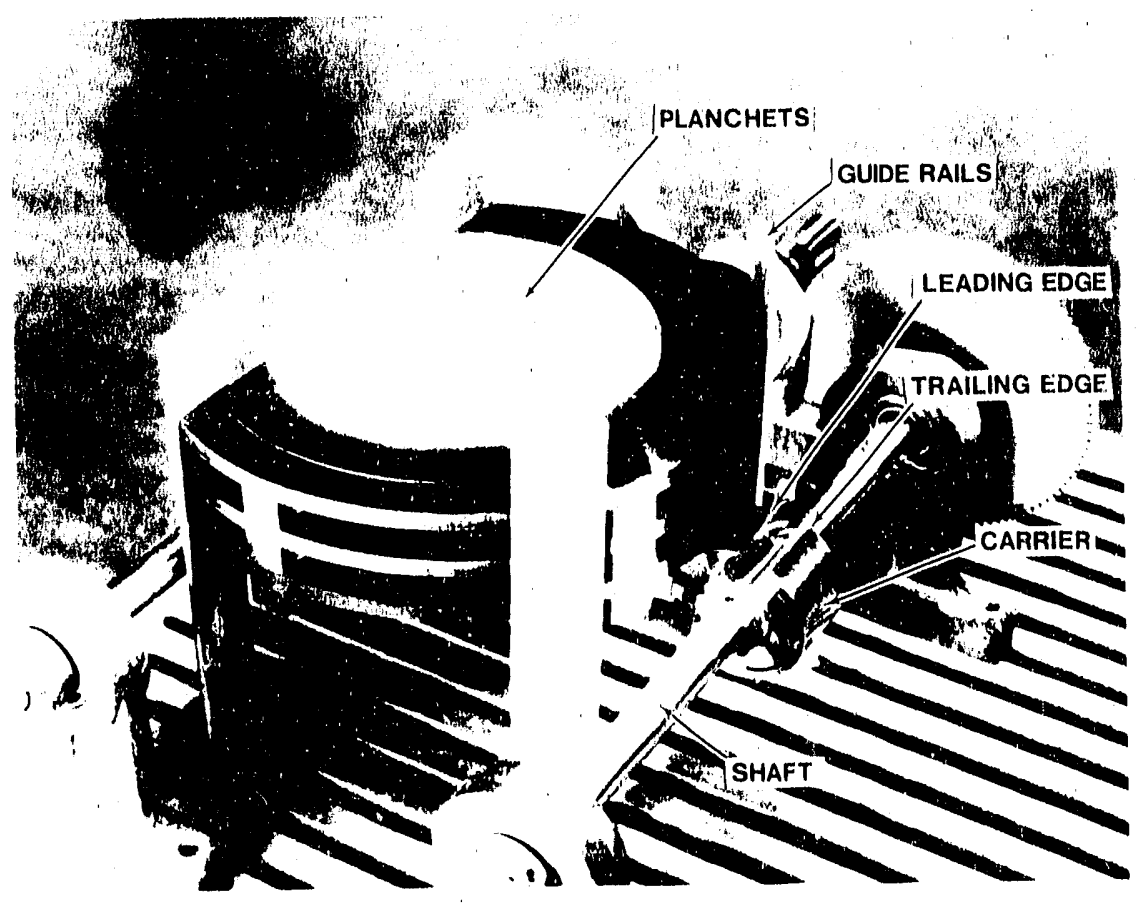

Figure D-6. Dispenser Carrier and Disk in the Dwell Phase

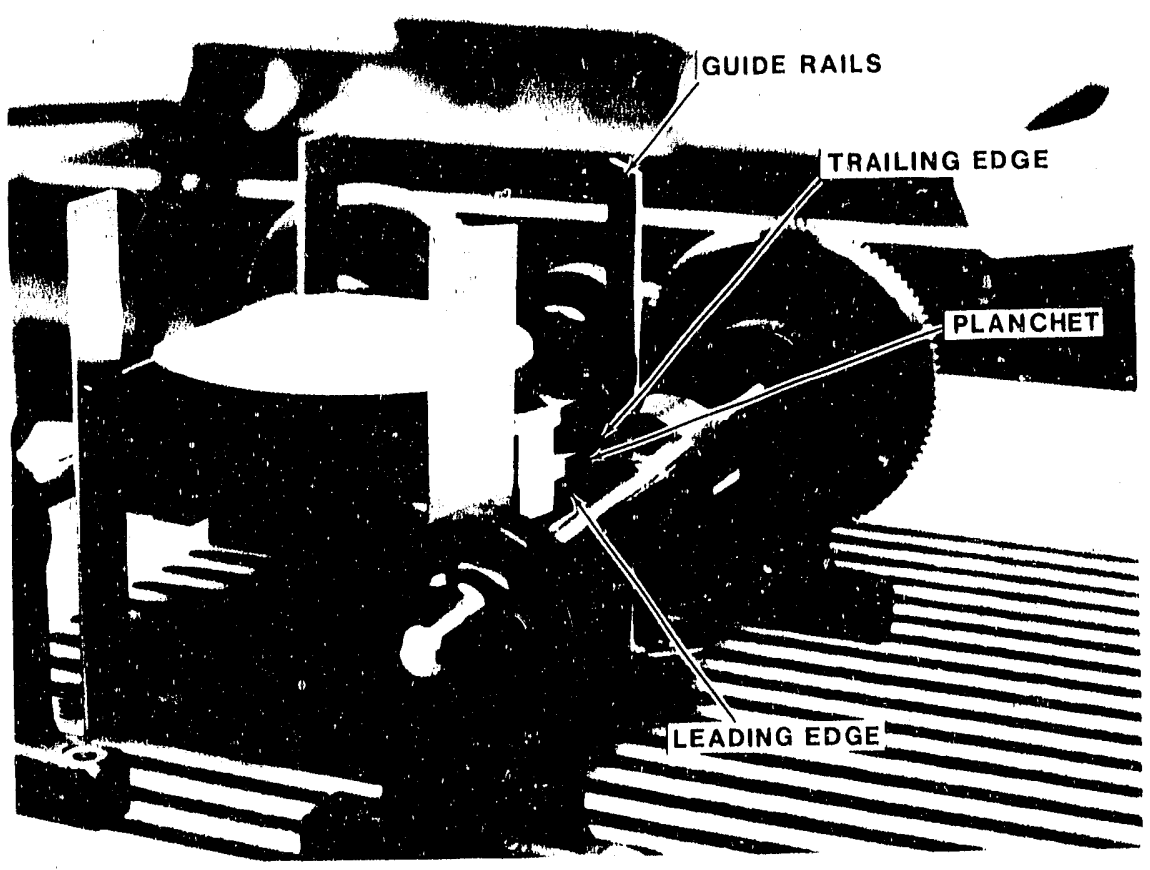

Figure D-7. Dispenser Carrier and Disk in the Second Phase 


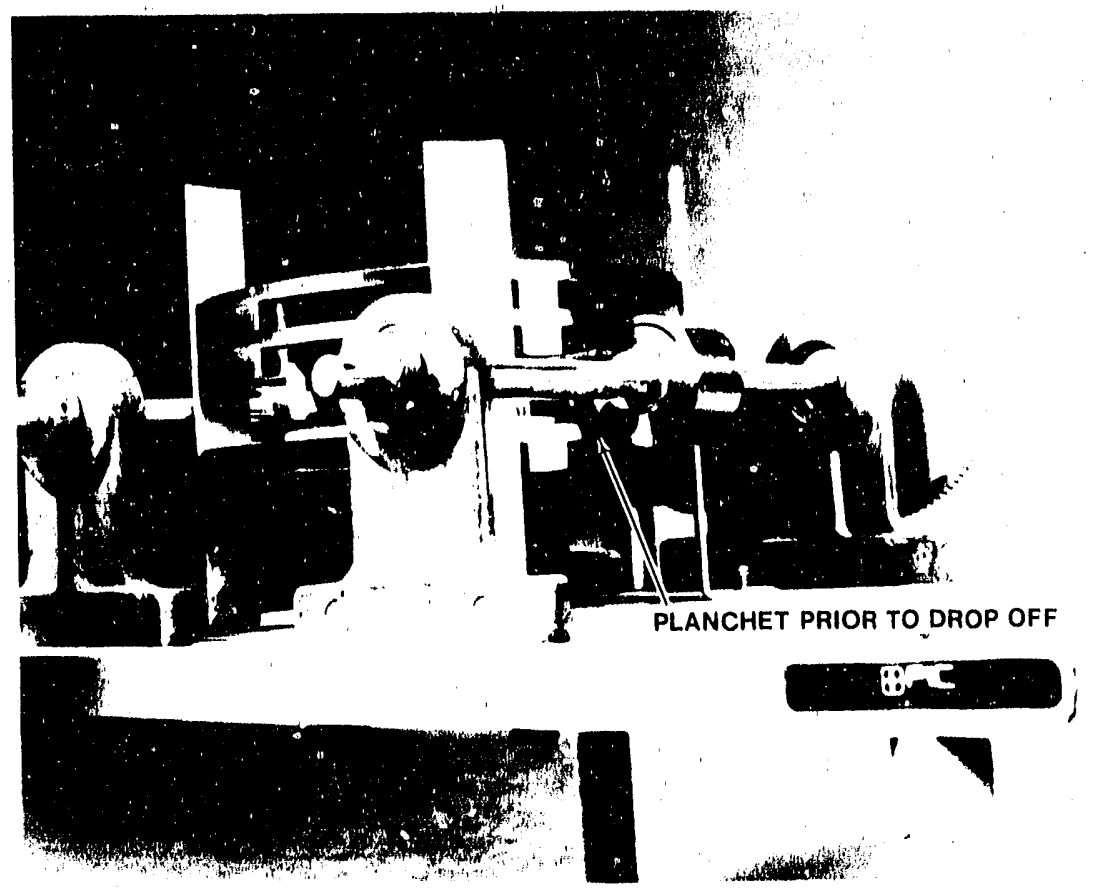

Figure D-8. Dispenser Carrier and Disk in the Final Phase (Drop-Off)

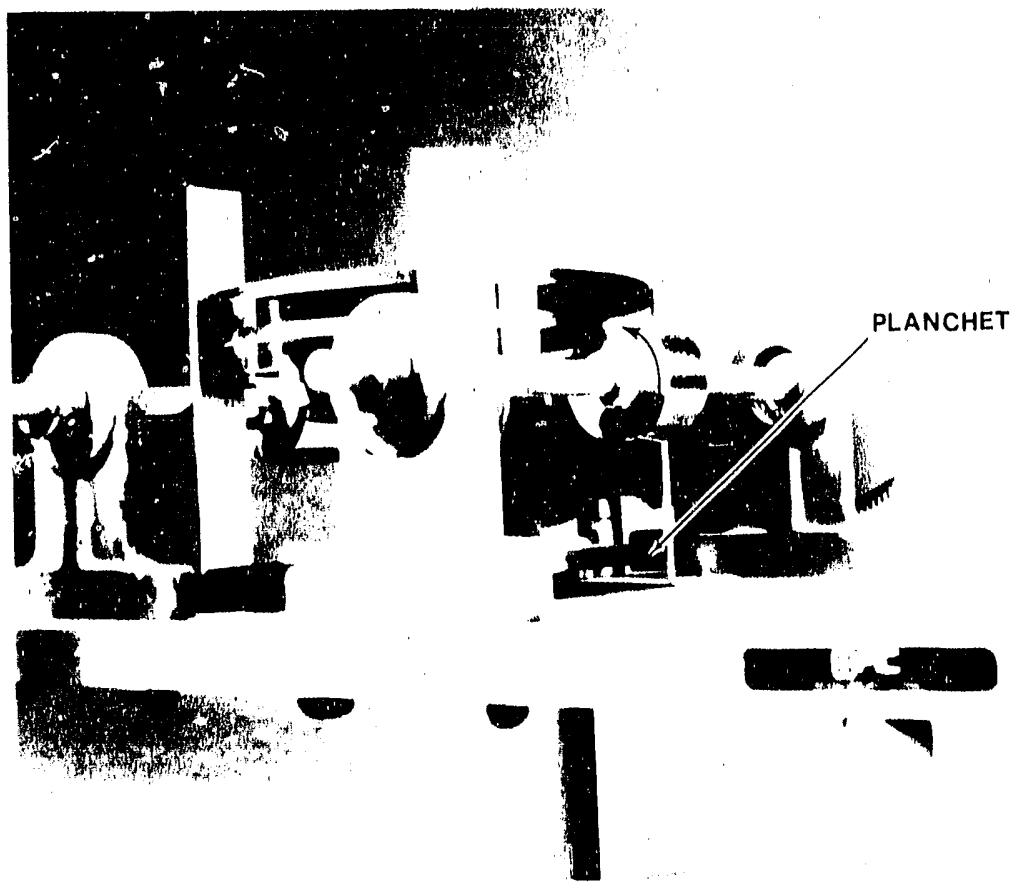

Figure D-9. Dispenser Carrier and Disk After Drop-Off 


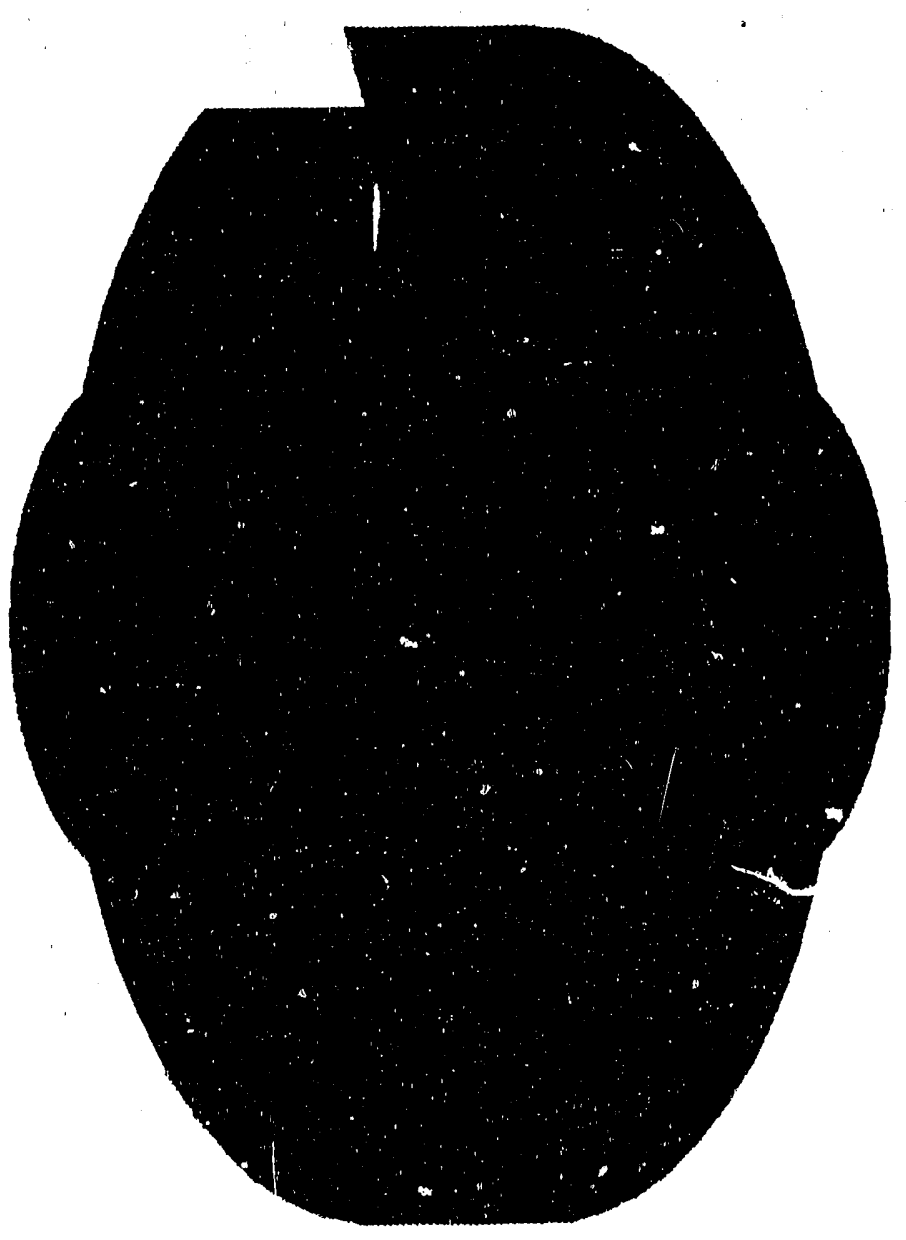

Figure D-10. Three-Dimensional Representation of the Cam

$$
D-3
$$




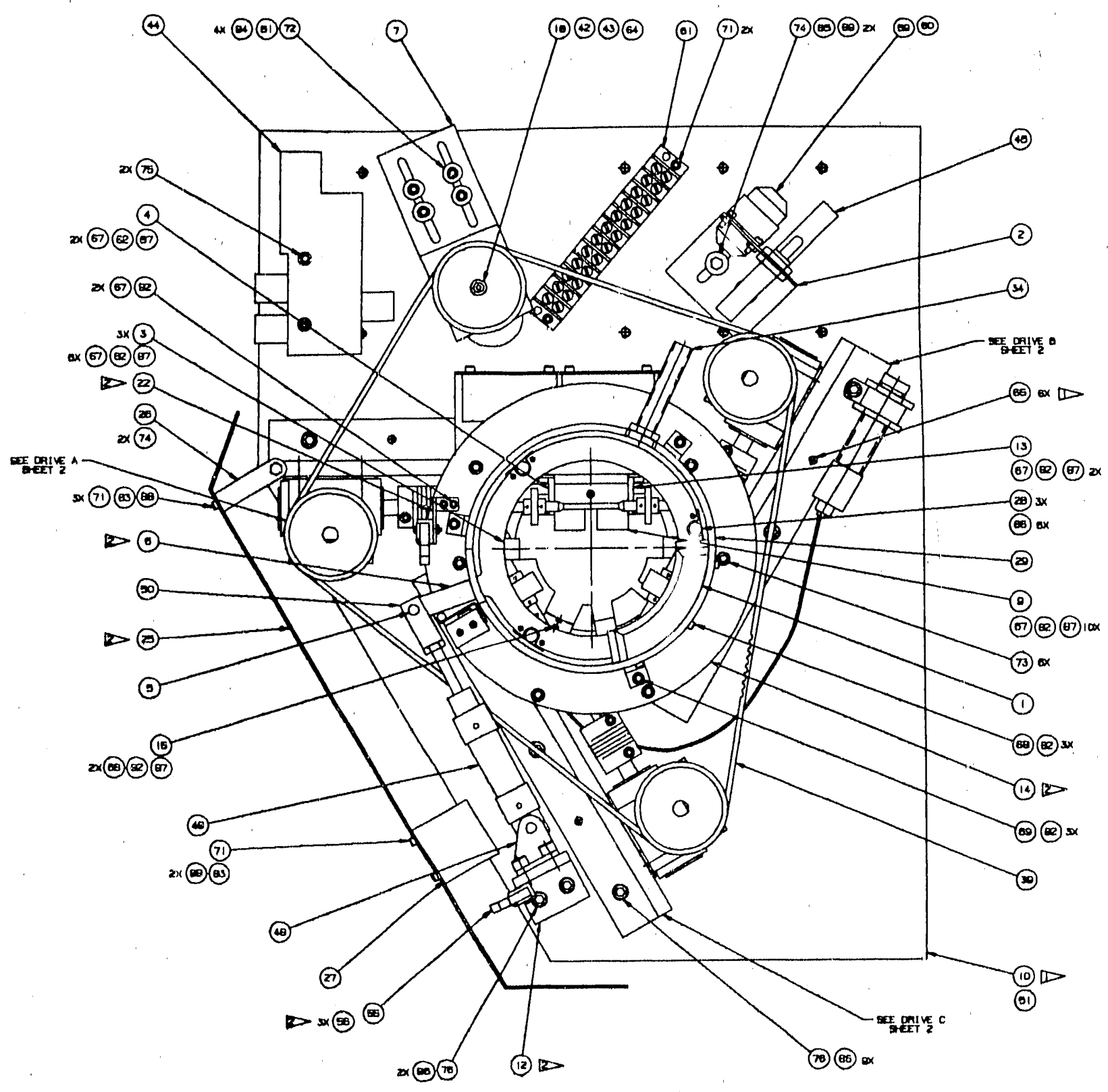

Figure D-11. Assembly Drawing of the Dispenser Mechanism 


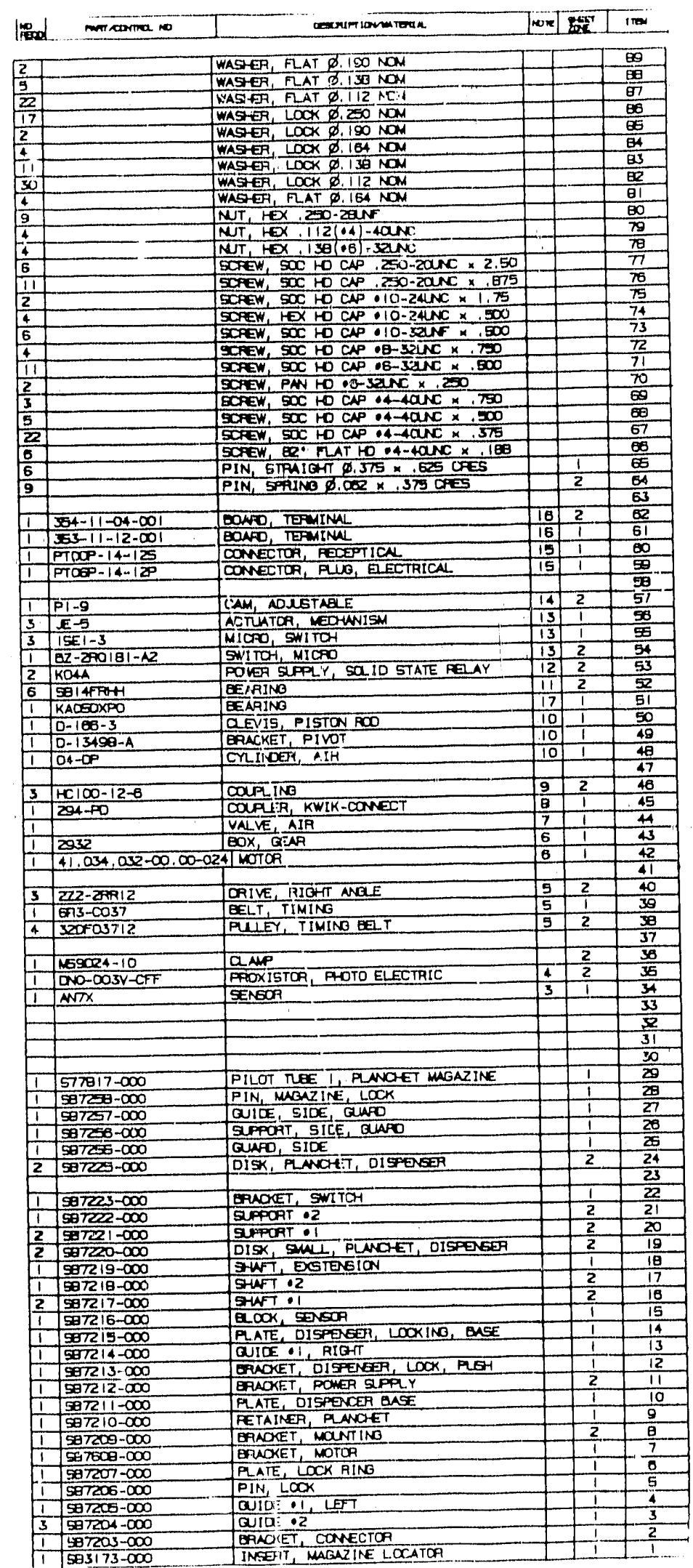

NOTES:

ID PIN!IENS 20 NO 21 TO 1 TEM 10, 1 TENS 19 ND 24

[2 MTCH OPIL ITENS I2 MO I4 MO LOCATE I TEM

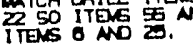

3. SORCE, THPC

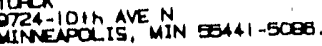

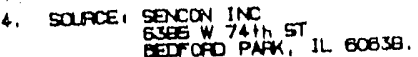

5. SQRCE, STOCK DOIVE

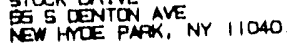

6. SORCE, MAXCN FFECISION NOTORS INC

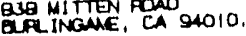

7. GOACE, SANDIA NATIONAL. LABCPLATORY

B. SOACE, IMPERIN EASTMAN OHICAGO, IL $60648-1700$

9. SOPOE, HELICAL SANTA MATIA, CA 23454

10. SOACE, BINEA MHAFACTUAING

11. SOACE, GOFOOS ARMSAS INC I000-T N SEDON T2T=0.

12. SORCE, STER,ING EECTRONICS ND. N

13. SOACE, MIODO SW!TDH FREEPOFा, IL 61032 .

14. SORCE, PIC porax 100 MIDOE EBury, CT 00782.

15. SORCE, NH1ED MPEDN PFocucts SIDNEY, NY $13830-1356$.

16. SORCE, TRW ELECTRONIC COMPNENETS CPOP MOFE

17. SOACE, KAYDON COFP, 40443.

Figure D-11. Assembly Drawing of the Dispenser Mechanism (Concluded) 
A vector, $\{A\}_{e}$, represents the temporal position of the upper edge of the disk relative to a Newtonian reference frame, e, placed at the center of the carrier. The equation for $(\mathbf{A})_{e}$ is

where

$$
(A)_{e}-l-e_{1}+\left(r \cos \theta+t_{p}\right) e_{2}
$$

$\ell=$ the distance from centerline to the edge of the disk (in.)

$r$ - the radius of the carrier (in.)

$t_{p}=$ the thickness of the disk or planchet (in.).

Similarly, a vector, $\{B\}_{e}$, represents' the position of the lower edge of the disk, rejative to the frame, e, of the carrier. The equation for $(B)_{e}$ is

$$
\text { (B) }\}_{e}=\ell-e_{1}+r \cos \theta e_{2} \text {. }
$$

If a reference frame; $u$, is attached to the carrier such that as the carrier rotates, the reference frame rotates with $i t$, then the position of the disk edges defined in the Newtonian frame, e, can be translated into the rotating frame, $u$. Such a transformation from the Newtonian reference frame to the rotating reference frame can be accomplished using a transformation matrix. A transformation matrix is used in engineering to translate coordinates of a vector in one frame of reference to another. The transformation matrix $\mathrm{T}_{\mathrm{U}}^{\mathrm{e}}$ will be used to transform the coordinates of the edges, (A $)_{e}$ and $\{B\}_{e}$, in frame e to corresponding coordinates, $(A\}_{u}$ and (B) $u$, in frame $u$. The equation representing $T_{u}^{e}$ is shown below.

$$
T^{e}=\left[\begin{array}{rr}
\cos \theta & \sin \theta \\
-\sin \theta & \cos \theta
\end{array}\right]
$$

Thus, the equations for $(A)_{u}$ and $(B)_{u}$ are

$$
\text { (A) } u=T_{u}^{e} A_{e}
$$

and

$$
\text { (B) } u=T_{u}^{B_{B}}
$$

or

$$
\begin{aligned}
& \{\mathrm{A}\}_{u}=\left[\begin{array}{rr}
\cos \theta & \sin \theta \\
-\sin \theta & \cos \theta
\end{array}\right]\left\{\begin{array}{l}
-\ell \\
r \cos \theta+t p
\end{array}\right\} \\
& (B)_{u}=\left[\begin{array}{rr}
\cos \theta & \sin \theta \\
-\sin \theta & \cos \theta
\end{array}\right]\left\{\begin{array}{l}
-l \\
r \cos \theta
\end{array}\right\} .
\end{aligned}
$$


The resulting equations are shown below.

$$
\begin{aligned}
& \{A\rangle_{u}=\left(-l \cos \theta+r \sin \theta \cos \theta+t_{p} \sin \theta\right) u_{1}+\left(l \sin \theta+r \cos ^{2} \theta+t_{p} \cos \theta\right) u_{2} \\
& (B)_{u}=(-l \cos \theta+r \sin \theta \cos \theta) u_{1}+\left(l \sin \theta+r \cos ^{2} \theta\right) u_{2} \\
& \text { (C) }-r \cos \theta u_{1}+r \sin \theta u_{2}
\end{aligned}
$$

Equation $\mathrm{C}$ is for the circle which describes the outer edge of the carrier. Note that this equation is not subscripted because it does not matter which reference frame is used to define the circle.

For the RRSAS project, the following values were chosen for the different variables:

$l=$ the distance from centerline to the edge of the planchet $(0.200 \mathrm{in.})$

$r$ - the radius of the planchet dispensér $(0.4375 \mathrm{in.})$

$t_{p}=$ the planchet thickness ( 0.135 in.).

The values of $l$ and $t_{p}$ have been increased to make room for planchet clearance as it passes through the mechanism, as well as to cover any differences in tolerances that build up during assembly. A computer-generated threedimensional representation of the cam is given in Figure D-10.

\section{MECHANISM ASSEMBLY DESCRIPTION}

The assembly drawing of the complete planchet-dispensing mechanism is shown in Figure D-11. Each of the major components is discussed below.

\section{TRANSMISSION}

As shown in Figure D-11, a series of toothed pulley wheels (Item 38), along with the drive pulley belt (Item 39) and right angle gear drive (Item 40), transmit power to the individual carriers. An important factor observed in choosing belts and pulleys is the contact area between the belt and the pulleys. Pulley positions are selected to maximize contact between the belt and the pulleys to prevent slippage. To prevent drive motor overload, however, the area of contact between the belt and the pulley on the drive motor are kept to a minimum. Thus, if the mechanism jams during operation, the belt will slip on the motor-mounted pulley. This prevents the mechanism from becoming damaged, and keeps the individual dispensing cams synchronized during a jam. Maintaining cam synchronization reduces the downtime required to clear the mechanism.

The motor chosen for the system, Items 42 and 43 in Figure D-11, is oversized to prevent stalling if a small disturbance is encountered. With the stronger motor, small disturbances can be overcome while famming can be handled with the overload protection scheme described above. 


\section{LOCKING MECHANISM}

The locking mechanism locks the magazine onto the robot (Figures D-11 and D-12). Its design is a modification of that used on the Canberra machine, produced by Canberra Industries, Inc., Mode1 2405, which compensates for inaccurate robot movements. The robot merely places the magazine into the mechanism where it is locked into place.

The mechanism is a plate (Item 6) with pins (Item 28) attached to it, mounted in a bearing (Item 31) and actuated by a pneumatic piston (Items 48, $49,50,5,12$ ). A pilot tube (Item 29) helps the robot with magazine placement. A wedge-shaped stop (Item 1) inside the pilot tube prevents the magazine from rotating during the latching operation. Microswitches (Item 55) indicate whether the locking mechanism is locked or unlocked. A proximity sensor (Item 34) indicates the presence of the magazine within the pilot tube.

\section{CONTROL}

To monitor and control the system, various switches have been installed in the dispenser to enable the operator/computer to verify the mechanism's status. Mechanical switches (Items 22 and 55 in Figure D-12) are used to indicate whether the locking mechanism is open or closed, and a proximity switch (Item 34 in Figure D-12) indicates whether a magazine is in place. A photoelectric switch (Item 35 in Figure D-12) signals if a planchet has been successfully dropped. Another mechanical switch (Items 27 and 55 in Figure D-12) shuts down the robot if it strikes the mechanism. One final camoperated 1'witch (Items 54 and 57 in Figure D-11) keeps the mechanism in an operational mode until 1 t reaches the end of 1 ts cycle. The sequence of events that occurs in mechanism operation is described in the following paragraphs .

At the beginning of any dispensing operation, several conditions must be verified by the system operator. One of the first items of interest involves verification of magazine placement: Is there a magazine of planchets placed in the mechanism? A proximity switch verifies the magazine's presence and allows the next step to be performed. If no magazine is detected, the supervising program alerts the operator of the status, and additional steps must be taken to remedy the situation.

The next condition checked is the status of the magazine lock. If a magazine is in place and is locked, a switch informs the system that it can proceed to the next step. If the magazine is not locked, then two states exist: either the operator intends to remove the magazine, or the magazine must be locked before the system can dispense a planchet.

The photoelectric switch is inspected before activating the dispenser. The photoelectric switch is used to verify the presence, or absence, of a planchet in the removal area of the mechanism. If a planchet is present, the robot can be instructed to remove the planchet for its own use. If, however, a planchet is not present, a start signal is transmitted to the dispenser.

A cam-operated switch powers the system during an operation cycle. An attached roller rides on a cam, which, in turn, resides on one of the dispenser shafts, When a surt signal is recelved by the dispenser, a relay 


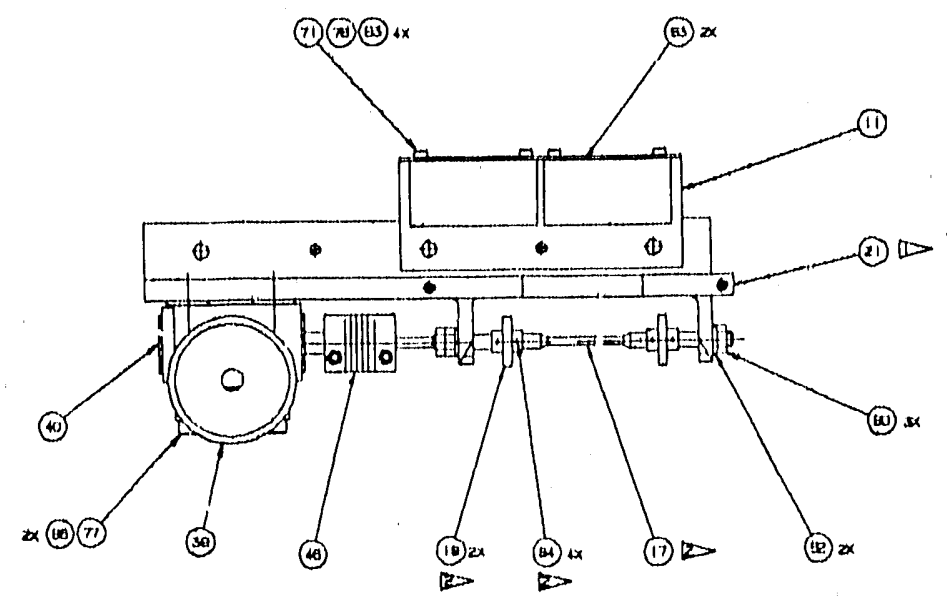

DRIVE A
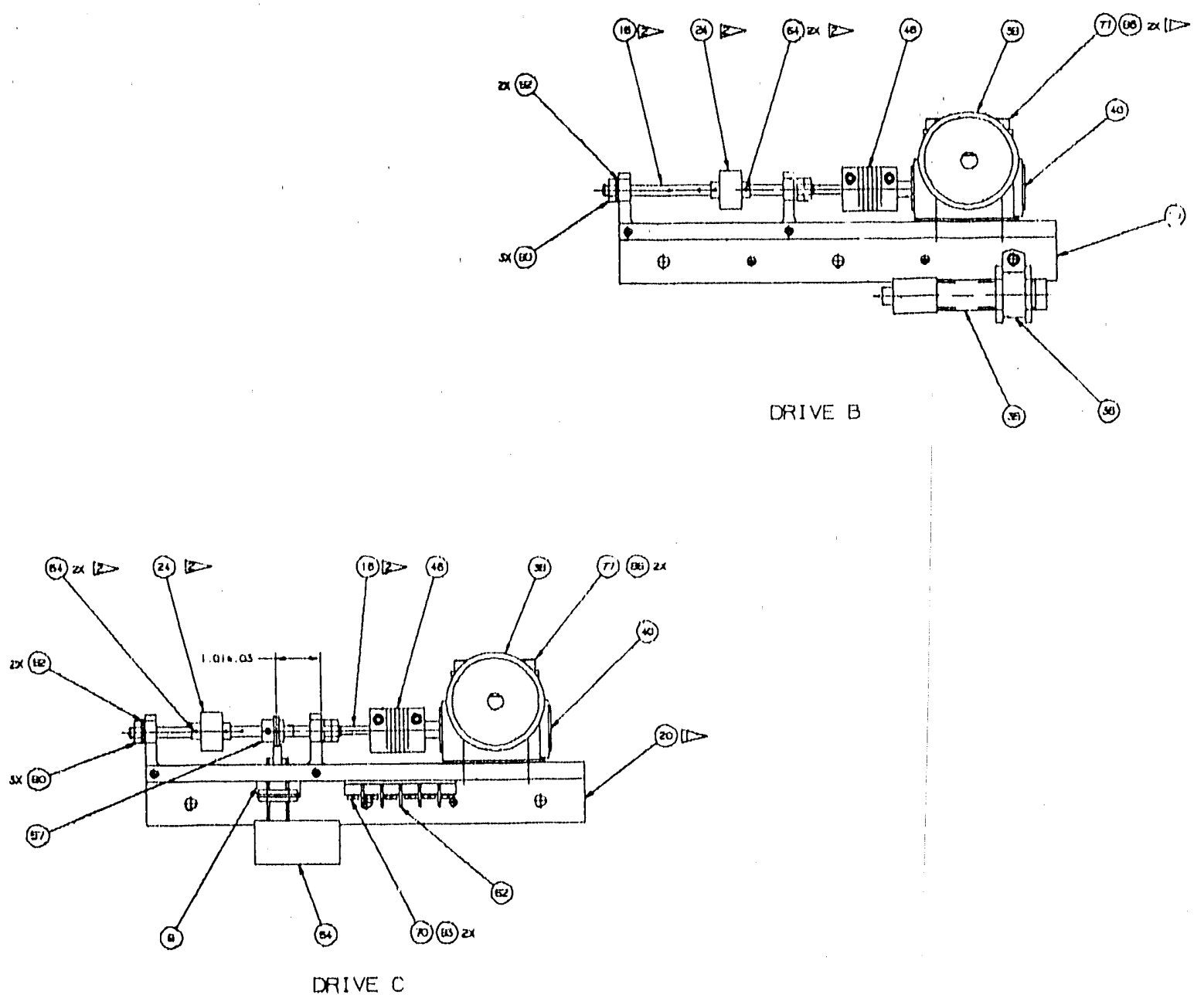

Figure D-12. Assemb1y Drawing of the Lock1ng Mechanism 
powers the dispenser motor for the duration of the start signal, which is a $100-\mathrm{ms}$ pulse. The motor rotates the mechanism to a point where the cam activates the mechanical switch, which, in turn, enables power to the motor. As long as the switch is engaged by the cam, the motor recelves power. When the switch reaches the dwell section of the cam, it disconnects power to the motor, completing the dispenser cycle. A planchet will have been dispensed from the magazine, and the photoelectric switch will register its presence. The flow diagram shown in Figure D-13 illustrates this process.

MISCELLANEOUS ITEMS

Three important elements of the system also deserve mention. A flexible shaft coupling, Item 46 in Figure D-12, is used because exact shaft alignment is difficult to maintain. In addition, flexible shaft couplings add a small amount of compliance which reduces the damage potential to the mechanism in the event of a jam.

Another item of interest is the planchet retainer (Item 9 in Figure D-12). The retalner provides a storage buffer for the dispenser, eliminating the need for the robot to wait for a planchet, thereby increasing considerably the speed of the swiping process. The retainer is made of a thin film of polye thylene. 


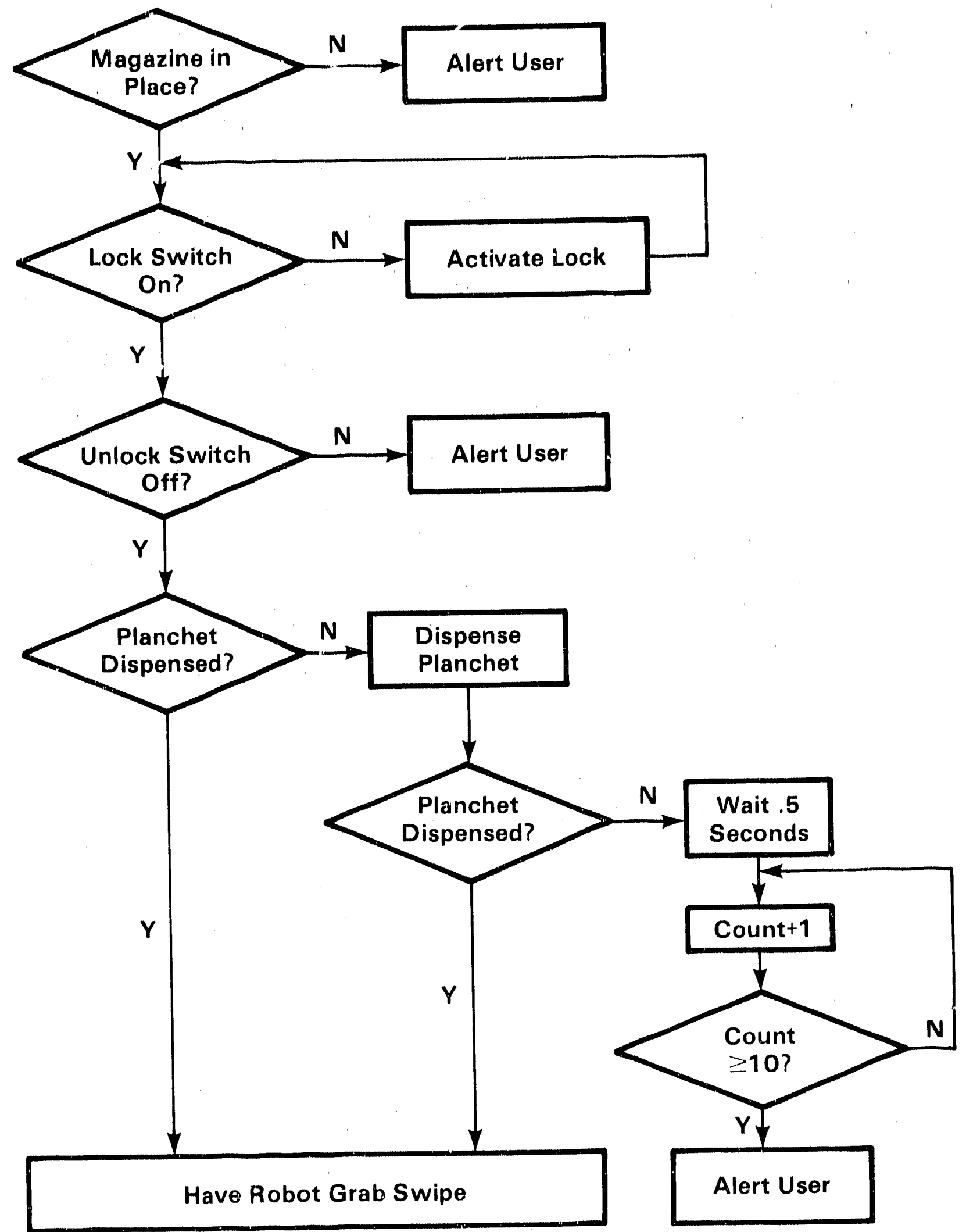

Figure D-13. Flow Diagram for Control of the Dispenser 


\section{REFERENCES}

Thuniorg, S., 1988. "A Robotic Radiation Survey and Analysis System," paper presented at Robots $12 / \mathrm{Vision} 88$ Conference, sponsored by the Society of Manufacturing Engineers, Detroit, MI. 


\title{
APPENDIX E \\ OSCILLATION-DAMPED MOVEMENT OF SUSPENDED OBJECTS*
}

James F. Jones

and

Ben J. Petterson

Sandia National Laboratories

Albuquerque, New Mexico 87185

\begin{abstract}
AB'STRACT
Transportation of an object using ar overhead crane or manipulator can induce pendulum motion of the object. Residual oscillation from transportation typically must be damped or allowed to decay before the next process can take place. By properly programing the acceleration of the transporting device, e.g., crane, al oscillation-damped transport and swing-free stop are obtainable. This appendix reviews the theory and presents the mathematics associated with oscillation-damped trajectories for simply suspended objects using controlled acceleration, and describes a particular implementation using a CIMCORP $X R{ }^{\circledR} 6100$ gantry robot.** In addition to the theoretical treatment, a specific hardware and software implementation currently in use at Sandia National Laboratories to generate oscillation-damped trajectories is discussed. Finally, sources of error resulting in small residual oscillations are identified and possible solutions presented.
\end{abstract}

*Paper presented at 1988 IEEE International Conference on Robotics and Automation, Philadelphia, Pennsylvania, April 25, 1988.

$* * \mathrm{XR}^{\circledR}$ is a registered trademark of CIMCORP, Inc. 


\section{INTRODUCTION}

Sandia National Laboratories (SNL) is currently investigating the feasibility of using intelligent machines at nuclear waste disposal sites. One class of operations necessary at a waste disposal site is transportation of nuclear waste shipping casks and other heavy objects to various locations throughout the installation. During overhead crane transportation, an object is free to swing. If any object oscillation begins, the oscillation must be damped by the operator, or the object must be allowed to swing until the amplitude decays sufficiently to allow the next operation to begin. Either situation results in reduced facility availability. However, damping the oscillation of simply suspended payloads during transportation is possible if the acceleration of the crane or manipulator is programmable.

\section{MATHEMATICAL FOUNDATION}

Figure E-1 is a simplified diagram of the transportation system under consideration. The transporting device moves in a horizontal direction that is normal to gravity, while the simply suspended payload is free to oscillate about the pivot point 0 . If the moving pivot point 0 undergoes a particular acceleration profile, the simply suspended payload will exhibit an oscillation-damped transport and a swing-free stop.

Figure E-2 shows one acceleration profile for the moving pivot point 0 that can result in an oscillation-damped trajectory for a simply suspended object. Point $O$ has constant acceleration for time, $t_{a}$. After time $t_{a}$, point 0 moves at an intermediate constant velocity for time, $T$. At time, $t_{a}+T$, point 0 accelerates again with constant acceleration for time, $t_{a} . T$ is selected such that the oscillation imposed on the object due to the second duration of acceleration is 180 degrees out of phase with initial oscillation of the swinging object, resulting in the object moving at constant velocity (during $\mathrm{T}_{\mathrm{m}}$ ) without oscillation. After an arbitrary length of time, $\mathrm{T}_{\mathrm{m}}$, applying the same procedure for deceleration results in a swing-free stop of the object. The objective is to determine the value of $T$, parameterized with respect to $t_{a}$, that yields oscillation-damped movement.

The motion of the swinging object can be described using the following differential equation (Karman and Biot, 1940; Tse et al., 1978; Thomson, 1981):

$$
\theta+\omega_{0}^{2} \sin \theta=0
$$

where

$$
\begin{aligned}
\theta & =\text { angular displacements } \\
\omega_{0} & =\text { the natural frequency of oscillation. }
\end{aligned}
$$

Equation 1 is a second-order, nonlinear differential equation with constant coefficients. For small angles of oscillation, Equation 1 is typicr-iy linearized, therefore, greatly simplifying its solution. However, for large oscillation angles, a linear approximation of Equation 1 will not yield accurate results. 


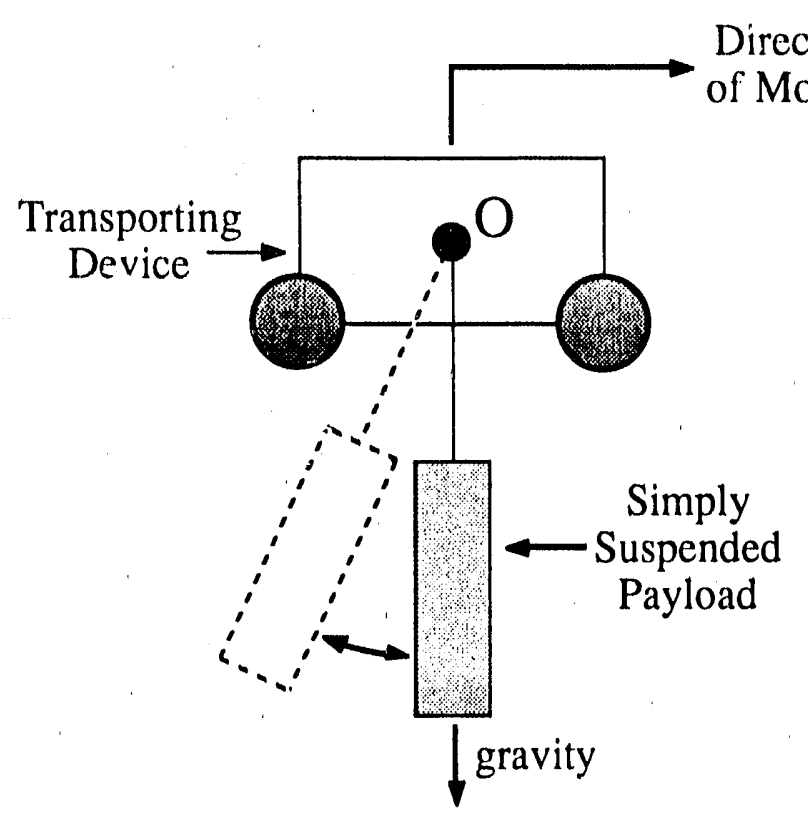

Figure E-1. Diagram of the Transportation System

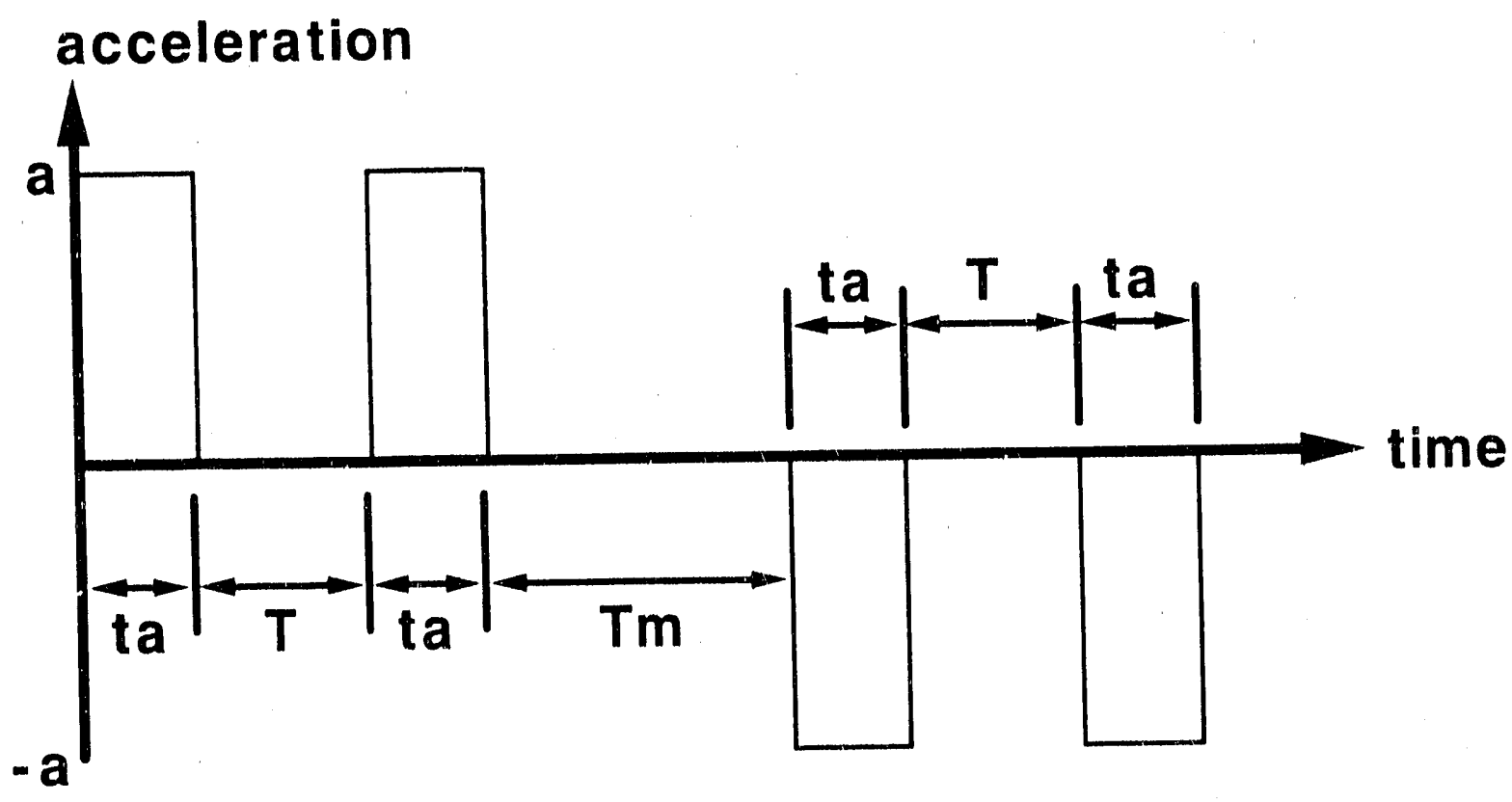

Figure E-2. Acceleration Profile 
Because large acceleration magnitudes of the transporting device will cause large oscillation angles of a simply suspended payload, the 1inear approximation to Fyution 1 will not always be sufficiently accurate. Ideal$1 y$, Equation 1 should be solved exactly. However, the exact solution to Equation 1. involves a complete elliptic integral of the first kind; hence, Equation 1 is insolvable in terms of elementary transcendental functions (Kaplan, 1952). Therefore, some method of accurately approximating Equation 1 for large oscillation angles becomes necessary.

Using a linear approximation and solving (1) for $\theta$ as a function of time yields (see Attachment A for details):

$$
\theta=\alpha \sin \left(2 \pi \frac{t}{r_{0}}\right)
$$

where

$\alpha=$ amplitude of oscillation

$\tau_{0}=$ period of the object for small amplitudes.

If $E_{1}$ uation 2 is used for large oscillation amplitudes, significant error can result, as shown in Figure E-3. Figure E-3 shows angular displacement plotted as a function of normalized time for a swinging object. Notice the linear approximation in Equation 2 yields a sinusoidal curve similar to the exact numerical solution. However, the linear approximation period is significantly different from the exact solution. An approximate solution to Equation 1 that yields good results for large oscillation angles can be obtained by collecting all the nonlinearities into one parameter, the period (see Attachment $A$ for details). Using the nonlinear approximation for the period of the swinging object and solving Equation 1 for $\theta$ as a function of time yields:

$$
\theta-\alpha \sin \left(\frac{2 \pi}{1+\left(\alpha^{2} / 16\right)}\left[\frac{t}{r_{0}}\right]\right) \text {. }
$$

The behavior of the nonlinear approximation, Equation 3, is close to that of the exact numerical solution shown in Figure $E-3$.

Figure E-4 shows the percent error in the calculated period using the linear and nonlinear approximations with respect to the exact solution as a function of maximum swing amplitude. The linear solution exceeds 1 percent error after approximately 20-degrees naximum amplitude. However, the nonlinear approximation exceeds 1 percent error only after 70-degrees maximum amplitude. Hence, if the system acceleration causes a maximum swing amplitude greater than a few degrees, the nonlinear aspects of the swinging object must be considered.

In theory, the analysis of the object's motion could continue to a maximum swing amplitude of 180 degrees before the transition from oscillatory to rotational motion occurs, and the analysis becomes invalid. However, in practice, the supporting member for simply suspended objects must always 


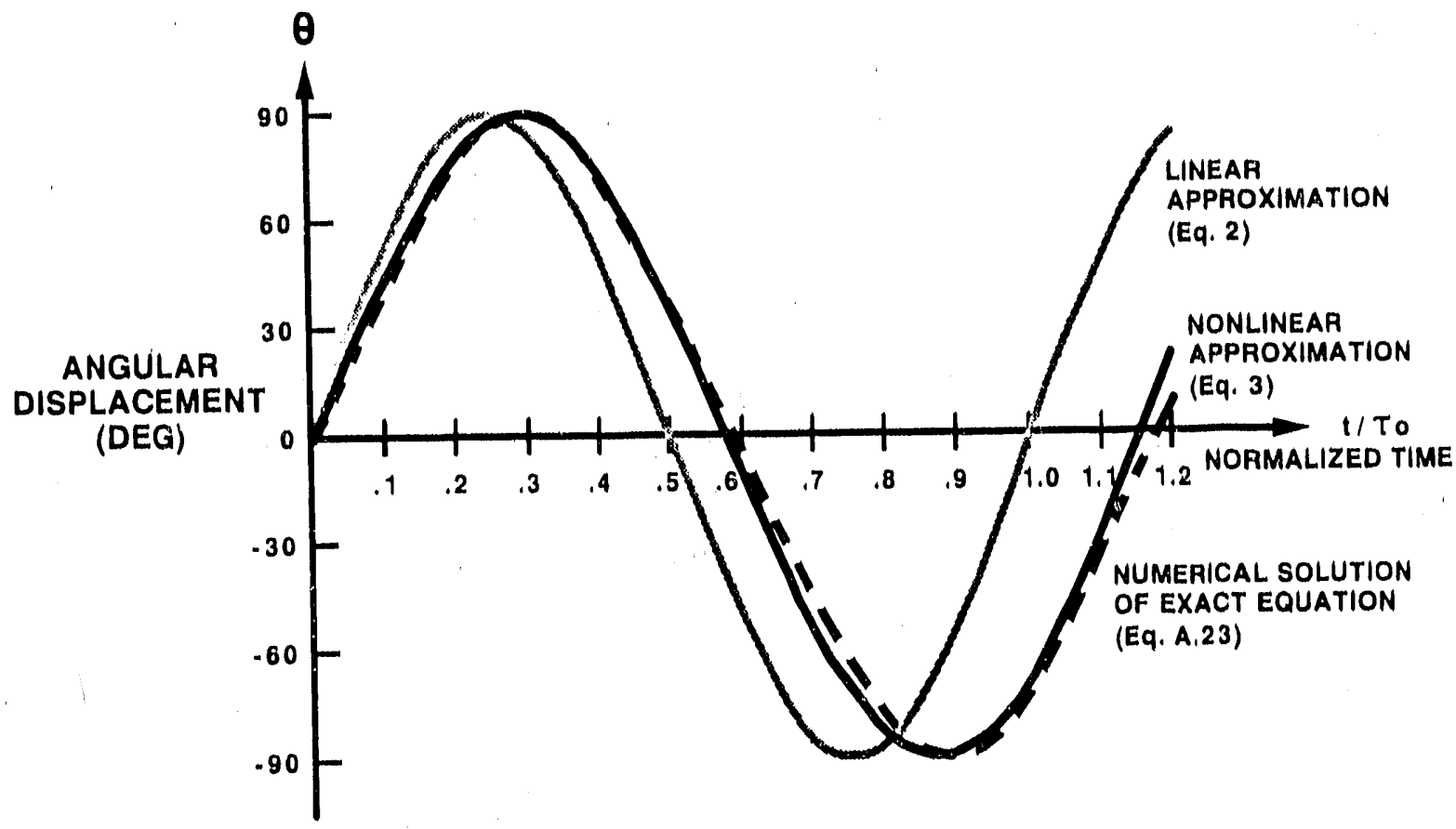

Figure E-3. Angular Displacement vs. Normalized Time

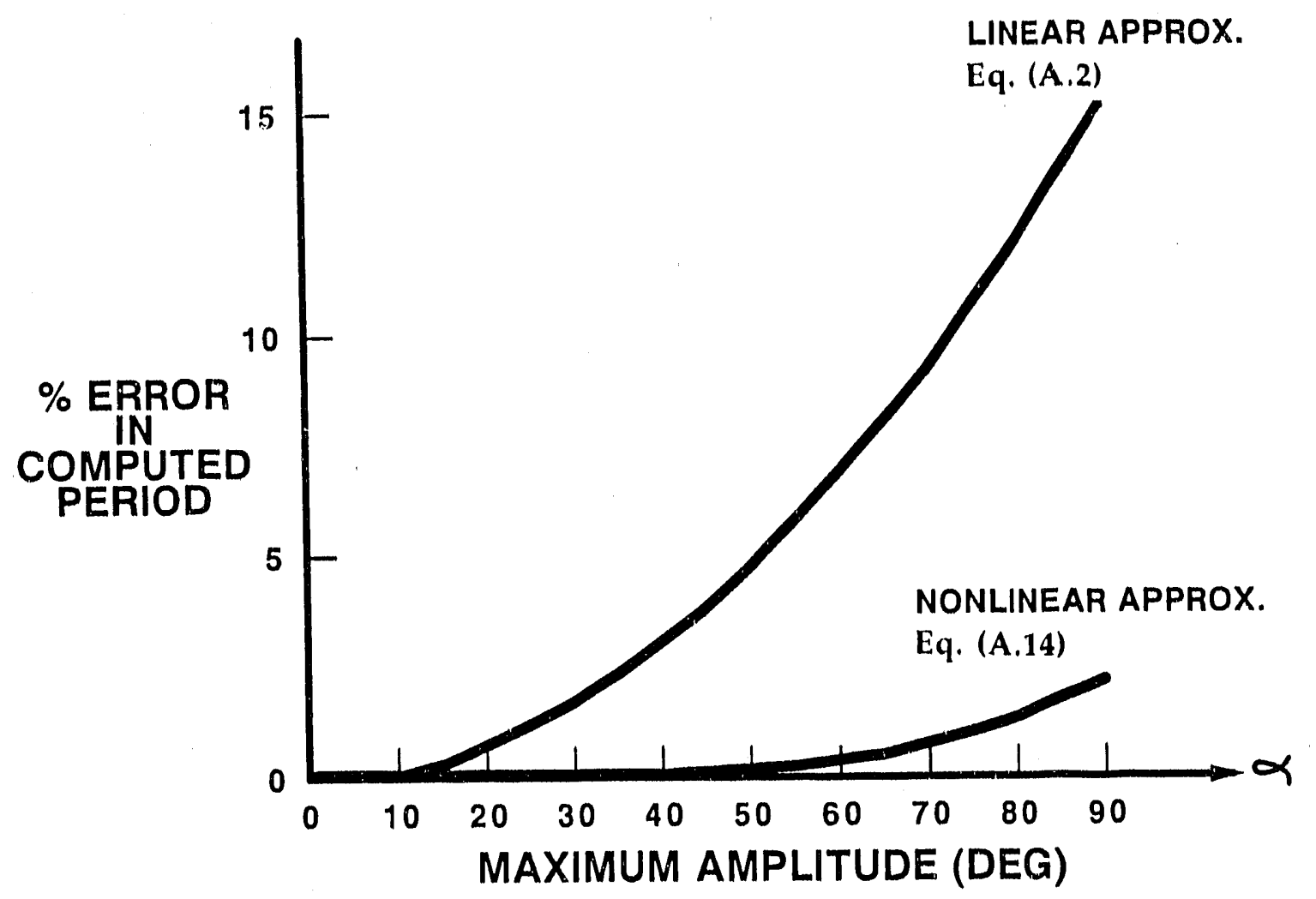

Figure E-4. Error in Computed Pendulum Periods 
remain in tension. At large swing amplitudes exceeding 90 degrees, the supporting member must go into compression to maintaln oscillatory motion. Therefore, the practical upper limits of analysis for the remainder of this paper is 90-degrees maximum amplitude.

\section{NUMERICAL RESULTS}

Using the acceleration profile shown in Figure E-2 and the nonlinear approximation for the differential equation of motion (Equation 1), a function may be written that expresses the constant velocity time, $T$, as a function of acceleration time, $t_{a}$, and the nonlinear approximations for the period of the swinging object, ${ }^{T} T$ and $r_{t_{a}}$, which are functions of acceleration magnitude, $a / g$, and other measurable system parameters (see Attachment A for mathematical development):

$$
\mathrm{T}=\frac{r}{\pi} \mathrm{T}^{-1}\left[\frac{\tau_{\mathrm{T}}}{r_{\mathrm{t}_{\mathrm{a}}} \tan \left(\pi \mathrm{t}_{\mathrm{a}} / r_{\mathrm{t}_{\mathrm{a}}}\right)}\right]
$$

where

\footnotetext{
$r_{\mathrm{T}}$ - the period of the swinging object, accounting for all nonlinearities during the time of intermediate constant velocity

$\mathrm{T}_{t}$ - the period of the swinging object, accounting for all nonlinearities during the time of constant acceleration.
}

Figure E-5 shows the surface defined by Equation 4 for intermediate constant velocity time, $T$, as a function of normalized acceleration, $a / g$, and acceleration time, $t_{a}$, for a swinging object with unit small angle period. Notice that the limits for acceleration time are zero and one-half. Zero acceleration time corresponds to impulse acceleration that results in an intermediate constant velocity time of one-half perlod, as demonstrated by Starr (1985).

An acceleration time of 0.5 corresponds to accelerating for one-half the small angle period of the swinging object, followed by an acceleration for another one-half period without an intermediate duration of constant velocity. This occurs if the magnitude of acceleration is infinitesimally small. Strip suggests this profile of acceleration time is equal to one-half the infini". tesimally small angle perıod (Strip, 1986).

Notice the division on the surface of Figure E-5 between real (shaded section) and nonreal, or nonpractical, (unshaded section) solutions. Bounding the real solutions are two curves shown on the solution surface: the curve defining the intersection of the surface and the $t_{a}, a / g$ plane, and the curve defining the boundary of nonpractical solutions.

The curve defining the intersection of the surface and the $t_{a}, a / g$ plane separates real from nonreal solutions. If a solution lies below the $t_{a}, a / g$ plane, the required constant velocity time has a negative value. Because 


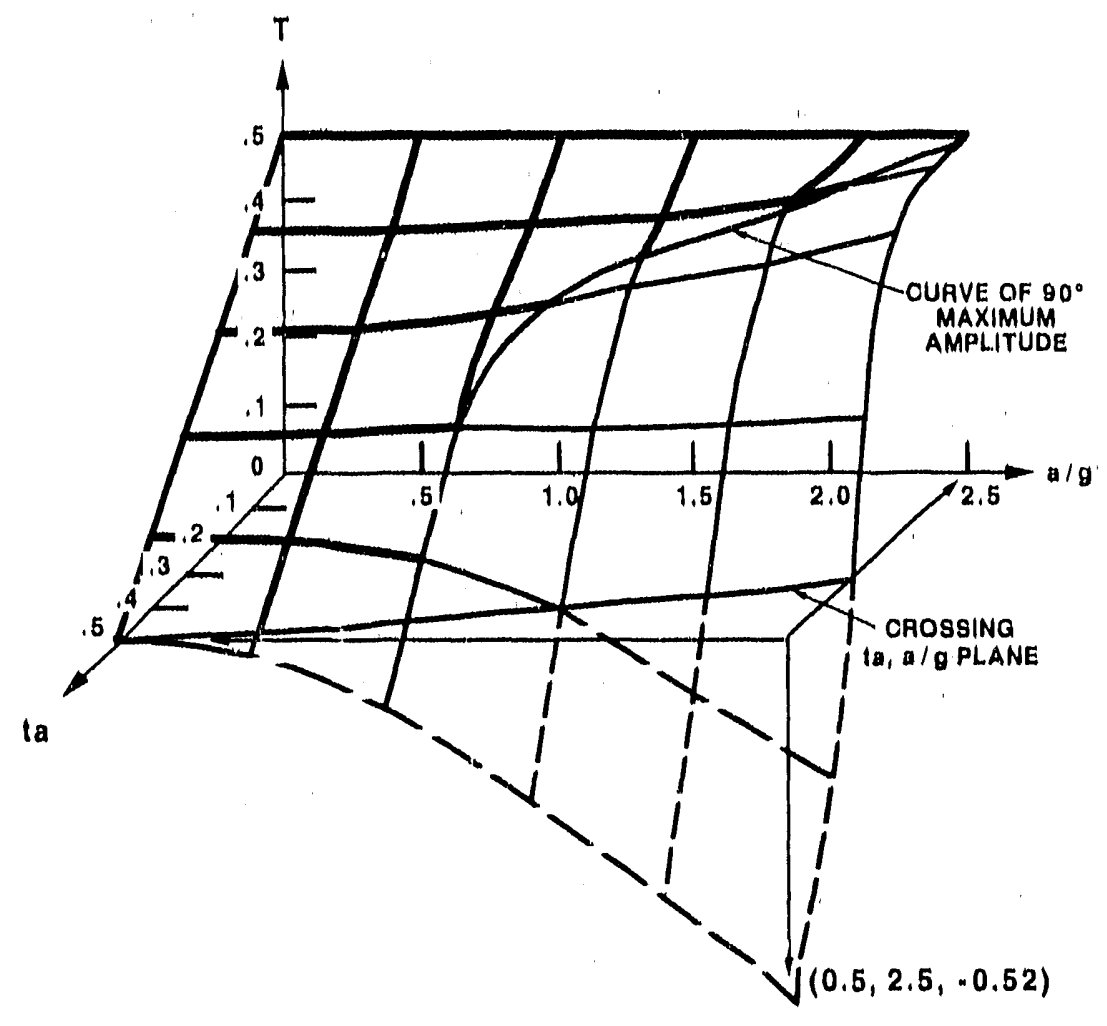

Figure E-5. Surface Defining Nonlinear Approximation

negative time is not a real solution, any part of the surface extending below the $t_{a}, a / g$ plane is ignored.

The curve shown in Flgure E-5 as the boundary of 90-degrees maximum amplitude defines the limit of maximum swing amplitude. If the angular displacement and velocity at time, $t_{a}$, are such that the swinging object has a maximum swing amplitude graater than 90 degrees during the intermediate constant velocity, it is not a practical solution. Furthermore, the characteristics of the actual system may reduce the practical limit of maximum swing amplitude to less than 90 degrees.

Figure E- 6 shows a surface similar to that in Figure E-5, except Figure E- 6 assumes a linear approximation for motion of the swinging object, while Figure F-5 uses the nonlinear approximation for the motion of the swing ing object. Notice both approximations approach the same true linear solution as acceleration approaches zero.

However, as acceleration increases, the two surfaces show a significantly different behavior. The surface for the linear approximation tends to bend up, indicating that the duration of constant velocity, $T$, increases as the system's acceleration magnitude, $a / g$, increases. In contrast, the surface for the nonlinear approximation (Figure E-5) tends to curve down toward reduced constant velocity time as acceleration magnitude increases.

Note that if the desired working region is in the area of increased acceleration magnitude, the nonlinear characteristics of the swinging object 


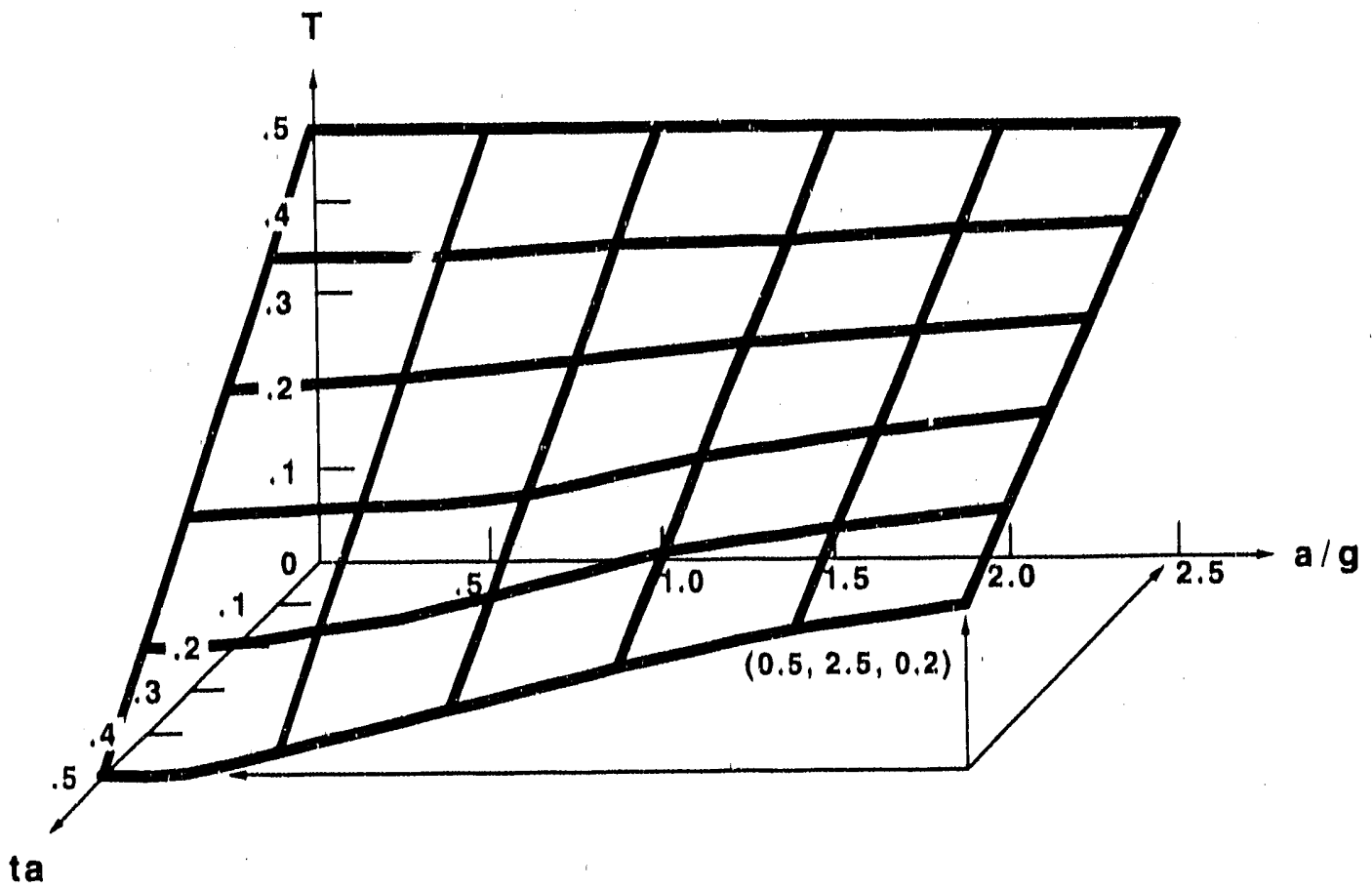

Figure E-6. Surface Defining Linoar Approximation

must be included. In fact, if the working region is in the area of large acceleration magnitude and time, it is more accurate to neglect the effects of acceleration and assume a linear approximation for the motion of the simply suspended object than to include the effects of acceleration and assume a linear approximation.

\section{IMPLEMENTATION}

\section{Hardware}

Figure E-7 shows the implementation for an oscillation-damped control strategy on a CIMCORP $X R^{\circledR} 6100$ robot at SNL. A desired displacement is entered into the control computer, which then generates the required robot acceleration profile needed to develop oscillation-damped trajectory for a simply suspended object. This acceleration profile is sent to the standard CIMROC ${ }^{B} * 2$ robot controller through a CIMCORP line tracker board in the form of robot position updates every $47 \mathrm{~ms}$. The standard robot controller determines tile robot trajectory required to achieve this new position and sends the results into the robot servo control loop.

\section{Software}

The software in the control computer provides both low-level interruptdriven communications and high-level trajectory computation.

\#CIMROC ${ }^{\circledR}$ is a registered trademark of CIMCORP, Inc. 


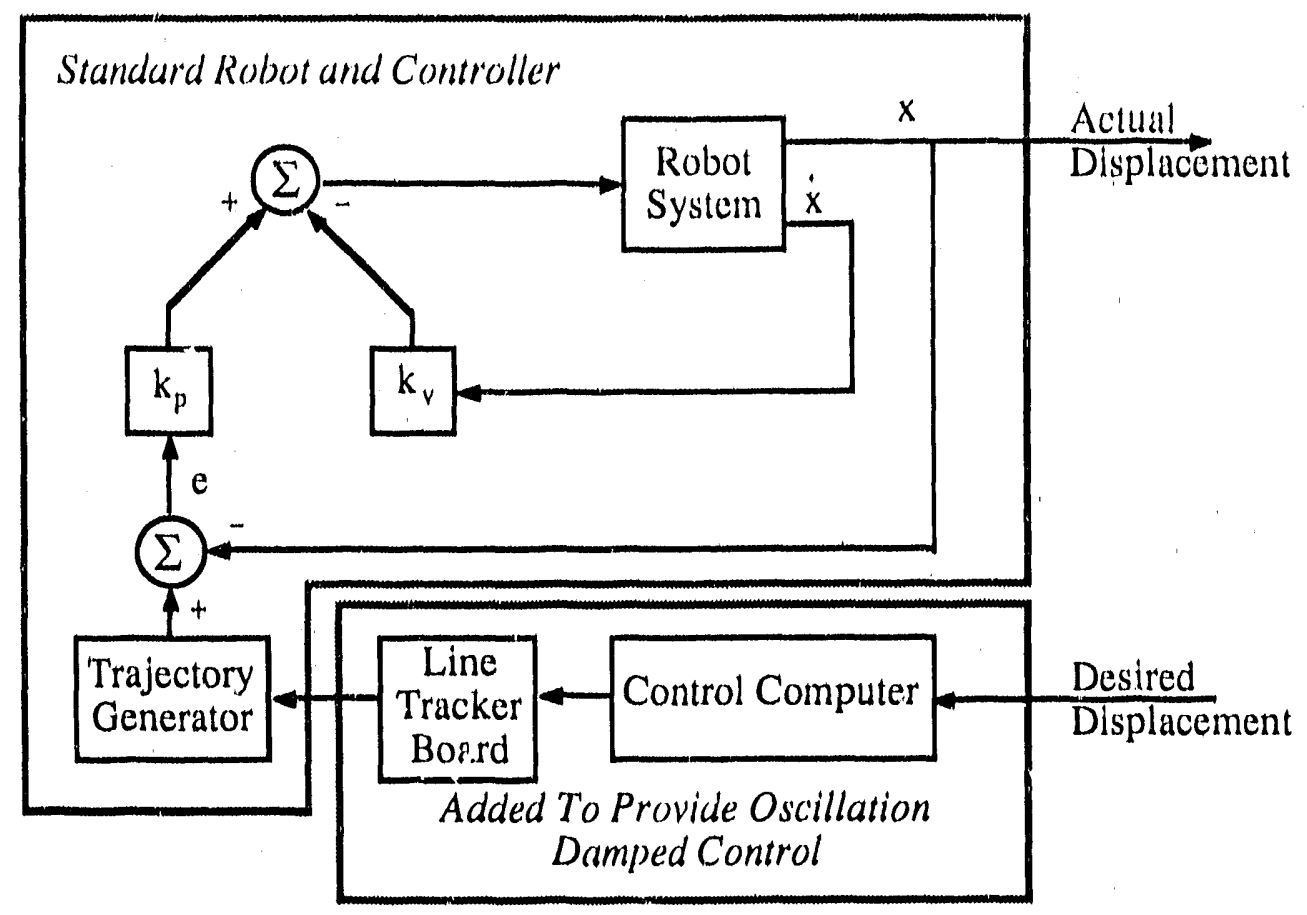

Figure E-7. Implemented Control Strategy

The communication between the robot controller and the control computer is syrichronized by the robot controller through the line tracker board. The board sends a synchronizing pulse to the control computer every $47 \mathrm{~ms}$. When the control computer receives the synchronizing pulse, it interrupts the currently active trajectory computation routine and sends the most current oosition update over a serial communication line to the line tracker board. After sending the position undate to the line tracker board, the communication rodtine running on the control computer returns control to the trafectory coinputation routine.

The trafectory computation routine calculates the required position updates to obtain an oscillation-damped trajectory by essentially selecting a point on the surface (Figure E-5) that satisfles the condition of desired displacement. After a desired displacement is entered into the trajectory computation routine, the routine assumes an acceleration time, $t_{a}$, and $a$ corresponding intermediate constant velocity time, $T$, thereby selecting a particular contour line on the surface, shown in Figure E-5. The trajectory computation routine then iterates a solution between acceleration magnitude, $a$, and maximum constant velocity time, $T_{m}$, using Equation 2, and the following equation for total. displacement of point 0 :

$$
S-4 a t_{a}^{2}+2 a t_{a} T+2 a t_{a} T_{m}
$$

where

S - total. displacement for point 0 . 
After all parameters are determined, the trafectory computation routine calculates the osclilation-damped trafectory position updates, based on the 47-ms update rate of the line tracker board.

To move the robot, the trajectory computation routine passes a position update to the communication routine. The communtcation routine blocks execution of the trajectory computation routine unt1 it recelves a synchronization pulse from the IIne tracker board, thereby properly synchronlzing the trajectory computation routine with the line tracker board. When the communication routine senses the synchronization pulse, 1 t transmits the next position update to the line tracker board, then returns rontrol to the trajectory computation routine. This process continues unti 1 the desired trajectory is complete.

\section{RESULTS}

To test the above control strategy, a 50-1b weight was suspended by an 80-in. cable from the $\mathrm{XR}^{\circledR} 6100$ robot gripper. The small angle period of the pendulum was measured to be $2.87 \mathrm{~s}$.

The results of a sample test are given in Table E-1. During this test, the acceleration of the pivot point, or robot gripper, remains constant for al1 trials at $12 \mathrm{ln} . / \mathrm{s}^{2}$ in a horizontal direction. Likewise, the total robot displacement holds constant at $100 \mathrm{in}$.

Concerning the residual oscillation shown in Table E-1, no residual oscillation in theory should occur after the robot has come to rest. In practice, deviations from theory resulting in residual osclilation stem from many sources. Based on computer simulations of this control strategy, the largest source of error results from the update rate of the digital control system. For the system described above, the position update rate is approximately $47 \mathrm{~ms}$; therefore, if the desired acceleration profile is not precisely definable in 47-ms intervals, some residual oscillation will rusult. Another source of error results from time delays due to the response of the mechanical subsystem. Any deviation in implementation from the desired acceleration profile can result in a distorted acceleration proflle and, hence, residual oscillation. Also, the servo control loop itself can induce error. The servo loop requires a position error to output power to the servo motors on the manipulator (Figure E-7). Therefore, the manipulator's actual position is always a nonconstant distance behind the desired position, resulting in a distortad acceleration profile. Finaliy, any initial. oscillation of the swinging object will, in genexal, result in residual oscillation.

As a comparison to the approach of generating constant acceleration profiles, a test was conducted wherein the standard CIMROC ${ }^{(\mathbb{B}} 2$ robot controller governed the acceleration profile of the robot gripper using a cubic spline trafectory (Sturm, 1983). The maximum acceleration was set to $1.2 \mathrm{in.} / \mathrm{s}^{2}$, and the maximun velocity, to $15 \mathrm{in.} / \mathrm{s}$. For a $100 \mathrm{in}$. move, the rasulting residual oscillation was 8.7 degrees. Residual osclilation of 8.7 degrees is significantly greater than the residual oscillation for the oscillation-damped 
Table E. 1

Reaults for Implemented systim

\begin{tabular}{|c|c|c|c|c|}
\hline $\begin{array}{l}t_{a} \\
(s)\end{array}$ & $\begin{array}{l}T \\
(s)\end{array}$ & $\begin{array}{l}T_{m} \\
(s)\end{array}$ & $\begin{array}{l}V_{\max } \\
\left(\ln _{1} / s\right)\end{array}$ & $\begin{array}{c}\text { Resldual } \\
\text { Osalilation } \\
\text { (degraes) }\end{array}$ \\
\hline $\begin{array}{l}1.44 \\
1.15 \\
0.861 \\
0.574 \\
0.287\end{array}$ & $\begin{array}{l}0.000 * \\
0.287 \\
0.574 \\
0.841 \\
1.15\end{array}$ & $\begin{array}{c}0.0336 \\
1.05 \\
2.54 \\
5.25 \\
12.8\end{array}$ & $\begin{array}{c}34.4 \\
77.6 \\
20.7 \\
13.8 \\
6.89\end{array}$ & $\begin{array}{l}0.1 \\
0.3 \\
0.3 \\
0.1 \\
0.1\end{array}$ \\
\hline 4 close & Iution & & & \\
\hline
\end{tabular}

trajectorles shown in Table E-1. Therefore, the proposed constant acceleration control strategy w111, in general, yleld a better osclilation. damped trajectory than possible with the CIMROC® 2 controiler.

\section{CONCLUSIONS}

While experimenting with the computer simulation and implemented control system, several practical observations have been made.

1. As the acceleration of the pivot point approaches zero, the equations of motion describing the swinging object approach linear behavior; hence, the equations that generate the oscillation-damped trajectory may be greatly simplified by making linear approximations for the motion of the swinging object:

$$
\theta+\omega_{0}^{2} \theta-0
$$

2. The implemented system w111 always deviate from the exact solution, resulting in residual oscillation of the payload due to the nonidealities in the control and mechanical systems. These nonldealities include the finite update rate of the controller, response delays in the mechanical system, and response delays in the servo loop. In general, all these nonidealities are characteristics of the particular system used. Therefore, care must be taken when selecting or designing a system to generate oscillation-damped trajectories to ensure that it behaves as close to ldeally as posiblie.

3. Restdual osclilation can also result from an initial osciliation of the payload. In general, the osc1llation-damped trafectory will not decrease this Initial movement. Moreover, the oscillation-damped trajectory may amplify the Inttial osclilation. 
4. From the above observations, it is obvious that an oscillation-dampea trajectory with zero residual oscillation may be difficult to implement in some cases, SNL is currently developing a hybrid force-control system to damp residual oscillation of simply suspended payloads by controlifing the dynamic forces created by the swing ing payload (strip, 1986).

5. One drawback of generating osclilation-damped trajectories as presented in this appendix is the necessity of a system able to produce a constant acceleration proflle. Many commerclally avallable programmable cranes and manipulators do not have the ability to generate a constant acceleration profile, However, many acceleration profiles can result in an oscillation-damped trajectory by applying the proper mathematical. conditions (Strip, 1986). 


\section{REFERENCES}

Kaplan, W., 1952. Advanced Calculus, Reading, MA: Addison-Wesley.

Karman and Blot, 1940. Mathematlcal Methods In Englneerlng, New York:

McGraw-H111.

Starr, G, P., 1985. "Swing-Free Transport of Suspended Objects with a PathControlled Robot Manipulator," Journal of Dynamic Systems, Measurement and Control, 101:97-100

Strip, D. R, , 1986, "Swing-Free Transport of Suspended Objects: A General Treatment," SAND87-0714, Sandia National Laboratories, Albuquerque, NM.

Sturm, A, J., 1983. "Robotic Trafectory Control of Acceleration and Velocity Using Cubic Splines," presented at the 8th Applied Mechanisms Conference, St. Louls, MO.

Thomson, W., 1981. Theory of Vibrations with Applications, New Jersey: Prentice-Hall.

Tse, F., H. E. Morse, and R. T. Hinkle et a1,, 1978, Mechanlcal Vibrations Theory and Applications, Boston: Allyn and Bacon. 


\section{ACKNOWLEDGMENTS}

The authors would like to thank Bill Davidson and Dave Strip of Sandia National Laboratories. Bill wrote the interrupt-driven software for communication between the control computer and the CIlAROC ${ }^{\circledR} 2$ controller. Dave suggested the feasibility of oscillation-damped transport using the gantry robot. 
Figure E- 8 shows a free-body diagram of a distributed mass with a moving pivot point where

0 - moving pivot point for the mass

$G$ - center of mass for the object

$m=$ mass of the object

1 - length from 0 to $G$

$J$ - mass movement of inertia about 0

$\mathrm{g}=$ the gravitational acceleration (along $\mathrm{y}$ )

$a$ - acceleration of point 0 (normal to $y$ )

$\theta$ - angular displacement of the object from $y$

$\theta^{\prime}$ - angular displacement of the object from $y^{\prime}$.

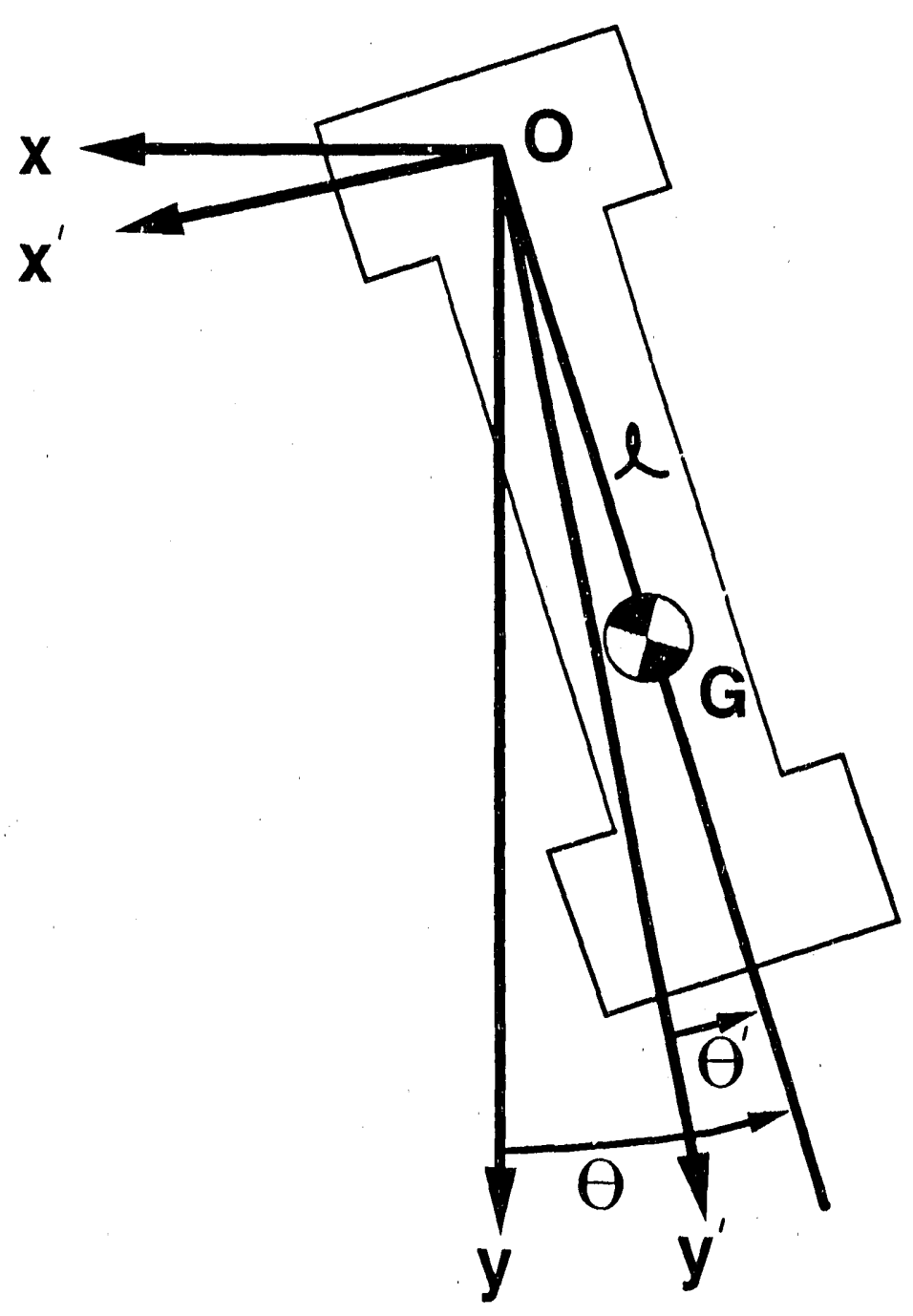

Figure E-8. Simply Suspended Object 
The object can pivot at 0 and oscillate freely about $y$ of the $x y$ coordinate frame while point 0 is stationary or moving with constant velocity. A second axis, $y^{\prime}$ of the $x^{\prime} y^{\prime}$ coordinate frame, is the axis about which the object oscillates while point 0 is mov: $g$ with constant acceleration. Using this second coordinate frame allows the use of standard relations to analyze the motion of the object. A simple coordinate transformation relates the two coordinate frames.

A dynamic analysis of the object yields the following nonlinear differential equation of motion that is valid while point 0 is stationary or moving with constant velocity (Karman and Biot, 1940; Tse et al., 1978; Thomson, 1981).

$$
\theta+\omega_{0}^{2} \sin \theta=0
$$

where the natural frequency of the object is

$$
\omega_{0}=\left[\frac{\mathrm{m} l \mathrm{~g}}{\mathrm{~J}}\right]^{1 / 2}
$$

While point 0 is moving with constant acceleration, the natural frequency changes due to a change in the magnitude of the effective acceleration vector; hence, tire new natural frequency becomes

$$
\omega_{0}=\left[\underline{m L a^{2}+g^{2} 1 / 2}\right]^{1 / 2} .
$$

The assumption is now made and verified below that a new natural frequency exists that approximates all the nonlinearities in the differential equation describing the motion of the swinging object. Equation A-1 then becomes

$$
\theta+\omega^{2} \theta=0
$$

where

$\omega=$ natural frequency, accounting for all nonlinearities.

Equation A-4 is a second-order, linear differential equation with constant coefficients and is solvable using Laplace transforms. After transforming Equation A-4, solving for the subsidiary equation, and then transforming back into the time domain, the solution for angular displacement with respect to time becomes

$$
\theta(t)=\theta_{1} \cos (\omega t)+\left[\dot{\theta}_{1} / \omega\right] \sin (\omega t)
$$


where

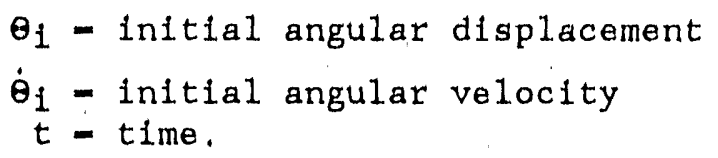
to time:

Differentiating with respect to time ylelds angular velocity with respect

$$
\dot{\theta}(t)=-\theta_{1} \omega \sin (\omega t)+\dot{\theta}_{1} \cos (\omega t) .
$$

\section{Osc11lation-Damped Trajectories}

The problem now is solving for the constant velocity time, $T$, in terms of acceleration time, $t_{a}$, and other system parameters. Assuming the two durations of constant acceleration are equal in time, $t_{a}$, and magnitude, $a$, the following conditions will result in an oscillation-damped transport and stop of the object (Starr, 1985).

$$
\begin{aligned}
& \theta\left(t_{a}\right)=\theta\left(t_{a}+T\right)=\theta \\
& \dot{\theta}\left(t_{a}\right)=-\dot{\theta}\left(t_{a}+T\right)=\dot{\theta}
\end{aligned}
$$

Substituting conditions in Equations A-7 and A-8 into Equations A-5 and A-6 gives

$$
\begin{aligned}
& \theta=\theta \cos \left(\omega_{T} T\right)+\left[\dot{\theta} / \omega_{T}\right] \sin \left(\omega_{T} T\right) \\
& -\dot{\theta}=-\theta \omega_{T} \sin \left(\omega_{T} T\right)+\dot{\theta} \cos \left(\omega_{T} T\right)
\end{aligned}
$$

where

$\omega_{T}$ - natural frequency of the swinging object, accounting for all nonlinearities during the intermediate constant velocity.

Solving Equation A-9 for $\sin \left(\omega_{T} T\right)$, substituting the result into Equation A-10, and using a tangent half angle substitution yields:

$$
\tan \left(\frac{\omega_{T} T}{2}\right)=\frac{\dot{\theta}}{\omega_{T} \theta}
$$

which is valid for

$$
\theta \cdot \dot{\theta} \geq 0
$$


where

$$
\begin{aligned}
& \theta \text { - angular displacement in the } x y \text { coordinate frame at time } t_{a} \\
& \dot{\theta} \text { - angular velocity at time } t_{a} \text {. }
\end{aligned}
$$

Using Equations $A-5$ and $A-6$ to obtain $\theta$ and $\theta$ at time $t_{a}$ in the $x^{\prime} y^{\prime}$ coordinate frame, transforming $\theta$ and $\theta$ to the $x y$ coordinate frame, and substituting into Equations $A-11$ yields

$$
T=\frac{\tau_{T}}{\pi} \tan ^{-1}\left[\frac{r_{T}}{r_{t_{a}} \tan \left(\pi t_{a} / r_{t_{a}}\right)}\right]
$$

where

$\tau_{T}$ - the period of the swinging object, accounting for all nonlinearities during the time of intermediate constant velocity

$r_{t_{a}}$ - the period of the swinging object, accounting for all nonlinearities during the time of constant acceleration.

Equation A-13 relates the duration of the intermediate constant velocity segment, $T$, tc the duration of a constant acceleration segment, $t_{a}$, as a function of the nonlinear approximations for the period of each segment. Now the nonlinear approximations for the perlod of each segment need to be expressed in terms of determinable system parameters.

\section{Nonlinear Approximation for Period}

One way of dealing with the nonlinear motion of a swinging object is to combine all the nonlinearities into one parameter, the exact period. Karman and Biot approximate the exact period as (Karman and Biot, 1940)

$$
\tau=2 \pi\left[\frac{\mathrm{J}}{\mathrm{mlg}}\right]^{1 / 2}\left[1+\frac{\alpha^{2}}{16}\right]
$$

where

$\alpha$ - maximum angular amplitude of the swinging object.

Using Equations A-3 and A-14, the nonlinear approximation for the period of the object while the moving pivot point 0 is accelerating becomes

$$
\tau-2 \pi\left[\frac{\mathrm{J}}{\mathrm{m} 1\left[\mathrm{a}^{2}+\mathrm{g}^{2}\right]^{1 / 2}}\right]^{1 / 2}\left[1+\frac{\alpha^{2}}{16}\right] .
$$

While point 0 is accelerating at a constant rate, $\alpha$ is the angle between the $x y$ and $x^{\prime} y^{\prime}$ coordinate systems. Hence, Equation A-15 can be expressed entirely in terms of determinable system parameters [see strip (1986) for expanded derivation]: 


$$
r_{t}-\tau_{0}\left[\frac{1}{\left[1+(a / g)^{2}\right]^{1 / 2}}\right]^{1 / 2}\left[1+\frac{\left[\tan ^{1}(a / g)\right]^{2}}{16}\right]
$$

where

$r_{0}$ - the period for an infinitesimally small angle of osclilation while point 0 is moving with constant velocity.

Using Equation A-14 to solve for the period of an object while point 0 is moving with constant velocity and expressing the maximum amplitude as a function of conditions at time, $t_{a}$, yields:

$$
\frac{2 \pi}{r_{0}}=\frac{2 \pi}{r_{T}}\left[1+\frac{\theta^{2}+\left(2 \pi \dot{\theta} / \tau_{T}\right)^{2}}{16}\right] \text {. }
$$

Solving this nonlinear approximation for the period while point 0 is moving with constant velocity results in the quadratic equation

$$
\frac{2 \pi}{r_{T}}=\frac{2 \pi / r_{0} \pm\left[\left(2 \pi / r_{0}\right)^{2}-4\left(1+\theta^{2} / 16\right)\left(\dot{\theta}^{2} / 16\right)\right]^{1 / 2}}{2\left(1+\theta^{2} / 16\right)}
$$

As the angular displacement and velocity approach zero, the nonlinear approximation for the perlod should approach that of the small angle period. Therefore, the proper cholce is the positive radical of Equation A-18. Hence, the nonlinear approximation for the period of the object during the time of intermediate constant velocity becomes

$$
\tau_{T}=\frac{2 \pi\left(1+\theta^{2} / 16\right)}{\pi / \tau_{0}+\left[\left(\pi / r_{0}\right)^{2} \cdot\left(1+\theta^{2} / 16\right)\left(\dot{\theta}^{2} / 16\right)\right]^{1 / 2}}
$$

Substituting Equations $A-16$ and A-19, along with angular displacement and velocity at time, $t_{a}$, in the $x y$ coordinate frame, into Equations $A-13$ yields a solution for the duration of constant velocity, $T$, in terms of acceleration time, $t_{a}$, for an oscillation-damped trajectory.

\section{Error Analysis}

Comparing the solutions to the linear and nonlinear approximations, an exact solution for the motion of a swinging object demonstrates the necessity and validity of combining all nonlinearities into an approximate period. Using Equations A-5, with the initial conditions of zero angular displacement and maximum angular velocity, the angular displacement as a function of time for the linear approximation is

$$
\theta-\alpha \sin \left(2 \pi \frac{t}{r_{0}}\right) \text {. }
$$


Using Equations A.14 for the norlinear approximation of the pertod of a swingling object and substituting this approximation for the perlod into Equations A-20 gives the nonlinear approximation for angular displacement as a function of time:

$$
\Theta-\alpha \sin \left(\frac{2 \pi}{1+\left(\alpha^{2} / 16\right)}\left[\frac{t}{r_{0}}\right]\right) \text {. }
$$

The exact solution for angular displacement as a function of time for the swingling object with the same inftial conditions as Equations A-20 and A-21 is (Karman and Blot, 1940)

$$
\sin \left(\frac{\Theta}{2}\right)-\sin \left(\frac{\Theta}{2}\right) \operatorname{sn}\left(2 \pi \frac{\mathrm{t}}{r}\right)
$$

where

$\sin =$ is a Jacobl olliptic function

$r$ - is the exact period.

Solving Equation A-22 for angular displacement and expanding the elliptic function yields

$$
\theta=2 \sin ^{-1}\left[\sin \left(\frac{\alpha}{2}\right) \sin \left(2 \pi \frac{\tau_{0}}{\tau_{\tau_{0}}}\right)\right]
$$

where the ratio of the exact perlod to the period for an infintesimally small angle of osciliation is (Karman and Biot, 1940)

$$
\frac{r}{r_{0}}-\frac{2}{\pi}\left[\int_{0}^{\frac{\pi}{2}}\left[\frac{d \Psi}{\left[1-\sin ^{2}(\alpha / 2) \sin ^{2}(\Psi)\right]^{1 / 2}}\right]\right]
$$

Equation A-24 is in the form of a complete elliptic integra1 of the first kind and is insolvable in terms of elementary transcendental functions (Karman and Biot, 1940). However, a numerical solution for Equation A-24 is possible for a given amplitude. 

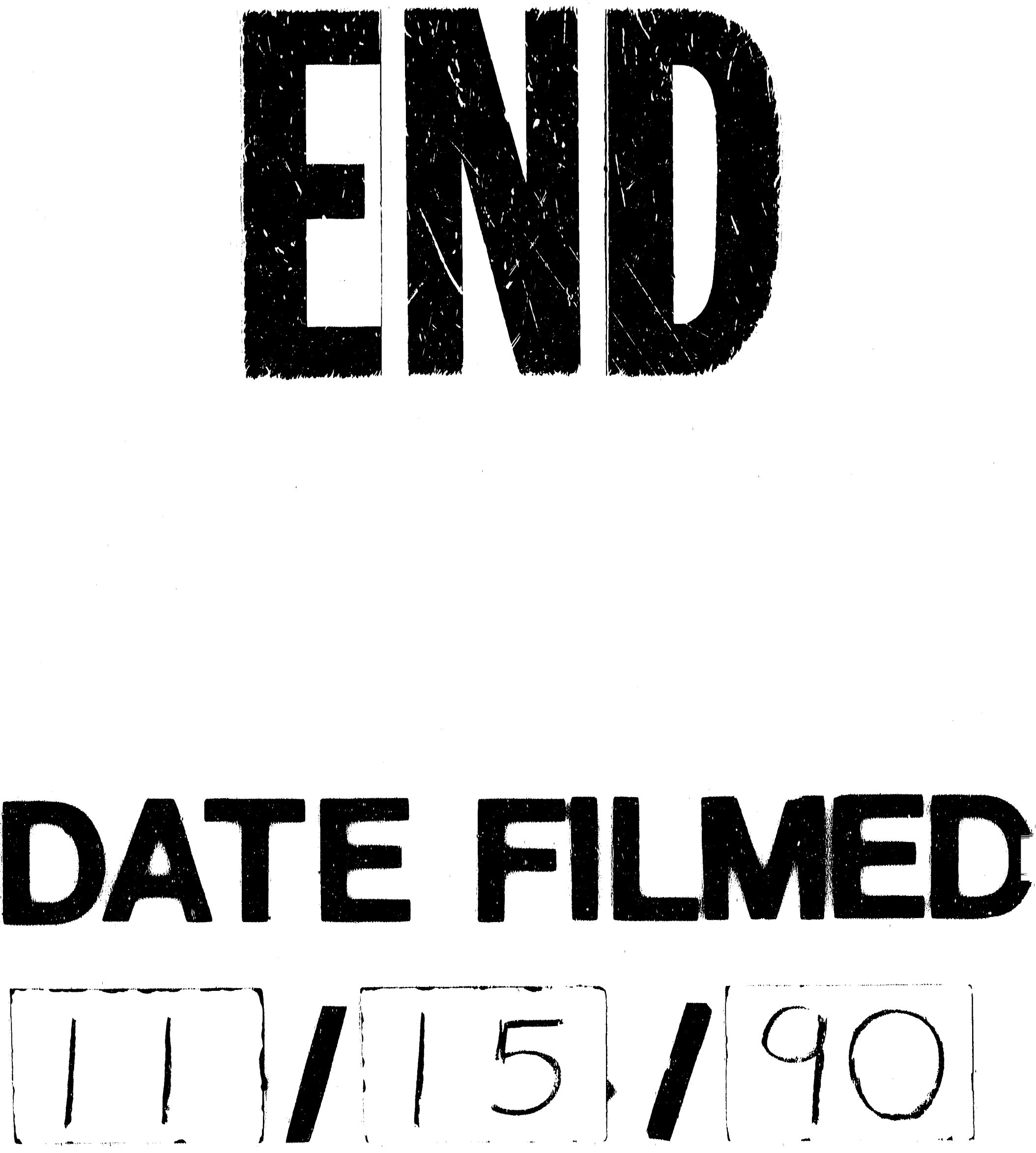
